\title{
Particulate Matter Concentrations in Social Housing
}

by

\begin{abstract}
Alexander Yves Mendell
A thesis submitted in conformity with the requirements for the degree of Master of Applied Science

Department of Civil and Mineral Engineering University of Toronto
\end{abstract}

(C) Copyright by Alexander Yves Mendell 2021 


\title{
Particulate Matter Concentrations in Social Housing
}

\author{
Alexander Yves Mendell \\ Master of Applied Science \\ Department of Civil and Mineral Engineering \\ University of Toronto
}

2021

\begin{abstract}
Residents of social housing are often exposed to higher concentrations of harmful indoor pollutants such as particulate matter (PM). This research is comprised of two parts: a study investigating variation in indoor PM concentrations measured in 91 social housing apartments in Toronto followed by an evaluation of particle filtration as means of exposure reduction. PM concentrations varied greatly within and between apartments and were two times higher than in single family homes measured using comparable methods. Smoking and other indoor sources are likely responsible for these concentration differences which may contribute to health disparities. Using simulated concentrations derived from the social housing field measurements, we found that particle filtration could greatly reduce indoor PM concentrations. Automation using fixed and adaptive thresholds can lower system runtime, thereby reducing noise and energy usage and making particle filter systems a more viable and sustainable approach to improving the health of social housing residents.
\end{abstract}




\section{Acknowledgments}

First and foremost, I would like to thank Prof. Jeffrey Siegel for his supervision and mentorship throughout this project as well as before it began. When I began to pursue this degree, it was still very unclear which direction I wanted my life and career to take. My conversations with Prof. Siegel helped me to realize that I want to move onto a doctoral program and continue working in research. He was incredibly supportive of this goal and graciously took me on as his student. I am grateful for the knowledge and skills that he has imparted upon me, which I know will be invaluable to my future work and success.

I would also like to thank Prof. Marianne Touchie for acting as the second reader for this thesis, as well as for being a wonderful teacher. Prof. Karl Peterson and Prof. Kim Pressnail also deserve recognition for their passion and creativity. These last two years have been a delightful learning experience.

None of this work would have been possible without the previous efforts of many people, not limited to those named here. Many thanks to Dr. Alireza Mahdavi, Alexander Olson, and Dr. Raheleh Givehchi for their collaboration and insight. Thank you to Dr. Amy Li, Dr. Donna Vakalis, Dr. Yuchao Wan, and Annabel Zhang for providing me with their knowledge, prior work, and the data used to conduct this research.

It is impossible to overstate how important the support of my family, especially my parents, has been in helping me get to this point. I am unbelievably lucky to have people who always believe in me, and I hope to continue making them proud. To Megan, thank you for your kindness and patience. To all of my friends, thank you for getting me out of the house every once in a while. 


\section{Table of Contents}

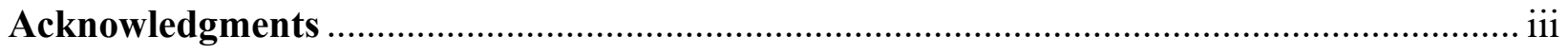

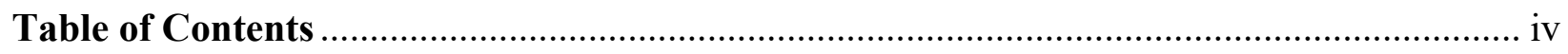

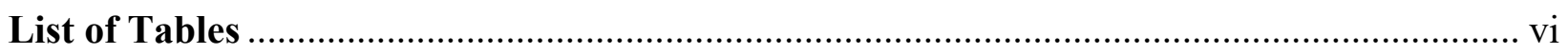

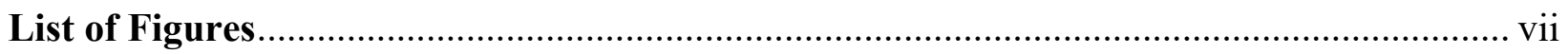

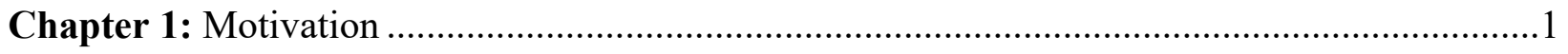

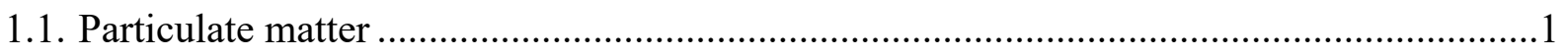

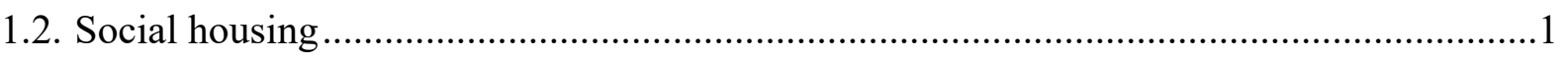

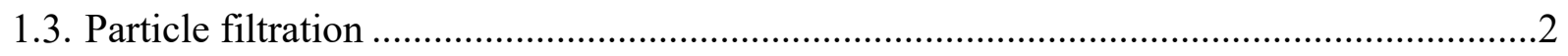

Chapter 2: Particulate matter concentrations in social housing ...........................................

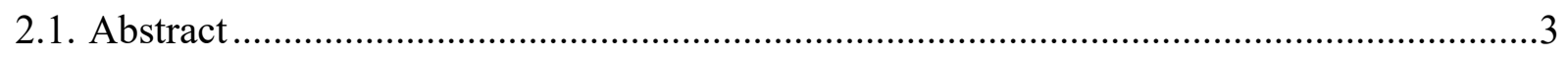

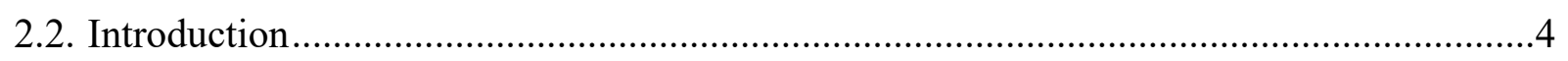

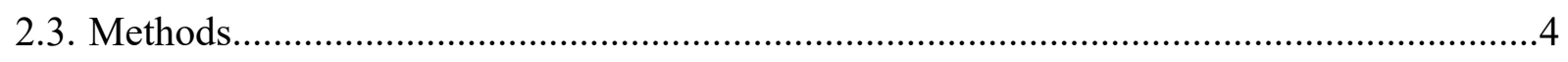

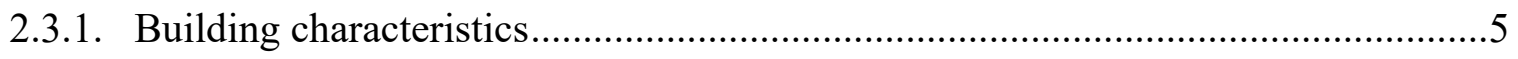

2.3.2. Measurements ...........................................................................................

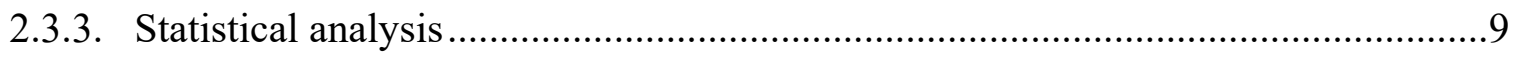

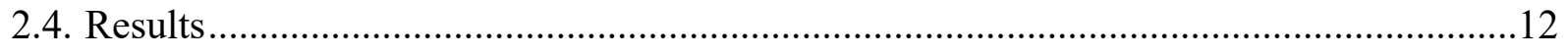

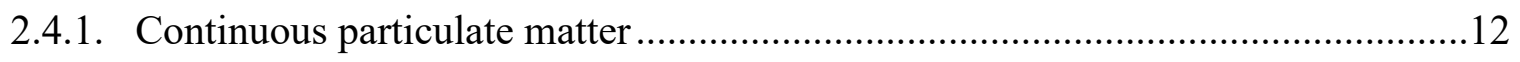

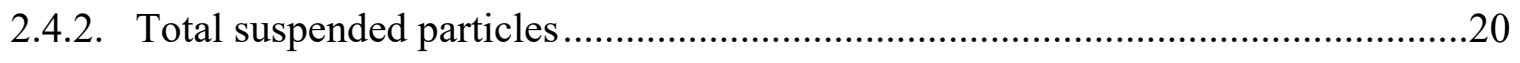

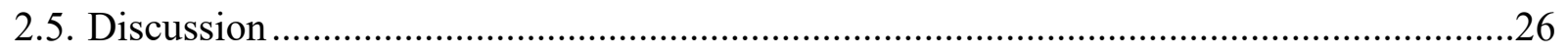

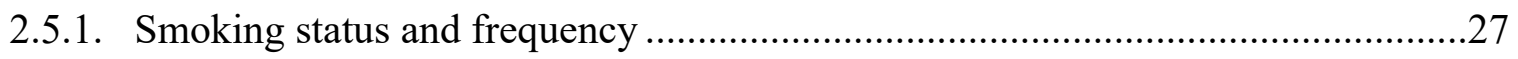

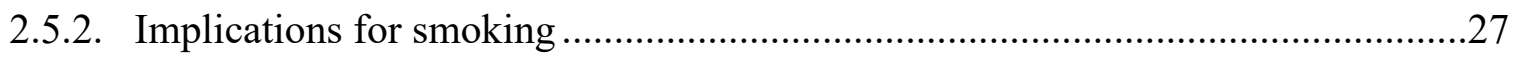

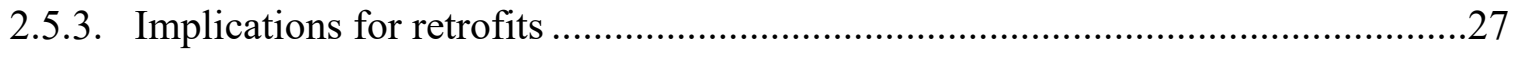

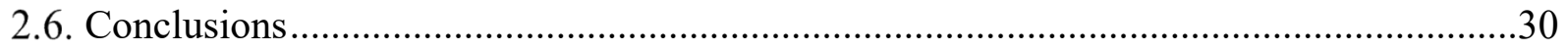


Chapter 3: Evaluation of fixed and adaptive thresholds for automating particle filter systems ..32

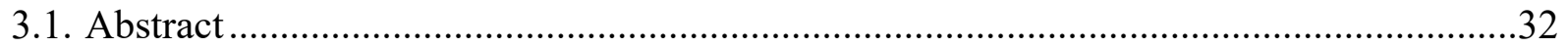

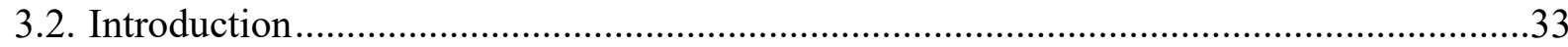

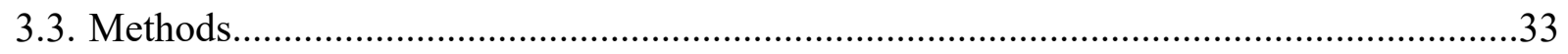

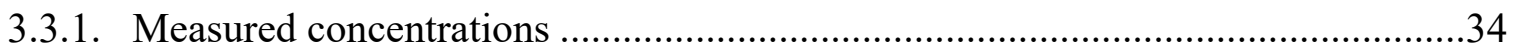

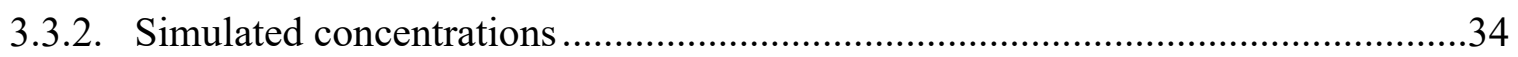

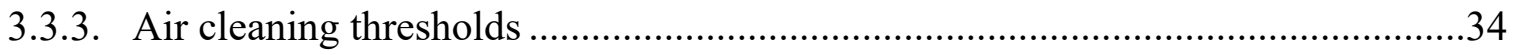

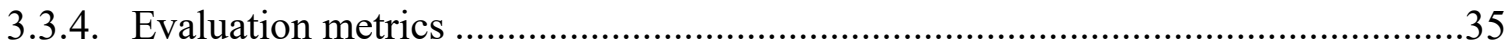

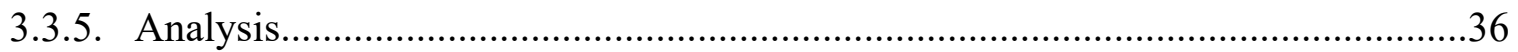

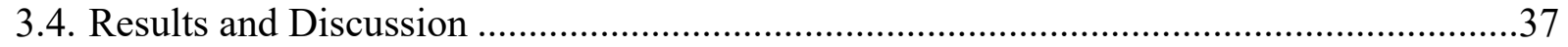

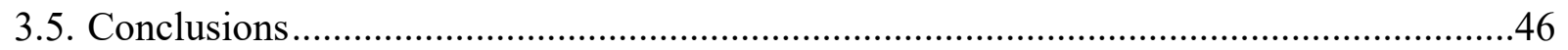

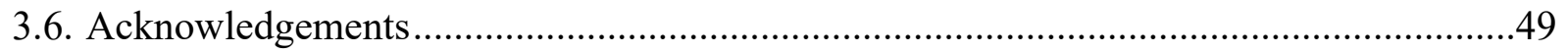

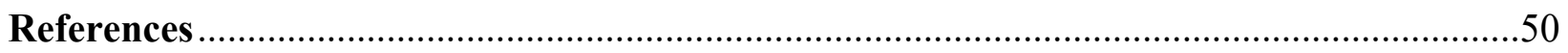

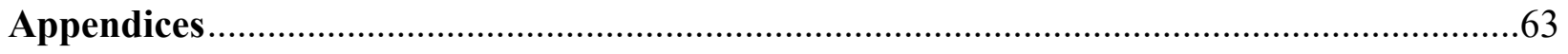

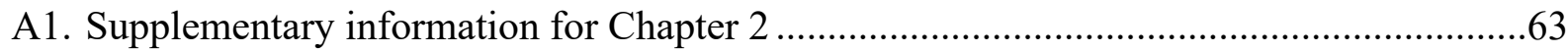

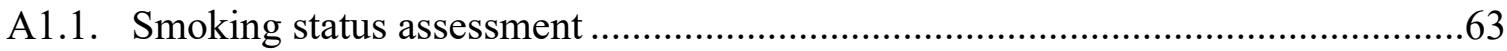

A1.2. Additional equipment deployment information..............................................65

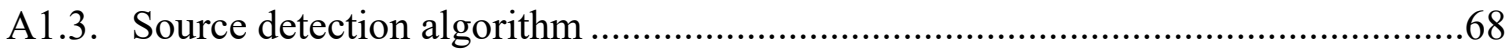

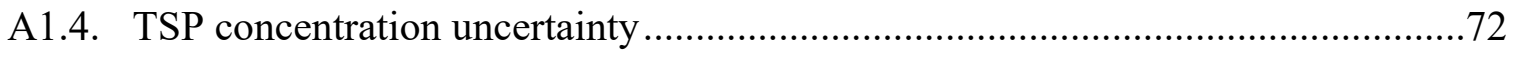

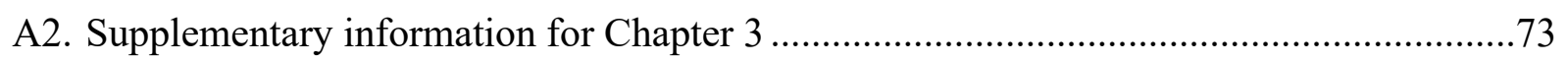

A2.1. Simulated concentration algorithm ....................................................... 73

A2.2. Complete figures for DC1700 derived simulations ......................................78

A2.3. Companion figures and tables for Alphasense OPC-N2 derived simulations .......80 


\section{List of Tables}

Table 1. Summary of building characteristics and number of apartments measured during each round

Table 2. Number and model of sensors deployed during each monitoring period and meeting quality control

Table 3. Runtime, absolute mean exposure reduction (AMER), absolute removal efficacy (ARE), normalized mean exposure reduction (NMER), and normalized removal efficacy (NRE) of constant air cleaning, fixed thresholds, and adaptive threshold for simulated data derived from Dylos DC1700 optical particle counters 


\section{List of Figures}

Figure 1. Pre-retrofit indoor PM number concentration of apartments measured by the Dylos DC1700 optical particle counter.

Figure 2. Post-retrofit indoor $\mathrm{PM}_{2.5}$ mass concentration of apartments reported by the Alphasense OPC-N2 optical particle counter 14

Figure 3. Median indoor $0.5-2.5 \mu \mathrm{m}$ particle count of apartments measured by the Dylos DC1700 monitors

Figure 4. Source affected proportion (SAP) of each Dylos DC1700 monitoring period in nonsmoking $(N=69)$ and smoking apartments $(N=35)$, grouped by building 20

Figure 5. Total suspended particles (TSP) concentration in each apartment measured by gravimetric analysis, grouped by retrofit stage and season 22

Figure 6. Size proportions of total suspended particles measured in each apartment measured by OPC-N2 monitors and gravimetric TSP analysis, grouped by season and evidence of smoking 24

Figure 7. Median indoor total suspended particles concentrations measured by gravimetric analysis. 26

Figure 8. Initial adaptive threshold values for the simulated environments derived from Dylos DC1700 measurements

Figure 9. Absolute mean exposure reduction (upper portion, left axis) and runtime (lower portion, right axis) of the selected thresholds using a CADR/V ratio of 2.5 for the simulated environments derived from Dylos DC1700 measurements

Figure 10. Absolute removal efficacy (absolute mean exposure reduction divided by runtime fraction) of constant air cleaning, a fixed threshold of $8.8 \mu \mathrm{g} \cdot \mathrm{m}^{-3}$, and an adaptive threshold for the simulated environments derived from Dylos DC1700 measurements. 
Figure 11. Marginal absolute mean exposure reduction (AMER, left axis) and marginal absolute increase in runtime (right axis) as the fixed threshold is reduced................................................. 44 


\section{Chapter 1: \\ Motivation}

\subsection{Particulate matter}

Particulate matter (PM) refers to an airborne mixture of small particles and liquid droplets [1]. PM is generated by a wide array of outdoor and indoor sources, both natural and anthropogenic [2-5]. Outdoor sources include emissions from vehicles and industrial processes, as well as wildfire smoke and the aerosolization of soils and sea salt [4,5]. Indoor sources of PM often involve combustion, such as cooking, smoking, and burning incense or candles [2-5]. However, PM is also generated by non-combustion sources such as electronic air fresheners and essential oil diffusers [6]. PM can also be generated or resuspended by movement, cleaning, and other agitation of surfaces [2]. PM can infiltrate from outdoors or from adjoining indoor spaces $[2,5,7,8]$. Simply put, PM is ubiquitous in virtually all environments. PM is nonetheless one of the most harmful air pollutants in terms of its chronic health impact [9], although its toxicity depends on both its size and composition. Smaller particles are able to more deeply penetrate the respiratory tract: chronic exposure to $\mathrm{PM}_{2.5}$ (PM with a diameter less than $2.5 \mu \mathrm{m}$, often referred to as fine PM) is widely linked to cardiovascular and respiratory illness while acute increases in concentration can aggravate existing conditions such as coronary heart disease and asthma [4,9]; ultrafine particles (PM with a diameter less than $0.1 \mu \mathrm{m}$, or $\left.\mathrm{PM}_{0.1}\right)$ can directly enter the bloodstream and lymphatic system through the lungs or by directly penetrating the skin and eyes $[5,10,11] . \mathrm{PM}_{2.5}$ produced by combustion sources including tobacco smoke, burning fuel and forest fires have been shown to be especially harmful, and in some cases carcinogenic [12-14]. Health Canada recommends that residential $\mathrm{PM}_{2.5}$ concentrations be kept as low as possible since there is no threshold that clearly eliminates health issues [15].

\subsection{Social housing}

In $2019,10.1 \%$ of the Canadian population and $10.5 \%$ of the American population were respectively classified as low-income persons [16,17]. Consequently, the 2018 Canadian Housing Survey reported 628,700 households living in social and affordable housing [18] while the 2019 American Housing Survey reported 906,000 occupied public housing units and approximately 3.6 million households receiving other forms of rental assistance [19]. Residents 
of low-income housing are largely children or seniors and/or have a disability [20-22], factors which increase their vulnerability to health problems [23-25]. It should therefore be of great concern that previous reviews of indoor environmental quality have reported that $\mathrm{PM}_{2.5}$ exposure is disproportionately higher for residents of social housing and other low-income housing [26,27]. The first component of this research investigates the variation of $\mathrm{PM}_{2.5}$ concentration in social housing to understand how this disparity arises and to inform the development of strategies which improve indoor air quality (IAQ) and promote universally better health outcomes for this large segment of the population.

\subsection{Particle filtration}

The second component of this research examines the efficacy of particle filtration as a strategy to reduce occupant exposure to indoor PM. Particle filtration systems such as HVAC filters and portable air cleaners (PACs) are commonly employed to reduce indoor PM concentrations and occupant exposure [28-31]. This has demonstrable health benefits for building occupants and seniors in particular $[28,31,32]$. PACs are a relatively inexpensive way to potentially improve IAQ as they can be easily deployed in homes without central HVAC systems and do not require retrofitting. In the context of social housing and low-income housing this is significant: many buildings such as those evaluated in this research do not have central HVAC systems, and performing major retrofits can be both expensive and disruptive to occupants. Efficacy concerns about PACs involve user compliance, especially when the system generates noise, as well as the level of exposure reduction that can be achieved and potentially the cost of energy usage [3335]. This research evaluates how the exposure reduction can be optimized while reducing the system runtime, and therefore fan noise and total energy usage as well. Improving the viability and sustainability of particle filtration means could, in combination with other IAQ strategies, help to improve the health of social housing residents and the wider population. 


\section{Chapter 2: \\ Particulate matter concentrations in social housing}

Reference: Mendell, A. Y., Mahdavi, A., Siegel, J. A. 2021. Particulate matter concentrations in social housing. Submitted to Sustainable Cities and Society.

\subsection{Abstract}

Multifamily buildings generally, and social housing specifically, are an important component of most urban environments. Residents of social housing are often exposed to higher concentrations of indoor pollutants. We measured particulate matter (PM) concentrations in 91 smoking and non-smoking apartments across seven social housing buildings in Toronto, Canada before and after energy retrofits. Particle concentrations varied greatly within and between apartments. Of the four environmental factors examined (smoking, season, building, and retrofit status), only smoking $(p<0.001)$ had a significant effect across all measurements. PM concentrations were two to three times higher in smoking apartments. PM concentrations in non-smoking apartments from this study were two times higher than comparable measurements from 21 single-family homes in Toronto that used the same particle monitor. A source detection algorithm reported elevated PM concentrations during $57 \% \pm 12 \%$ of each monitoring period, which was higher than in the single-family homes, suggesting that indoor sources are likely responsible for the concentration differences. Overall, we found that PM concentrations are disproportionately higher in social housing buildings which likely contribute to health disparities and highlight the importance of exposure reduction strategies in this important urban building type. 


\subsection{Introduction}

Particulate matter (PM) is an important air pollutant that arises from a number of indoor and outdoor sources [2-5]. Despite its ubiquity, PM is among the most harmful air pollutants in terms of its cumulative health impact [9]. Chronic exposure to $\mathrm{PM}_{2.5}$ (PM with a diameter less than $2.5 \mu \mathrm{m}$ ) is widely linked to cardiovascular and respiratory illness while acute increases in concentration can aggravate existing conditions such as coronary heart disease and asthma [4,9]. There is no concentration threshold at which the adverse health effects of $\mathrm{PM}_{2.5}$ exposure are clearly eliminated [15,36-39]. Given that North Americans spend more than $65 \%$ of their time in the home [40,41], the indoor environments of residential buildings are a major component of $\mathrm{PM}_{2.5}$ exposure. Health Canada recommends that residential $\mathrm{PM}_{2.5}$ concentrations be kept as low as possible [15].

Multi-unit residential buildings are one of the dominant building types in urban areas, many of which provide social housing (rental units subsidized by the government or government-funded agencies) or low-income housing. The 2018 Canadian Housing Survey reported 628,700 households living in social and affordable housing [18] while the 2019 American Housing Survey reported 906,000 occupied public housing units and approximately 3.6 million households receiving other forms of rental assistance [19]. In 2019, low-income persons accounted for $10.1 \%$ of the Canadian population and $10.5 \%$ of the American population respectively $[16,17]$. Social housing and low-income housing are likewise prevalent in cities outside of North America [42-46]. Reviews of indoor environmental quality by Adamkiewicz et al. [26] and Diaz Lozano Patiño and Siegel [27] reported that $\mathrm{PM}_{2.5}$ exposure is disproportionately higher for residents of social housing. This disparity has been attributed to numerous factors, many of which arise from the tendency of social housing to be built in urban areas where outdoor air quality is generally worse and housing density is greater. Low-income housing is disproportionately located near outdoor sources of $\mathrm{PM}_{2.5}$ such as major roadways and industrial buildings [26]. $\mathrm{PM}_{2.5}$ and other pollutants can spread between apartments in multi-unit residential buildings [7,8,47-49]. The impact of indoor and outdoor sources can be compounded by building factors such as underventilation or increased infiltration from outdoors respectively [26], and social factors such as an increased prevalence of smoking among populations with lowsocioeconomic status (SES) $[26,50,51]$ given that smoking has been shown to significantly 
increase indoor $\mathrm{PM}_{2.5}$ concentrations [3,7,8,52-55]. Although energy retrofits are sometimes cited as a means to reduce carbon emissions and improve thermal comfort in social housing, the impact of retrofits on $\mathrm{PM}_{2.5}$ concentration is mixed [27]. Considering that residents of lowincome housing disproportionately have low-SES, are largely children or seniors [20,21], and/or have a disability [22], there is an increased vulnerability to health problems among this large segment of the population [23-25]. Therefore, it is crucial to investigate the variation of $\mathrm{PM}_{2.5}$ concentration in social housing to understand how this disparity arises and to inform the development of strategies which improve IAQ and promote universally better health outcomes.

This study examined PM concentrations measured in smoking and non-smoking apartments across seven social housing buildings in Toronto, Canada. Measurements were collected before and after comprehensive retrofits were performed with the goal of lowering the energy use of these buildings. Previous investigations of these buildings have reported on pre-retrofit thermal comfort [56], occupant perceptions of indoor environmental quality [57], semivolatile organic compound concentrations [58], and the impact of energy retrofits on thermal comfort and carbon savings [59]. This paper considers PM concentrations in the context of smoking, season, building, and retrofit status with the larger goals of evaluating potential exposure disparities in this study population and assessing the impacts of building retrofits. To examine potential disparities in PM exposure, results are compared with a contemporaneous investigation of PM concentrations in 21 single-family dwellings (SFDs) in Toronto by the same research team using similar methods (previously reported in Zhang et al. [60] and Mahdavi and Siegel [61]). To our knowledge, there has not previously been a direct comparison between PM concentrations measured in homes with lower- and higher-SES. This study is also among the first to investigate PM concentrations in Canadian social housing buildings.

\subsection{Methods}

\subsubsection{Building characteristics}

Seven multi-unit social housing buildings located at three sites in Toronto, Canada were selected for a larger project evaluating the influence of energy retrofits on indoor environmental quality and energy efficiency. The retrofitting performed on these buildings primarily addressed thermal comfort and energy usage concerns by improving the space heating systems, a common approach 
for social housing buildings [59]. Retrofits did not include any changes to the building enclosure [59]. Occupant surveys were administered to occupants of 180 apartments, and participants were recruited from this larger group in approximate apportionment to the number of apartments in each building. Altogether, measurements were collected from 91 different apartments. Participants who dropped out of the study were replaced throughout the duration of the investigation.

Measurements for this study were collected during four rounds, two before and two after the buildings were retrofitted (2015 and 2017 respectively). In each year, there was one term during the spring season (late May, June, and early July) and one during the fall season (November and early December). In Toronto, summer concentrations are 30-40\% higher than in winter, while differences between spring and fall are very small [62]. Each monitoring period in a given apartment lasted for seven days during one of these rounds. Table 1 summarizes the characteristics of each building and the total number of apartments where any measurements were collected in these buildings during each round. 
Table 1. Summary of building characteristics and number of apartments measured during each round. Parentheses indicate the number of suites with evidence of smoking.

\begin{tabular}{|c|c|c|c|c|c|c|c|c|c|}
\hline \multirow[b]{2}{*}{ Site } & \multirow[b]{2}{*}{ Bldg. } & \multirow[b]{2}{*}{$\begin{array}{l}\text { Year } \\
\text { built }\end{array}$} & \multirow[b]{2}{*}{$\begin{array}{c}\text { No. } \\
\text { floors }\end{array}$} & \multirow[b]{2}{*}{$\begin{array}{l}\text { Total } \\
\text { no. of } \\
\text { suites } \\
\end{array}$} & \multirow[b]{2}{*}{$\begin{array}{c}\text { Intended } \\
\text { occupancy } \\
\text { type* }\end{array}$} & \multicolumn{4}{|c|}{ Number of participating apartments } \\
\hline & & & & & & $\begin{array}{c}\text { Spring } \\
2015 \\
\end{array}$ & $\begin{array}{c}\text { Fall } \\
2015\end{array}$ & $\begin{array}{c}\text { Spring } \\
2017 \\
\end{array}$ & $\begin{array}{c}\text { Fall } \\
2017\end{array}$ \\
\hline \multirow{2}{*}{1} & A & 1972 & 4 & 213 & Senior & $10(2)$ & $9(2)$ & $12(2)$ & $13(2)$ \\
\hline & $\mathrm{B}$ & 1972 & 4 & 184 & Senior & $9(4)$ & $7(3)$ & $8(3)$ & $8(3)$ \\
\hline \multirow{3}{*}{2} & $\mathrm{C}$ & 1965 & 7 & 217 & Bachelor & $12(6)$ & $11(7)$ & $12(8)$ & $10(7)$ \\
\hline & $\mathrm{D}$ & 1965 & 7 & 58 & Senior & $4(1)$ & $3(1)$ & $3(1)$ & $3(1)$ \\
\hline & $\mathrm{E}$ & 1965 & 11 & 196 & Bachelor & $11(4)$ & $11(4)$ & $12(3)$ & $12(3)$ \\
\hline \multirow{2}{*}{3} & $\mathrm{~F}$ & 1974 & 19 & 175 & Family & $10(2)$ & $9(2)$ & $10(2)$ & $10(2)$ \\
\hline & $\mathrm{G}$ & 1974 & 18 & 204 & Family & $10(0)$ & $7(1)$ & $9(1)$ & $9(1)$ \\
\hline
\end{tabular}

*Senior occupancy buildings were comprised of studio (Buildings A and B only) and onebedroom apartments. Bachelor occupancy buildings were studio apartments only. Family occupancy buildings were comprised of one- to three-bedroom apartments.

All seven buildings were built between 1965 and 1974, had exterior concrete masonry walls clad with brick, and range in height from 4 to 19 storeys. The fenestration ratio and orientation of apartments are described in Vakalis et al. [57]. The sites are located in the northwestern quadrant of the city and are between $1.3 \mathrm{~km}$ and $2.1 \mathrm{~km}$ away from major roadways. Ventilation was supplied to the buildings using corridor pressurization, which preliminary investigations found to underperform design requirements [57]. To address this issue, larger air handling units were installed in four buildings (comprising Sites 1 and 3) during retrofitting [59]. Previous research in buildings of a similar age and construction type has found that inter-unit airflow can present a significant concern and that corridor pressurization can fail to reliably deliver ventilation to individual apartments [49].

It has also been established that smoking is an important source of indoor $\mathrm{PM}_{2.5}[3,7,8,52-55]$, and that second-hand smoke can transfer between apartments in multi-unit buildings $[7,8,47,48]$. To allow for investigation of tobacco smoke as an environmental factor, the smoking status of 
each apartment was assessed through the occupant survey as well as through evidence (such as the odour of tobacco smoke or visible smoking items) noted during the deployment of instruments. Cannabis use (illegal for recreational use at the time) was not evaluated, and electronic cigarettes (reported by residents in two apartments) were not considered to be smoking for the purposes of this investigation. Additional information regarding the determination of smoking status can be found in Appendix A1.1.

\subsubsection{Measurements}

The two types of PM measurements that we collected were time-resolved number concentrations and integrated total suspended particles (TSP) mass concentrations. Continuous number concentrations were measured with optical particle counters owing to their low cost, robustness, and acceptability to occupants. Two optical particle counters were used: Dylos DC1700 sensors were deployed during pre-retrofit monitoring periods, as well as limited post-retrofit monitoring during the fall season. Alphasense OPC-N2 sensors were deployed only in post-retrofit monitoring periods. TSP concentrations provide an additional measure of total particle mass during each monitoring period. High efficiency media filters were deployed in Amaircare XR100 portable air cleaners to allow for evaluation of TSP. The collection of these filter samples also provides the opportunity for compositional analysis of the PM during other investigations. All measurement devices were installed high on the walls of living rooms. A complete list of the recruited apartments and the respective measurement devices installed in them during each monitoring period can be found in Appendix A1.2. Sample sizes for the optical particle counter and TSP measurements during each monitoring period are reported in Table 2. 
Table 2. Number and model of sensors deployed during each monitoring period and meeting quality control (discussed below). Parentheses indicate the number of apartments with evidence of smoking.

\begin{tabular}{|c|c|c|c|c|c|c|}
\hline \multirow[b]{2}{*}{ Measurement type } & \multirow[b]{2}{*}{ Device } & \multirow[b]{2}{*}{ Retrofit stage* } & \multicolumn{4}{|c|}{ Season } \\
\hline & & & All & Spring & Fall & Both \\
\hline \multirow{4}{*}{$\begin{array}{l}\text { Continuous } \\
\text { particulate matter }\end{array}$} & \multirow{3}{*}{$\begin{array}{l}\text { Dylos } \\
\text { DC1700 }\end{array}$} & Pre & $66(20)$ & $56(16)$ & 48 (18) & $39(14)$ \\
\hline & & Pre \& Post & $5(2)$ & - & $5(2)$ & - \\
\hline & & Post & $8(2)$ & - & $8(2)$ & - \\
\hline & $\begin{array}{l}\text { Alphasense } \\
\text { OPC-N2 }\end{array}$ & Post & $63(16)$ & 49 (12) & $53(15)$ & $39(11)$ \\
\hline \multirow{3}{*}{$\begin{array}{l}\text { Total suspended } \\
\text { particles }\end{array}$} & \multirow{3}{*}{$\begin{array}{l}\text { Amaircare } \\
\text { XR-100 } \\
\text { with high- } \\
\text { efficiency } \\
\text { media filter }\end{array}$} & Pre & $33(12)$ & - & $33(12)$ & - \\
\hline & & Pre \& Post & $24(9)$ & - & $24(9)$ & - \\
\hline & & Post & $60(20)$ & $53(18)$ & 49 (17) & $42(15)$ \\
\hline
\end{tabular}

*Pre \& Post retrofit stage indicates the number of paired measurements from the same unit

PM concentrations were measured by Dylos DC1700 sensors as particle counts $\left[\mathrm{m}^{-3}\right]$ for two channels of $>0.5 \mu \mathrm{m}$ (small) and $>2.5 \mu \mathrm{m}$ (large) sampled at intervals of one minute. A particle count with size range $0.5-2.5 \mu \mathrm{m}$ was calculated by subtracting the large channel from the small channel as this has been found to correlate with $\mathrm{PM}_{2.5}$ mass concentrations [63-65]. An equivalent mass concentration was computed using the $\mathrm{PM}_{2.5}$ conversion factor from Semple et al. [63] because that investigation also considered homes with smoking. The Dylos DC1700 may underestimate measurements at concentrations exceeding the equivalent of $600 \mu \mathrm{g} \cdot \mathrm{m}^{-3}$, which is rarely exceeded in homes with or without smoking [63]. OPC-N2 monitors measured particle counts in discrete bins and computes a mass concentration of $\mathrm{PM}_{2.5}$ and $\mathrm{PM}_{10}\left[\mu \mathrm{g} \cdot \mathrm{m}^{-3}\right]$ determined by the device software sampled at $15.379 \mathrm{~s}$ intervals [66]. OPC-N2 monitors have been found to considerably overestimate and underestimate mass concentrations of various aerosols, and have demonstrated a tendency to overestimate measurements when relative humidity is high [67-69]. To our knowledge, there has not been an evaluation of the OPC-N2 response to tobacco smoke. After comparing particle counts measured synchronously by the DC1700 and OPC-N2 $(0.54-2.07 \mu \mathrm{m}$ bins $)$ in five apartments as well as in a controlled laboratory environment, we determined that there is too much difference in response to make direct comparisons between the two devices. 
While each monitoring period lasted seven days, data were not always successfully collected for the entire period. On occasion, the optical particle counters lost power, were unplugged by the occupants, or otherwise failed resulting in missing or unusable data. To ensure that each monitoring period was a representative sample, we required that approximately 2.5 days of nonzero measurements be collected to be included in analysis. For the DC1700, this corresponded to 3,500 measurements at one-minute intervals. For the OPC-N2, this corresponded to 15,000 measurements at 15.379-second intervals. This requirement resulted in the exclusion of 15 preretrofit DC1700 (4 smoking), 3 post-retrofit DC1700 (1 smoking), and 22 OPC-N2 (11 smoking) monitoring periods. All zeros (approximately 4.3\% of Dylos DC1700 measurements not previously excluded) were replaced with missing values because zero values are an indication of a monitor failure rather than zero concentrations.

In addition to characterizing the PM concentrations in these homes using the optical particle counter measurements, we were interested in characterizing how frequently these PM concentrations were elevated during each monitoring period. The purpose of this was to assess whether the frequency of activity drives the median particle concentration in these homes and to compare our findings to previous studies in other homes. A source detection algorithm similar to the one described in Zhang et al. [60] was developed to provide an approximate measure of these source affected proportions (SAPs). The source detection algorithm was designed to determine the beginning and end of each source event (an activity such as cooking or smoking that would increase the measured PM concentration). In the context of the source detection algorithm, source events were defined by the following criteria: 1) all concentrations in a source event exceed a baseline threshold (peak value of the probability density function of all sample plus 0.35 times the median average deviation of the sample), 2) the instantaneous rate of change between two measurements must exceed a threshold at least once during a source event $\left(85^{\text {th }}\right.$ percentile of sample), and 3) each source event must be longer than a defined length of time (10 minutes). The source detection algorithm and the justification for the specific values used is further detailed in Appendix A1.3. The SAP reports the percentage of time during a monitoring period that the source detection algorithm determines are source events. The method from Dobson and Semple [70] to differentiate smoking from other sources detection was incorporated 
into our source detection algorithm to evaluate smoking frequency in the DC1700 monitoring periods.

TSP concentrations were measured using the mass collected on $12.7 \mathrm{~cm}$ diameter circular high efficiency media filters deployed in Amaircare XR-100 air cleaners, the device flow rates, and the operation duration. The TSP mass was measured by the differential weighing of the filters before and after the 1-week deployments using a Sartorius MSE225S microbalance after at least 48 hours of filter conditioning under a relatively constant temperature and relative humidity condition. Besides the filters deployed in XR100 air cleaners, blank filter samples were also deployed randomly in a small fraction of suites in each deployment round for gravimetric correction purposes and TSP mass uncertainty evaluations. The flow rates of the XR100 air cleaners were measured using an Energy Conservatory Microleakage meter (MLM) and a test chamber. Briefly, we used each air cleaner to pressurize a sealed box and used the MLM to adjust the box to zero pressure difference with respect to the surrounding environment. The flow through the MLM is therefore the flow through the air cleaner. The flow was measured before and after the deployment of each air cleaner and the average flow value was used to calculate the TSP concentrations. Additional information regarding the TSP concentration uncertainty is described in Appendix A1.4 and elsewhere in Wan et al. [71].

To understand how the measurements collected in this study compare to homes with different occupants and building types, we have included a comparison with measurements from two prior studies. One study examined a group of 21 single family dwellings (SFDs) in Toronto measured for a period of one year. These homes were previously described in Zhang et al. [60] and Mahdavi and Siegel [61], consisting primarily of detached and semi-detached houses with nonsmoking occupants (smoking evidence was observed in only one home at a very low selfreported frequency). These homes have continuous PM number concentrations measured by Dylos DC1700 as well as TSP measurements measured with differential weighing of filters in the central forced air HVAC systems. The second study examined 59 SFDs in semi-rural areas of Central Texas, USA, for which there are only comparable TSP measurements also from central forced air systems. These homes were previously described in Givehchi et al. [72]. Self-reported smoking rates were very low (2 homes out of 59), potentially owing to the fact that the investigation included many households of children with asthma. 


\subsubsection{Statistical analysis}

Due to the lack of the normality of the measured concentrations (as verified by Shapiro-Wilk tests) and to correct for multiple comparisons, we used non-parametric Bonferroni-corrected statistical tests. If an environmental factor (e.g., smoking, season, building, retrofit status) is found to have a significant influence, then all subsequent tests separate the data by that factor. Unpaired factors with two levels (smoking) are tested by apartment using a Wilcoxon rank sum test; paired factors with two levels (season) are tested by apartment using a Wilcoxon signed rank test; unpaired factors with more than two levels (building) are tested by building using a Kruskal-Wallis $H$ test; paired factors with more than two levels (retrofit status by building) are tested using a Friedman test. For factors tested by building, small sample sizes as well as variations in smoking prevalence and frequency may influence results. For the optical particle counter measurements, tests were performed using the median measurement from each monitoring period. All statistical tests were performed with R 4.0.3 and box plots were generated with R package ggplot2 3.3.2 [73,74].

\subsection{Results}

The continuous particulate matter measurements are presented first and are followed by the TSP measurements. Each of these sections tests the influence of environmental factors on the PM concentrations and compares the results with prior studies.

\subsubsection{Continuous particulate matter}

Figures 1 and 2 show the PM concentrations in each apartment as measured by the Dylos DC1700 (pre-retrofit) and Alphasense OPC-N2 (post-retrofit) optical particle counters respectively. Both figures distinguish monitoring periods by the smoking status of the apartment, the season when measurements were collected, and the building in which the apartment is situated. Figure 1 displays PM concentrations as both a particle count measured by the DC1700 monitor and an approximate mass concentration using the conversion factor reported in Semple et al. [63]. Given the differences between the two optical particle counters, caution should be exercised when directly comparing the concentrations in Figures 1 and 2. Similar caution should be exercised when comparing these results with other studies given the differences in 
instrumentation and monitoring approach. In general, these concentrations are lower than $[7,44,75]$ or similar to $[8]$ those reported in other investigations of social housing.

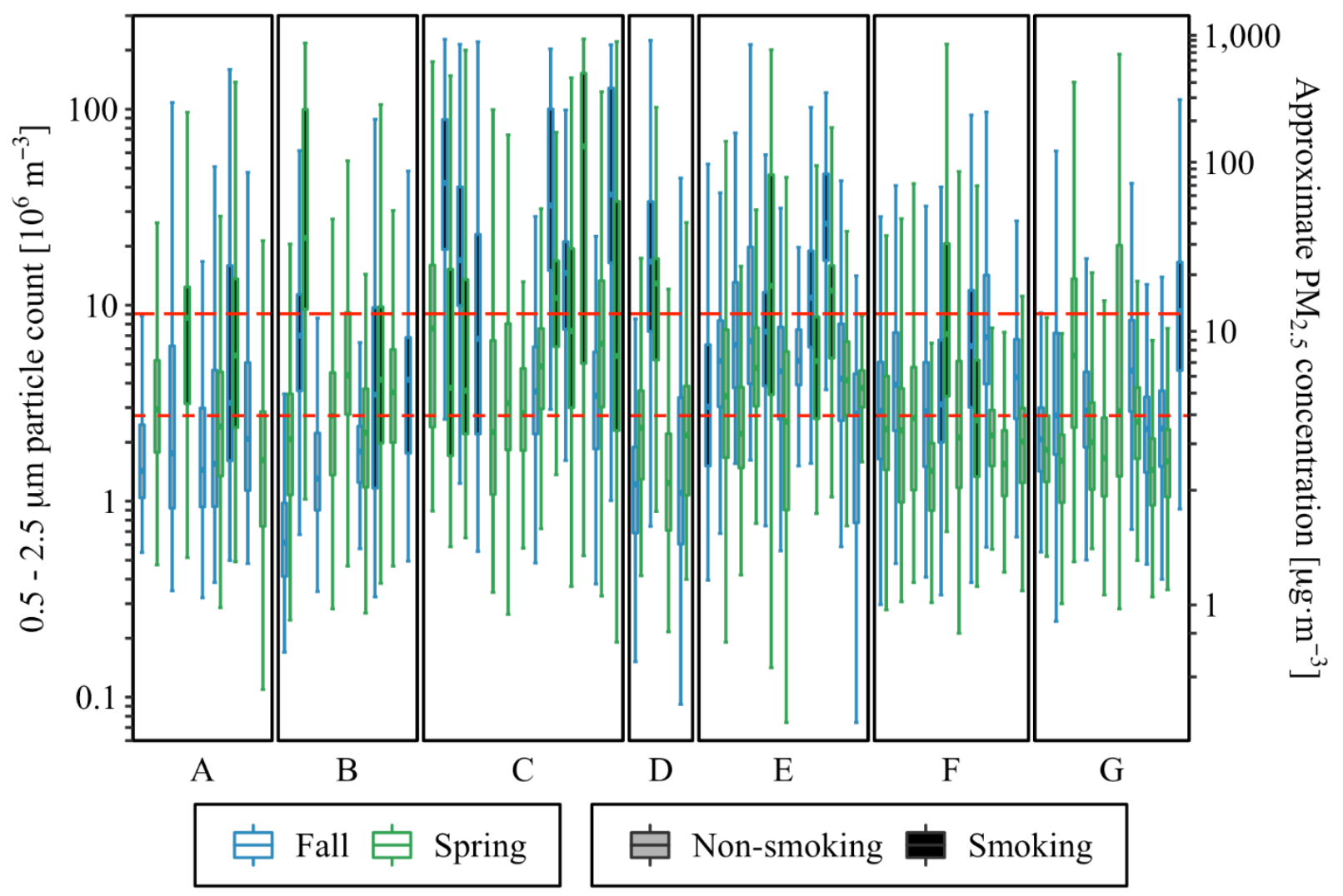

Figure 1. Pre-retrofit indoor PM number concentration of apartments measured by the Dylos DC1700 optical particle counter. Each box represents one period of measurement for one apartment. Apartments measured during both seasons are represented by adjacent boxes. Measurements are grouped by building (letters) and sorted from lowest to highest floor. For each box shown, the middle line represents the median concentration, the upper and lower box boundaries represent the 25 th and 75 th percentile of concentrations, and the whiskers represent 1.5 times the interquartile range from the upper or lower quartile. Outliers are not included to improve visual clarity. Red lines represent the median non-smoking (short dash) and smoking (long-dash) apartments. PM2.5 mass concentration (right-hand axis) is calculated using the conversion factor reported in Semple et al. [63]. 


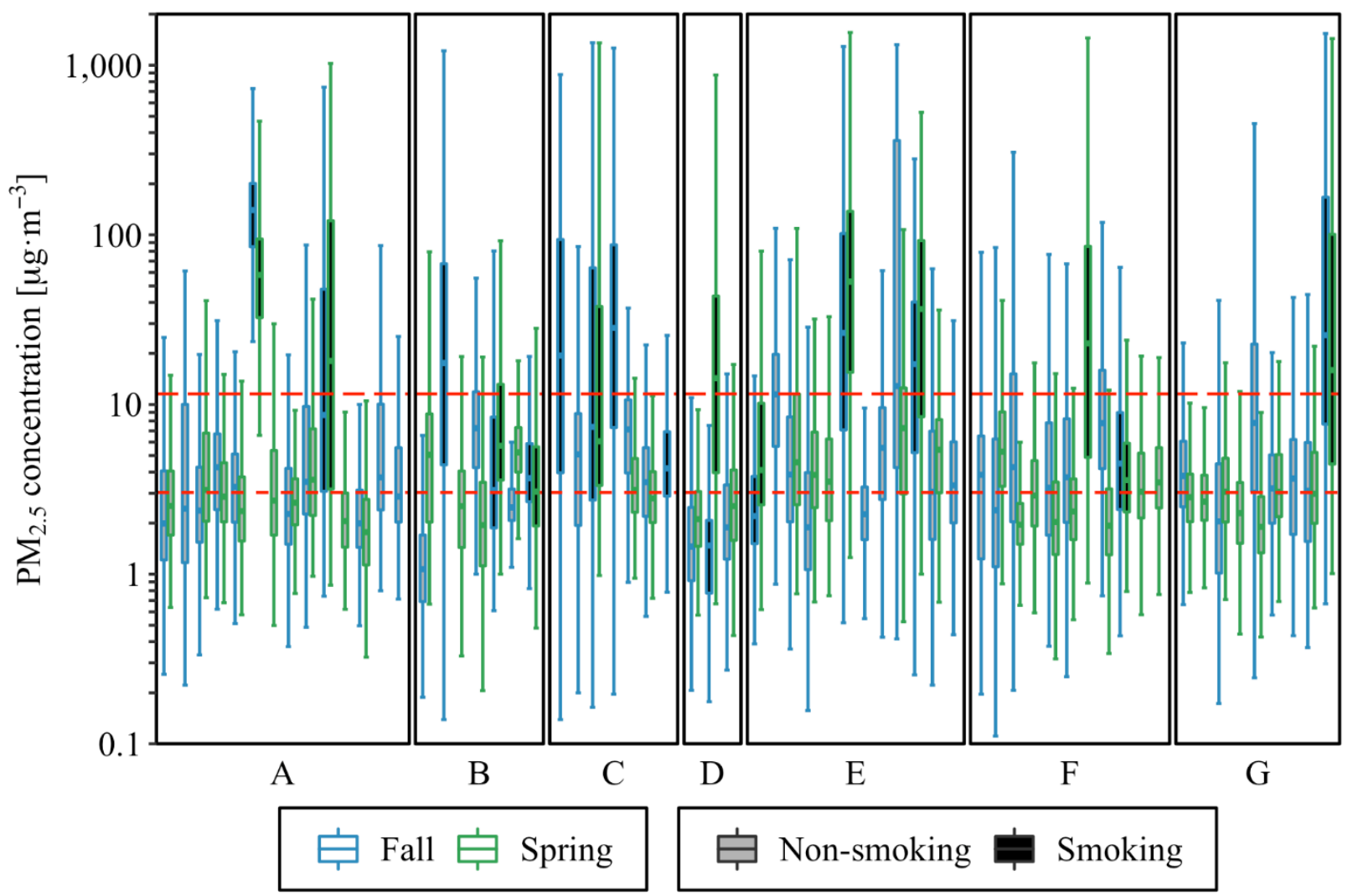

Figure 2. Post-retrofit indoor $\mathrm{PM}_{2.5}$ mass concentration of apartments reported by the Alphasense OPC-N2 optical particle counter. Each box represents one period of measurement for one apartment. Apartments measured during both seasons are represented by adjacent boxes. Measurements are grouped by building (letters) and sorted from lowest to highest floor. For each box shown, the middle line represents the median concentration, the upper and lower box boundaries represent the $25^{\text {th }}$ and $75^{\text {th }}$ percentile of concentrations, and the whiskers represent 1.5 times the interquartile range from the upper or lower quartile. Outliers are not included to improve visual clarity. Red lines represent the median non-smoking (short dash) and smoking (long-dash) apartments.

The median concentration was significantly different and two to three times higher in smoking apartments measured with both the DC1700 $(p<0.001)$ and the OPC-N2 $(p<0.001)$ monitors. For the DC1700 monitors, the median concentration was $8.4 \cdot 10^{6} \mathrm{~m}^{-3}(N=20)$ in smoking apartments compared with $2.7 \cdot 10^{6} \mathrm{~m}^{-3}(N=46)$ in non-smoking apartments. For the OPC-N2 monitors, the median concentration was $8.1 \mu \mathrm{g} \cdot \mathrm{m}^{-3}(N=16)$ in smoking apartments compared with $3.0 \mu \mathrm{g} \cdot \mathrm{m}^{-3}(N=47)$ in non-smoking apartments. The elevation of $\mathrm{PM}_{2.5}$ in homes with smoking is a common finding in other investigations, including those in multifamily low-income 
housing. Russo et al. [8] found that, in public housing buildings, $75^{\text {th }}$ percentile measurements in smoking apartments $\left(64.6 \mu \mathrm{g} \cdot \mathrm{m}^{-3}\right)$ when indoor smoking was permitted were more than six times greater than in non-smoking apartments $\left(10.6 \mu \mathrm{g} \cdot \mathrm{m}^{-3}\right)$, although this was reduced to a factor of more than two following a smoking ban. Semple et al. [53] measured PM using a DC1700 in primarily detached and semi-detached houses and found that smoking contributed to an increase by a factor of approximately 10 times. Median non-smoking homes had a concentration of 3 $\mu \mathrm{g} \cdot \mathrm{m}^{-3}$, similar to both our DC1700 and OPC-N2 PM2.5 measurements, whereas smoking homes had a median concentration of $31 \mu \mathrm{g} \cdot \mathrm{m}^{-3}$. While this concentration is three to four times higher than the median of all smoking homes in this study, several of the smoking homes have median measurements that are much higher and in closer agreement with Semple et al. [53]. This may be due the varying frequency with which occupants smoke tobacco (discussed further in Appendix A1.1) as well differences in building volume and ventilation rate. King et al. [7] found $\mathrm{PM}_{2.5}$ concentrations in multi-unit buildings were approximately three times higher in smoking (29.4 $\left.\mu \mathrm{g} \cdot \mathrm{m}^{-3}\right)$ vs. non-smoking $\left(10.2 \mu \mathrm{g} \cdot \mathrm{m}^{-3}\right)$ apartments and that inter-unit transfer was prevalent, as evidenced by the elevated concentrations in hallways $\left(18.9 \mu \mathrm{g} \cdot \mathrm{m}^{-3}\right)$. Continuous $\mathrm{PM}_{2.5}$ monitoring in Arku et al. [52] found that $\mathrm{PM}_{2.5}$ concentrations were higher in common areas of public housing buildings where smoking was permitted, and that $\mathrm{PM}_{2.5}$ concentrations were higher in the smoking-permitted buildings during the winter likely because of reduced air exchange due to keeping windows closed during colder weather. MacNaughton et al. [54] found reductions in continuous $\mathrm{PM}_{2.5}$ measurements of common spaces in public housing buildings after the implementation of a smoking ban. Since smoking has a large effect on the PM concentrations, all subsequent analysis will separate smoking from non-smoking homes.

We explored seasonal effects only in apartments measured in both seasons. The median concentration was not significantly different among smoking apartments measured with either the DC1700 $(p=0.091)$ or the OPC-N2 $(p=0.46)$ monitors. For the DC1700 monitors $(N=14)$, the median concentration was $7.6 \cdot 10^{6} \mathrm{~m}^{-3}$ in spring and $10.8 \cdot 10^{6} \mathrm{~m}^{-3}$ in fall. For the OPC-N2 monitors $(N=11)$, the median concentration was $9.3 \mu \mathrm{g} \cdot \mathrm{m}^{-3}$ in spring and $5.7 \mu \mathrm{g} \cdot \mathrm{m}^{-3}$ in fall. Among the non-smoking units, the median concentration was not significantly different measured with either the DC1700 $(p=0.084)$ or the OPC-N2 $(p=0.41)$ monitors. For the DC1700 monitors $(N=24)$, the median concentration was $2.5 \cdot 10^{6} \mathrm{~m}^{-3}$ in spring and $3.0 \cdot 10^{6} \mathrm{~m}^{-3}$ in fall. For the OPC-N2 monitors $(N=28)$, the median concentration was $2.8 \mu \mathrm{g} \cdot \mathrm{m}^{-3}$ in the spring 
and $3.1 \mu \mathrm{g} \cdot \mathrm{m}^{-3}$ in the fall. This result is not entirely consistent with the literature. Liu and Cui [62] found that $\mathrm{PM}_{2.5}$ concentrations in Toronto and 11 other cities in Ontario, Canada have considerable seasonal variation, with summer $\mathrm{PM}_{2.5}$ concentrations $30-40 \%$ higher than in winter. However, in Toronto the reported differences between spring and fall are very small. Our measurements were collected near the cusp of atmospheric seasons, with some spring measurements collected in early summer and some fall measurements collected in early winter. Zhang et al. [60] also reports similar outdoor $\mathrm{PM}_{2.5}$ concentrations during the spring and fall months of 2017 in Toronto (the same year as our post-retrofit measurements). We anticipated a larger seasonal effect because of the variation in ambient $\mathrm{PM}_{2.5}$ previously seen in Toronto (although there is substantial year-to-year variation as well) and because windows in these apartments were often opened year-round due to overheating (especially pre-retrofit) which would increase the air exchange rate.

Building-level effects were examined for all monitoring periods, combining measurements from both seasons when necessary. In smoking apartments, there was no significant difference in the median concentrations for either the DC1700 $(H(6)=8.8, p=0.18)$ or the OPC-N2 $(H(6)=5.0$, $p=0.54)$. In non-smoking apartments, there was a significant difference in the median concentrations measured by both the DC1700 $(H(6)=21.2, p=0.0017)$ and the OPC-N2 $(H(6)=$ $16.2, p=0.013)$. Post hoc analysis using a pairwise Wilcoxon signed rank test with Bonferroni correction only found a significant difference between the DC1700 measurements from Buildings A and $\mathrm{E}(p=0.012)$. The primary difference between the seven buildings in this study are their height and intended occupancy type, as they were built within a 10-year period using similar materials. Similar to our results, Arku et al. [52] did not find building height or occupancy type to have a statistically significant effect on $\mathrm{PM}_{2.5}$ measurements in common areas of public housing buildings. Caution should be taken with interpreting building-level effects in our study because of small sample sizes (as low as one in some buildings), varying amounts of smoking in the measured sample, and varying amounts of smoking in the buildings as a whole.

Owing to differences between the two optical particle counters, we restricted pre- and postretrofit comparisons to the small number of homes that had a Dylos DC1700 monitor installed post-retrofit; this comparison is also made using TSP measurements later in this section. Despite an approximately $25 \%$ reduction in the median particle concentration in non-smoking apartments after retrofitting $\left(2.0 \cdot 10^{6} \mathrm{~m}^{-3}\right)$ compared to before $\left(2.7 \cdot 10^{6} \mathrm{~m}^{-3}\right)$, this is not a significant result $(p$ 
$=0.55)$ likely due to the small sample size of post-retrofit measurements. To examine whether the increased corridor pressurization ventilation at Sites 1 and 3 had a noticeable effect on postretrofit concentrations, the ranks of the median apartment in each building were compared preand post-retrofit using the DC1700 and OPC-N2 monitors respectively. No significant difference was found in smoking $\left(\chi^{2}(6)=4.3, p=0.64\right)$ or non-smoking $\left(\chi^{2}(6)=12.0, p=0.062\right)$ apartments, although similar caution should be taken when interpreting these results due to the sample sizes and variation in smoking prevalence between buildings.

Figure 3 shows a considerable overlap in the particle concentrations measured with the DC1700 monitors before and after retrofitting. This comparison is particularly valuable given that the same particle counters were used in both studies and can therefore be directly compared with one another. In the post-retrofit group, the two apartments with smoking had the highest median particle concentration. The median particle concentrations are significantly higher than the single-family dwellings in Zhang et al. [60], both when considering all apartments $(p<0.001)$ and only non-smoking apartments $(p<0.001)$. The non-smoking apartments have a median particle concentration that is greater than the SFDs by a factor of approximately two $\left(2.7 \cdot 10^{6} \mathrm{~m}^{-3}\right.$ vs. $\left.1.4 \cdot 10^{6} \mathrm{~m}^{-3}\right)$. 


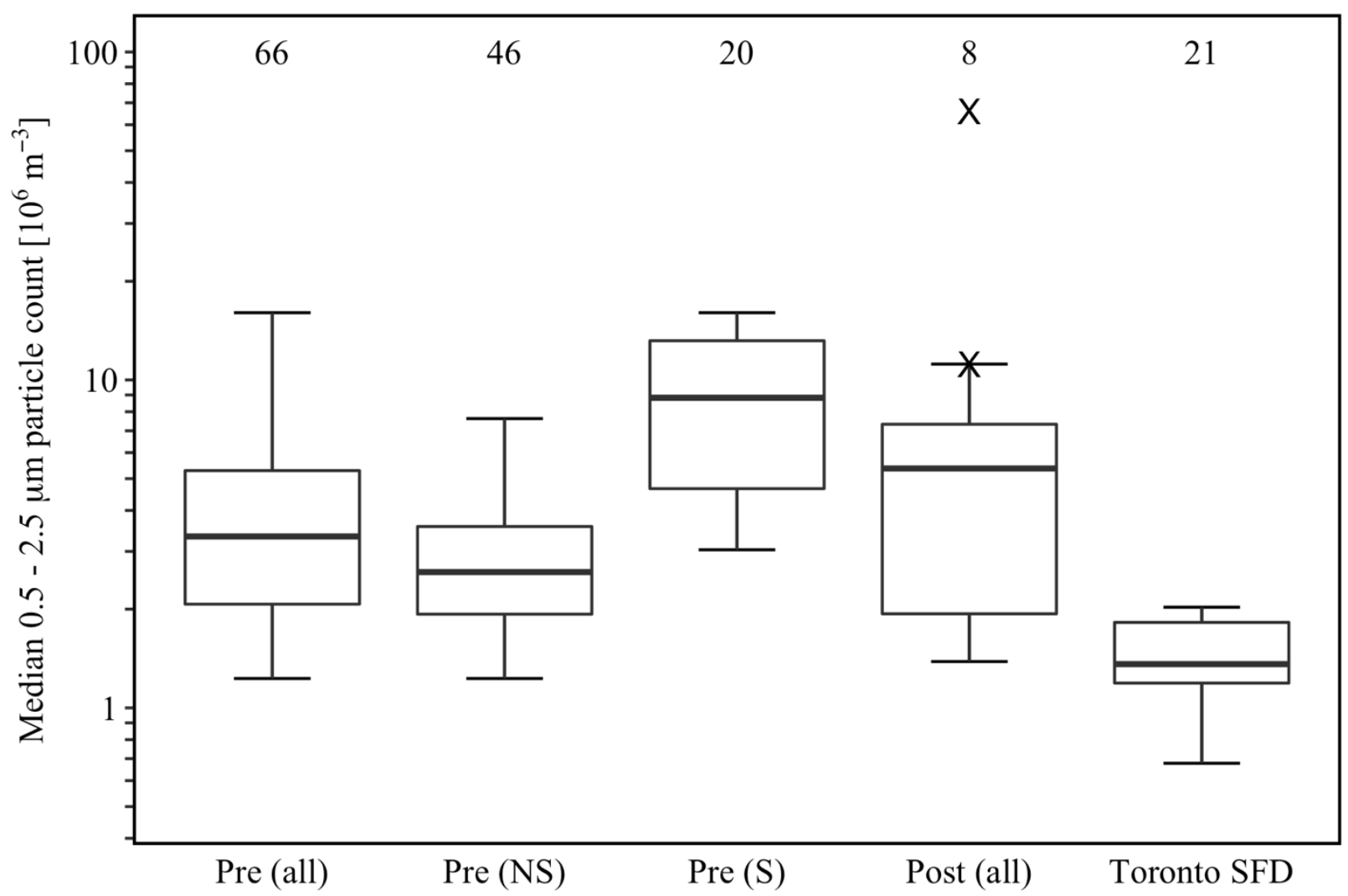

Figure 3. Median indoor $0.5-2.5 \mu \mathrm{m}$ particle count of apartments measured by the Dylos DC1700 monitors. The numbers displayed at the top indicate the number of apartments in each group. NS and S refer to non-smoking and smoking respectively. The two smoking apartments measured post-retrofit are represented by X's. Toronto single-family dwelling (SFD) measurements are from Zhang et al. [60].

Although the same particle counters were used in both studies, there are differences in how they were deployed between this investigation and the SFDs that may influence the results. Namely, the length of monitoring periods (one week compared with one year), the frequency of measurement (every minute vs. every hour), and where the sensors were installed (high on the walls of living rooms in these apartments compared with convenient central locations in the SFDs). However, the higher concentrations in social housing apartments can be explained by factors common in multi-unit buildings, especially those which serve as low-income and social housing. The average floor area of these homes is much smaller than the single-family dwellings, resulting in a greater source density. This means that a larger proportion of activities (e.g., cooking, cleaning, smoking) in the home take place in closer proximity to the optical particle counters and the indoor air pollution generated by these activities is concentrated in a smaller 
space [76]. As described in Vakalis et al. [57], residents of these apartments reported being frequently bothered by unwanted odours from their own cooking, neighbours' cooking, neighbours' smoking, and from outdoors. This suggests that infiltration from neighbouring units may be a significant source of pollutants and $\mathrm{PM}_{2.5}[7,8]$. Cooking odours may be explained by the reportedly infrequent use of range hoods and because many apartments did not have one in their kitchen [57]. Cooking has been shown to be an important source of PM in homes, and the inadequate use or availability of range hoods may contribute to elevated concentrations of $\mathrm{PM}_{2.5}$ $[3,55,77]$. Another consideration is that low-SES housing tends to be found in closer proximity to major sources of outdoor air pollution such as roadways and industrial buildings [26]. To our knowledge, there have not been any other direct comparisons between continuous PM measurements from lower- and higher-income homes. The results of this study indicate that a disparity in indoor air quality exists between residents of these housing types, which may result in negative health outcomes.

To determine how indoor PM concentrations are influenced by source frequency and source strength, the source affected proportion measured by our source detection algorithm was compared with the median concentration from each respective monitoring period. Smoking and non-smoking apartments were tested separately to determine whether the source strength of tobacco smoke influences this relationship. Measurements from the Dylos DC1700 monitors are compared with the Toronto SFD homes using the SAPs reported in Zhang et al. [60]. While measurements from both studies were processed using a similar source detection approach, there are differences in the sampling frequency (every minute vs. every hour) and duration (one week vs. one year) that should be considered when making comparisons. Figure 4 shows the source affected proportion of each monitoring period measured with the DC1700 monitors. Smoking does significantly affect the SAPs $(p=0.030)$, corresponding to only a small increase of $61 \%$ in smoking apartments compared to $57 \%$ in non-smoking apartments. 


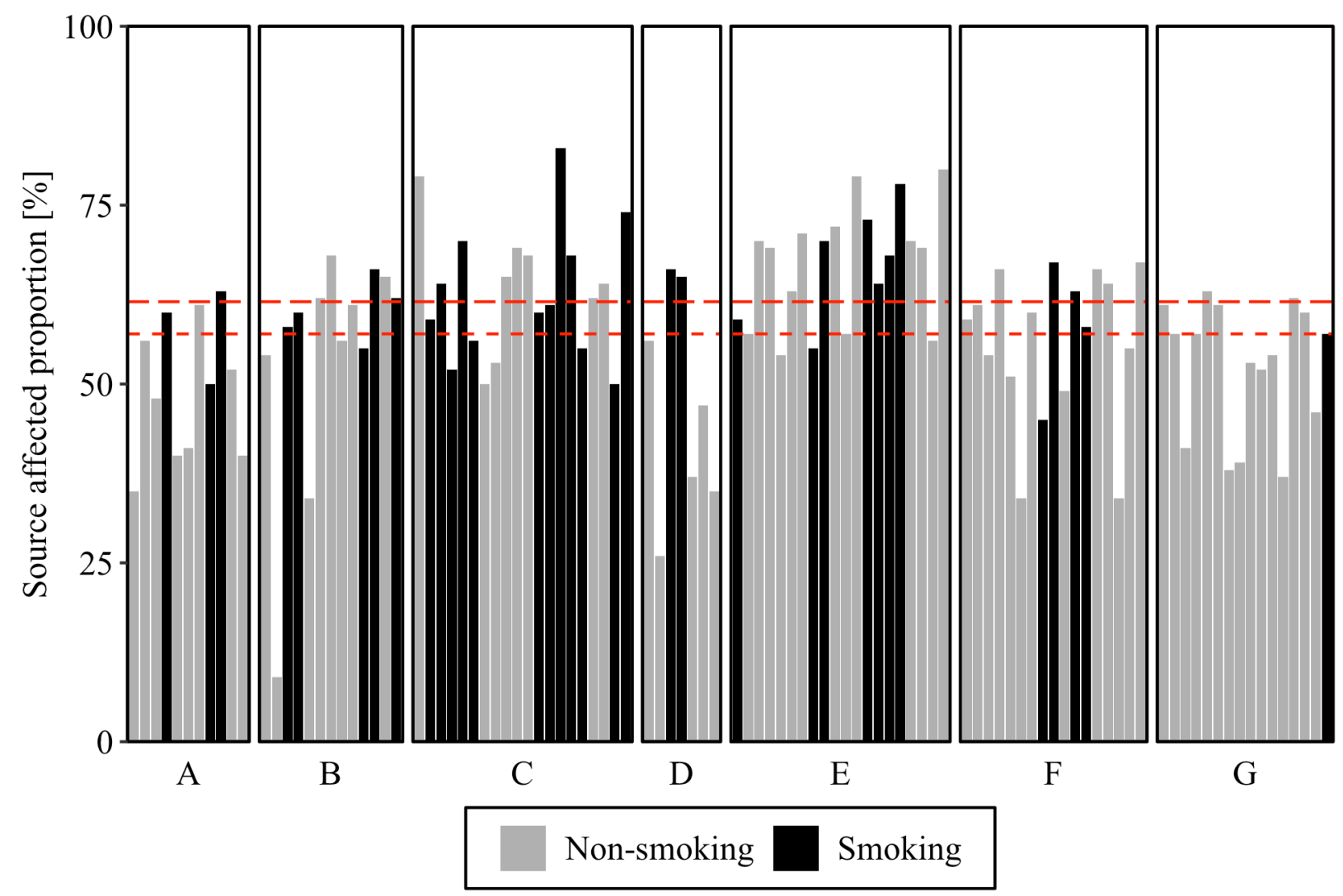

Figure 4. Source affected proportion (SAP) of each Dylos DC1700 monitoring period in nonsmoking $(N=69)$ and smoking apartments $(N=35)$, grouped by building. Red lines represent the median SAP of all monitoring periods from non-smoking (short dash) and smoking (longdash) apartments.

The SAPs measured in the social housing apartments are significantly larger than in the SFDs $(p$ $<0.001$ ), ranging from $9 \%$ to $83 \%$ (mean $57 \% \pm 11 \%$ std. dev.) compared with $39.5 \%$ to $51.6 \%$ (mean 44.9\% $\pm 3.1 \%$ std. dev.) [60]. The one apartment/monitoring period with a SAP of $9 \%$ does appear to have very low activity during that week while the second-lowest SAP is $26 \%$. There are several possible reasons why the SAPs would be higher in the social housing apartments: the occupants may be home for a larger proportion of time, since many of the people living in social housing are older, unable to work, and/or underemployed which can lead to spending more time at home. There is also the issue of greater source density due to the smaller size of the homes (discussed previously). It is also likely that some proportion of the sources being detected are due to infiltration from neighbouring apartments or from outdoors, which our measurements cannot distinguish from indoor sources. The Spearman rank correlation between SAP and median particle concentration in this study is 0.86 for non-smoking apartments and 0.37 
for smoking apartments, a result which suggests that the median PM concentration is higher in homes with smoking regardless of other activities, perhaps due to the strength of tobacco smoke as a source. This result suggests that residents of social housing buildings, even when they do not smoke or live with a smoker, spend a relatively greater period of their time at home in a space with elevated PM compared to those who live in single-family dwellings. This finding is discussed in more detail in the Discussion, but it is particularly important in the context of urban carbon footprints and building retrofits which may increase building air tightness and thus increase exposure to indoor-generated particles.

When the source detection algorithm is applied to measurements from the OPC-N2 monitors which report mass concentrations rather than particle counts, the SAPs range from $0 \%$ to $77 \%$ (mean 29\% $\pm 19 \%$ std. dev.) with an interquartile range from 15\% to 44\%. The Spearman rank correlation between SAP and median particle concentration is 0.87 for non-smoking apartments and 0.93 for smoking apartments. Despite the difference in results, the algorithm performs with a similar level of accuracy (visually confirmed) when applied to both optical particle counters. This may indicate that the source detection algorithm is less accurate when applied to mass concentration measurements because of resolution and/or accuracy issues at low mass concentrations.

Using the method described in Dobson and Semple [70], we found that the smoking-source affected proportion ( $\mathrm{SAP}_{\text {smoking}}$ ) ranged from $13 \%$ to $69 \%$ (mean $42 \% \pm 14 \%$ std. dev.) of monitoring periods in smoking apartments. In non-smoking apartments, $\mathrm{SAP}_{\text {smoking }}$ ranged from $0 \%$ to $51 \%$ (mean $15 \% \pm 13 \%$ std. dev.). The high $\mathrm{SAP}_{\text {smoking }}$ in some non-smoking apartments could indicate that these homes were misclassified and/or that this method is sensitive to other sources that generate particles of a similar size to tobacco smoke. In both groups there was often substantial variation between monitoring periods in the same apartment. The Spearman rank correlation between $\mathrm{SAP}_{\text {smoking }}$ and median particle concentration is 0.77 for smoking apartments, a much stronger correlation than SAP, which suggests that indoor PM concentrations may be lowered by reducing the frequency of indoor smoking.

\subsubsection{Total suspended particles}

Figure 5 shows the TSP concentrations in each apartment, grouped by season and retrofit stage. Buildings are not distinguished due to lower rates of deployment in some cases, and because this 
allows for a better illustration of the effects of the three other environmental factors. Whereas the optical particle counter measurements shown in Figures 1 and 2 displays the variation in concentration during each monitoring period, these TSP concentrations provide a more accurate measure of the mean PM concentration (not influenced by the optical properties of the aerosol) and consider a larger size range of particles. TSP concentrations were approximately 3 times higher in smoking apartments $(p<0.001)$, while the influence of season, building, and retrofit stage were not significant.

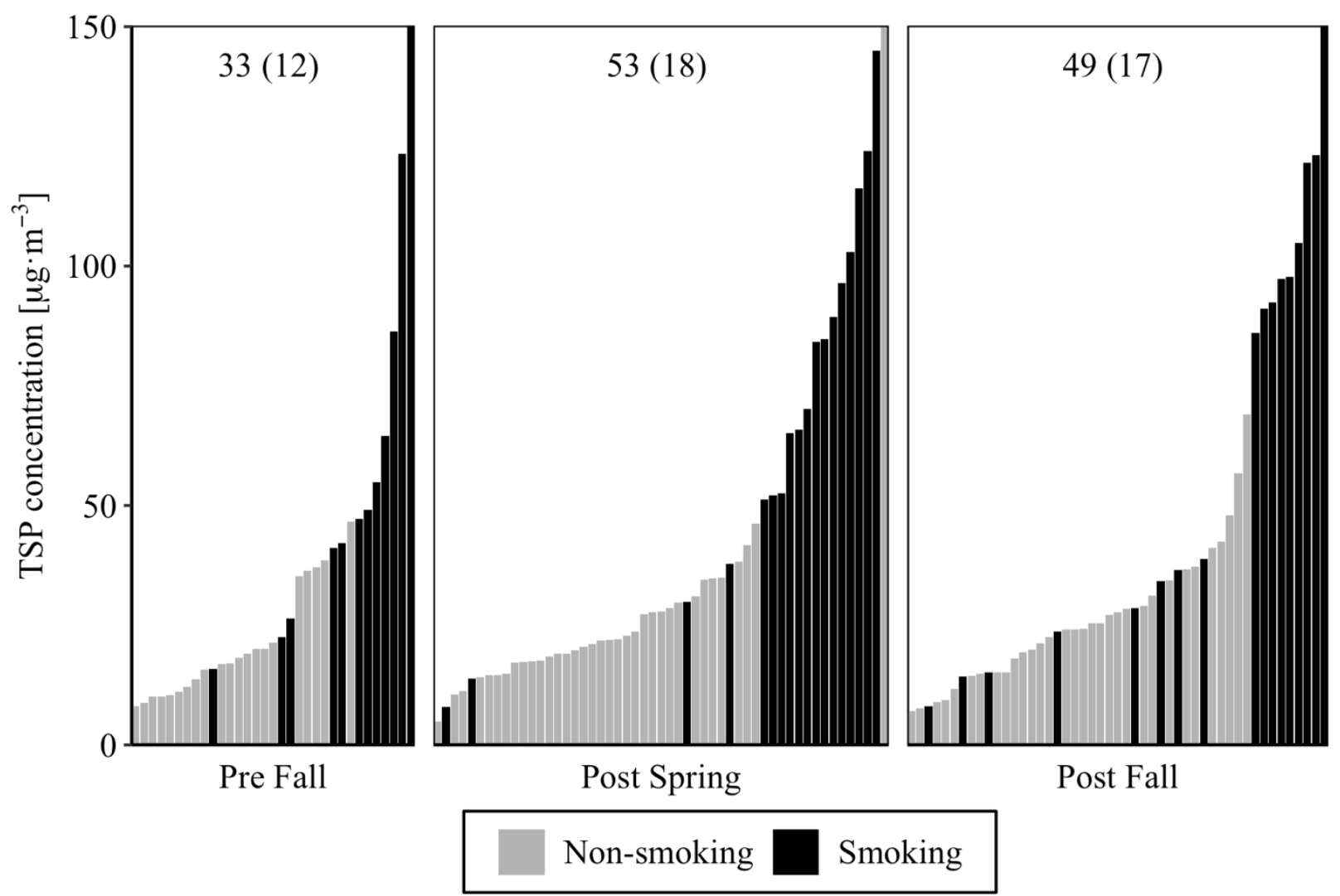

Figure 5. Total suspended particles (TSP) concentration in each apartment measured by gravimetric analysis, grouped by retrofit stage and season. Each bar represents one period of measurement for one apartment. The numbers displayed at the top indicate the number of apartments in each group. Bars are arranged from lowest to highest concentration within each group. To reduce white space, the TSP concentration is cut off at $150 \mu \mathrm{g} \cdot \mathrm{m}^{-3}$, which affects one measurement from each period; the Pre Fall concentration is $208.9 \mu \mathrm{g} \cdot \mathrm{m}^{-3}$; the Post Spring concentration is $180.2 \mu \mathrm{g} \cdot \mathrm{m}^{-3}$; the Post Spring concentration is $208.4 \mu \mathrm{g} \cdot \mathrm{m}^{-3}$. 
TSP concentration was significantly different among smoking and non-smoking apartments when testing all monitoring periods $(p<0.001)$, with the median smoking apartment $\left(70.1 \mu \mathrm{g} \cdot \mathrm{m}^{-}\right.$ ${ }^{3}$ ) having a concentration approximately three times higher than the median non-smoking apartment $\left(22.0 \mu \mathrm{g} \cdot \mathrm{m}^{-3}\right)$. Brugge et al. [78] reported that gravimetric $\mathrm{PM}_{2.5}$ measurements collected in in public housing buildings were approximately 3 times higher in smoking apartments $\left(33.8 \mu \mathrm{g} \cdot \mathrm{m}^{-3}\right)$ than in non-smoking apartments $\left(12.3 \mu \mathrm{g} \cdot \mathrm{m}^{-3}\right)$. Their reported mean concentrations are much lower than those shown in Figure 5 and this can be attributed to differences in particle size, filter type, measurement location, and monitoring duration. Similar limitations apply when comparing these concentrations to TSP concentrations reported in other investigations of social housing [76,79-81]. Season did not have a significant effect on either the smoking $(p=0.14)$ or non-smoking $(p=0.63)$ apartments. Median concentrations in the smoking apartments were approximately $10 \%$ higher in spring $\left(84.2 \mu \mathrm{g} \cdot \mathrm{m}^{-3}\right)$ than in fall $\left(69.7 \mu \mathrm{g} \cdot \mathrm{m}^{-3}\right)$. Concentrations were more similar in the non-smoking apartments, measuring $21.9 \mu \mathrm{g} \cdot \mathrm{m}^{-3}$ in spring compared with $22.0 \mu \mathrm{g} \cdot \mathrm{m}^{-3}$ in fall. Building had a significant effect on the non-smoking apartments $\left(\chi^{2}(6)=15.4, p=0.017\right)$ but not the smoking apartments $\left(\chi^{2}(6)=3.0, p=0.81\right)$. Post hoc analysis using a pairwise Wilcoxon signed rank test with Bonferroni correction only found a significant difference between the measurements from Buildings A and $\mathrm{F}(p=0.039)$. The effects of season and building in previous studies are discussed with regards to the optical particle counter measurements however there is a lack of other TSP data in the literature for similar comparisons. Retrofit stage did not have a significant building-level effect when examining the smoking $(p=0.65)$ or non-smoking $(p=0.059)$ apartments. This result would be expected since the retrofitting did little to change building-level factors that would influence indoor pollutant concentrations. While the corridor pressurization ventilation was improved in four of the buildings, previous investigations including Ricketts and Straube [49] have found that this is an unreliable method for delivering ventilation to individual apartments, which these results would support.

Smoking is the dominant environmental factor influencing PM concentration in these homes, regardless of measurement method. When considering the potential health consequences of exposure to PM, the two most important characteristics are the size and composition of particles. The particulate phase of cigarette smoke, which is widely linked to cardiovascular and respiratory disease as well as forms of cancer, is comprised of more than $99 \% \mathrm{PM}_{2.5}$ (often $90 \%$ 
$\left.\mathrm{PM}_{1}\right)[12,82]$. Figure 6 apportions the TSP data using the $\mathrm{PM}_{2.5}$ and $\mathrm{PM}_{10}$ concentrations reported by the OPC-N2 measurements and shows that the additional TSP in smoking apartments consists primarily of particles with a diameter smaller than $2.5 \mu \mathrm{m}$, as would be expected. In many of the non-smoking apartments, the TSP from particles with a diameter larger than $10 \mu \mathrm{m}$ is the same magnitude as, or greater than, $\mathrm{PM}_{10}$. While these particles are too large to deeply penetrate the respiratory tract after inhalation they may be ingested instead, although the importance of this route remains unclear [83].

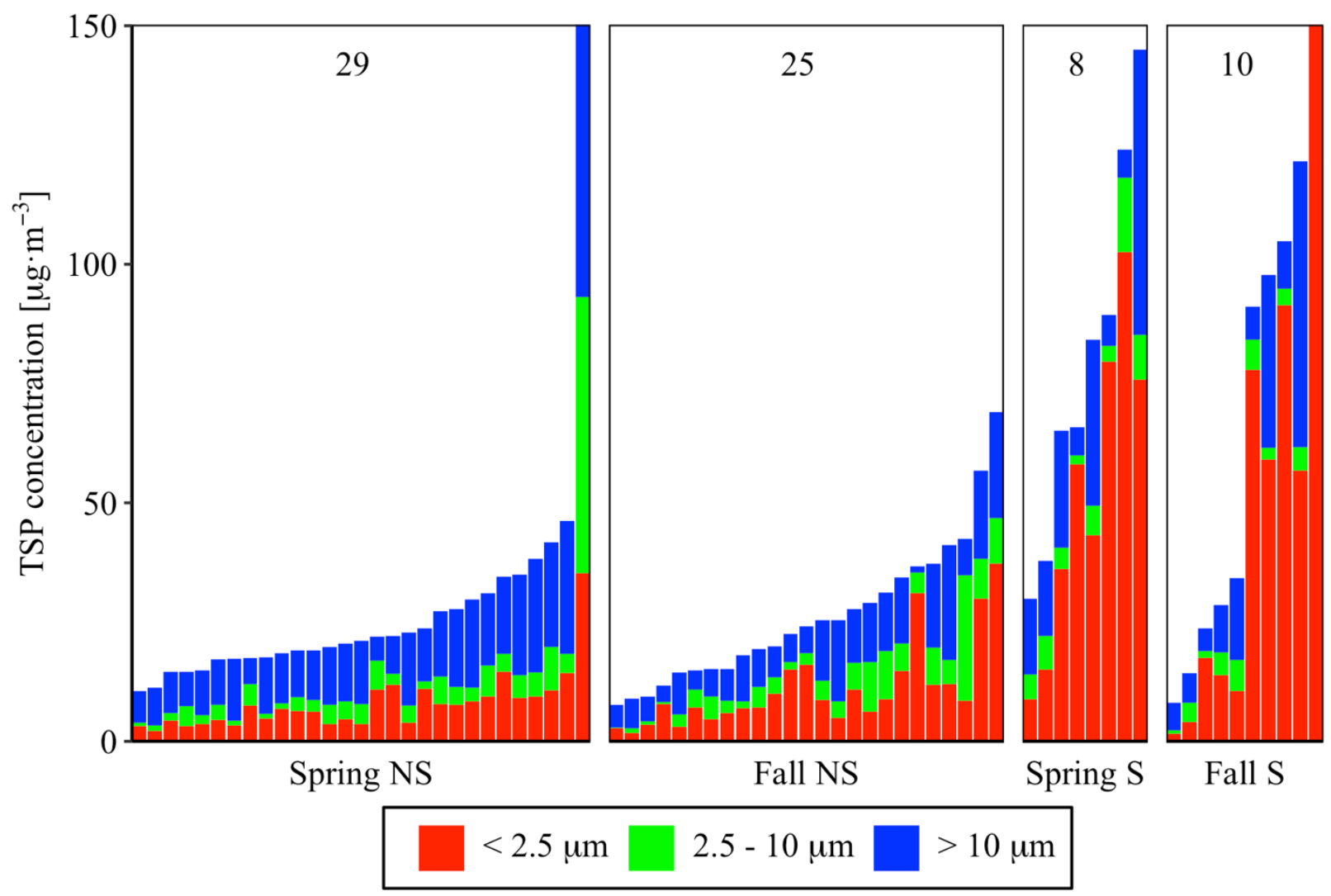

Figure 6. Size proportions of total suspended particles measured in each apartment measured by OPC-N2 monitors and gravimetric TSP analysis, grouped by season and evidence of smoking (NS and $\mathrm{S}$ refer to non-smoking and smoking respectively). Each bar represents one period of measurement for one apartment. Bars are arranged from lowest to highest total concentration within each group. The numbers displayed at the top indicate the number of apartments in each group. 9 measurements (6 smoking) were excluded because TSP measurements were smaller than measurements from the OPC-N2. 
Figure 7 shows the TSP measurements (together and separated by smoking status) and two comparator datasets of SFDs. For homes with multiple monitoring periods, the median measurement is used to avoid overweighting that home. In addition to showing the significant difference between smoking and non-smoking apartments $(p<0.001)$ that was previously established, Figure 7 demonstrates that TSP concentrations in the smoking apartments are significantly higher than in the Central Texas SFDs $(p=0.0097)$. Unlike with the optical particle counters, the non-smoking apartments do not have a higher PM concentration than the comparator SFDs. The TSP concentrations from the Toronto SFDs are included because measurements from the same home are previously shown in Figure 3. However, there are important differences in how these measurements were collected, namely from central-system filters with very low runtimes (see Li et al. [84]) and a tendency for the system to operate when occupants were at home and active (Zhang et al. [60]), and that these older homes may contain more large dust particles and have higher leakage areas (Mahdavi and Siegel [61]). All of these factors likely contribute to higher TSP measurements in the Toronto SFDs. The similar concentrations in the non-smoking apartments and Central Texas SFDs $(p=1)$ may be explained by higher runtimes and flow rates (see Givehchi et al. [72]) and that these were newer homes which may have lower dust levels and be more airtight, all of which contribute to lower TSP measurements. In both comparator datasets, there is additional uncertainty from measuring the change in mass from each filter sample [61]. These results suggest that optical particle counters may be better suited for making direct comparisons between studies as they are less biased by methodology and factors (such as system runtime and flow rate) that cannot be easily controlled. 


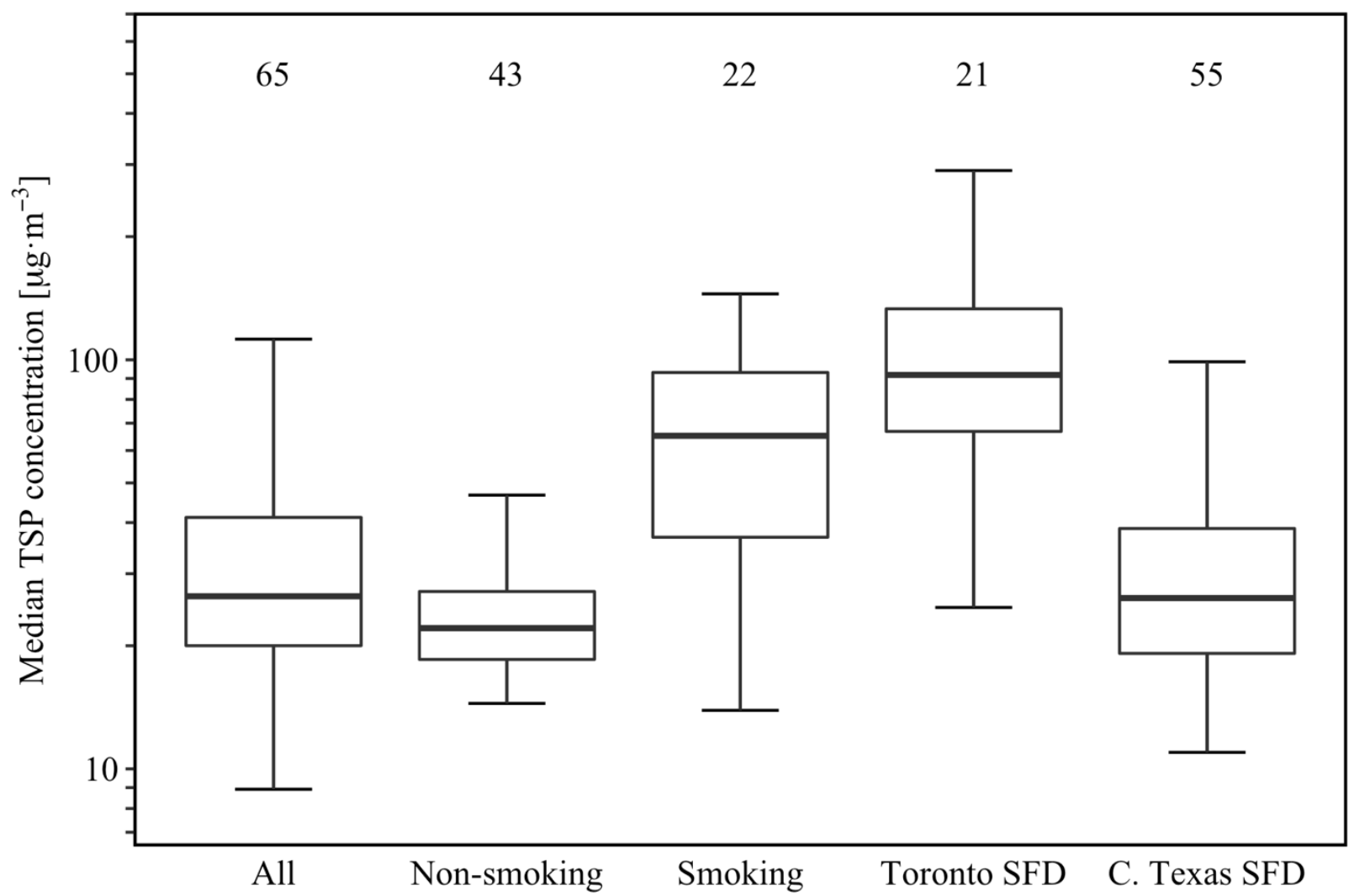

Figure 7. Median indoor total suspended particles concentrations measured by gravimetric analysis. The numbers displayed at the top indicate the number of apartments in each group. NS and $\mathrm{S}$ refer to non-smoking and smoking respectively. Toronto single-family dwelling (SFD) measurements are from Mahdavi and Siegel [61]. Central (C.) Texas SFD measurements are from Givehchi et al. [72].

\subsection{Discussion}

There are limitations to this research that should be considered when interpreting these results. The air exchange rate of these homes was not measured during this investigation, and we are therefore unable to comment on how ventilation affects the PM concentrations in these homes. Diaz Lozano Patiño et al. [56] reported that there was insufficient evidence from $\mathrm{CO}_{2}$ concentrations measured pre-retrofit to conclude that the apartments were under-ventilated. There were no changes to the building enclosure during retrofitting [59], and no evidence that the additional corridor pressurization ventilation had any significant effect on PM concentrations. We are also unable to comment on the frequency of window-opening in these apartments, which we would expect to influence the air exchange rate of these homes. This could not be monitored 
using the resources available in this study or without causing significant disruption to the residents, although it would be an interesting component to supplement this analysis. Outdoor ambient concentrations were not measured during this investigation as the optical particle counters used in this investigation would not be robust for outdoor monitoring, and it may not be possible to reliably compare results from different monitors (as evidenced by the disagreement between Dylos DC1700 and Alphasense OPC-N2 measurements). Measurements from environmental monitoring stations encounter this monitor difference, and have not been demonstrated to be a reliable source of outdoor concentration measurements beyond their immediate location. While accurate and comparable outdoor measurements would allow for more comment on the lack of seasonal difference in our results, it has been noted that Toronto, Canada has relatively low ambient $\mathrm{PM}_{2.5}$ concentrations [62].

\subsubsection{Smoking status and frequency}

In order to evaluate the influence of smoking, apartments were strictly classified as smoking or non-smoking. This approach does not consider the frequency with which tobacco is smoked in the home or whether this frequency changes. This study ran from May 2015 through December 2017 during which it is likely that some participants smoking habits changed, however there were no apartments whose smoking status clearly changed. Smoking cessation is rare, although attempts to quit are common. In 2019, 42\% of daily smokers in Canada attempted to quit [85]. In $2018,55.1 \%$ of daily smokers in the United States attempted to quit while only $7.5 \%$ were successful [86]. Given this, it is likely that some variation in smoking frequency would be occur between monitoring periods in some subset of the apartments and this is something that we saw

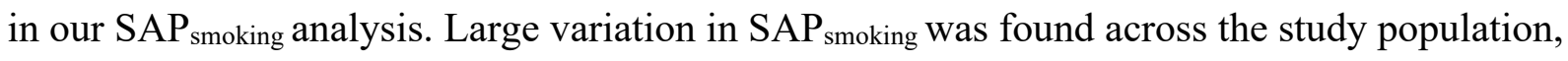
and in smoking apartments this was moderately correlated with median particle concentration. Future investigations of pollutants generated by tobacco smoke, as well as other variable indoor sources such as incense and candles, should attempt to gauge the frequency with which these products are used in the home to provide additional context to the measurements.

\subsubsection{Implications for smoking}

Smoking is the dominant environmental factor influencing PM concentration in these homes. While season and building-level factors may be significant as well, their influence is much smaller than smoking. Investigations have found that $\mathrm{PM}_{2.5}$ from tobacco smoke can transfer 
between apartments in multi-unit housing, potentially increasing the exposure of neighbouring residents $[7,8]$. Indeed, many non-smoking occupants in these buildings reported smelling tobacco smoke originating from other apartments as well as from outside [57]. It is clear that strategies for controlling tobacco smoke in multi-unit buildings are necessary for improving the health of all occupants.

While smoking inside was not prohibited in individual apartments during this study, the public housing authority (PHA) has since indicated their intention to follow other Canadian and American PHAs by implementing smoke-free policies. In the case of HUD-funded PHAs, smoking must be prohibited indoors and within 25 feet of all buildings [87]. Russo et al. [8] and MacNaughton et al. [54] found that smoke-free policies can significantly reduce indoor concentrations of $\mathrm{PM}_{2.5}$ which can attributed to the reduced frequency of indoor smoking [54]. Nonetheless, smoking remains quite common in some buildings with these same policies: both Hernández et al. [88] and Rokicki et al. [89] report persistent smoking indoors (in apartments and common spaces) and outdoors near entrances in buildings with smoke-free policies. Field personnel from this investigation reported smoking (both tobacco and cannabis) occurring in stairwells and roof access areas, and this may increase in the presence of a ban. This indicates that the potential improvements from these policies are not universal and can be ineffective when not strictly enforced. However, increased enforcement such as fines, preventing lease renewal, or eviction can be highly problematic. Both Hernández et al. [88] and Levy et al. [90] make the point that eviction is antithetical to the goals of social housing. This is similarly true for fines, which can significantly burden people with already limited resources. Another reason why smoke-free policies may be difficult to implement in social housing buildings is that smoking is far more prevalent among their residents when compared with the general population. An analysis of the 2013-14 Canadian Community Health by Chaiton et al. [51] reported that smoking prevalence was significantly higher among home renters $(29.0 \%)$ than with homeowners (14.8\%), and large increases were associated with factors such as ethnicity, low socioeconomic status, and poor mental health. Similar trends are found in other high-income countries such as the United States and the United Kingdom [50]. While tobacco use has decreased in Canada and the United States in recent decades, the legalization of cannabis in a greater number of jurisdictions is likely increase its use (in many cases for therapeutic purposes, either prescribed or self-medicated) presenting a growing source of indoor smoking and $\mathrm{PM}_{2.5}$ to 
be addressed [50,91-93]. While not currently permitted in many cases, it may be worth allowing residents who find it difficult to comply with smoke-free policies to live in designated buildings although this does not reduce exposure to non-smoking cohabitants such as children. Otherwise, smoke-free policies must be combined with other strategies to achieve the desired result without resorting to punitive enforcement.

One such strategy for reducing the transmission of $\mathrm{PM}_{2.5}$ and other pollutants would be compartmentalization (improved sealing and ventilation of individual apartments). In this study, only ventilation from corridor pressurization was increased and this did not significantly reduce PM concentrations in the apartments, and has similarly been found to inadequately provide ventilation to individual apartments [49]. Bohac et al. [48] attempted compartmentalization by retrofitting 6 multi-unit buildings with improved air sealing and increased ventilation (serving each apartment) to meet minimum standards, finding that inter-unit airflow was not substantially reduced and that the source strength of tracer gases were only reduced by $30 \%$ in non-smoking apartments. Bohac et al. [48] note that it is difficult to achieve improvements in these areas through retrofitting, but that compartmentalization could be highly effective when implemented during the design and construction of buildings. It should be noted that in Bohac et al. [48] and these buildings (discussed in Vakalis et al. [59]), the improved ventilation contributed to increased energy demands, which increases costs and may undermine other sustainability goals. Even if only modest improvements can be achieved in existing buildings, this strategy may help address additional pollutants such as cooking odours (a common complaint in these buildings) and incense (noted during instrument installation in nine apartments) both of which have been found to contribute to elevated PM concentrations [3]. Sealing also helps to reduce the impact of some pest infestations, which are a common complaint among residents of social housing $[26,94]$. Another way to improve the efficacy of compartmentalization in existing buildings may be to specify ventilation rates exceeding minimum standards. The American Society for Heating, Refrigerating, and Air-conditioning Engineers (ASHRAE), does not publish guidelines as it is their official position that smoking must be banned indoors and near all buildings to improve occupant health, as any exposure to environmental tobacco smoke may lead to adverse health effects [95]. However, if smoke-free policies cannot effectively eliminate the problem of secondhand smoke it is worth revisiting whether other strategies (such as compartmentalization) can be effective in conjunction with a broader IAQ strategy. 


\subsubsection{Implications for retrofits}

We did not find any difference in PM concentrations before and after retrofitting. This result could be expected considering that, with the exception of the corridor pressurization ventilation, the retrofitting performed on these buildings primarily addressed thermal comfort and energy usage concerns by improving the space heating systems and there were no changes to the building enclosure [59].

There is evidence that lower-SES homes disproportionately have higher leakage areas and that outdoor air pollution is worse in urban areas with lower-SES populations [26]. These cumulatively result in higher infiltration of outdoor pollutants. Increasing the airtightness of the building, thereby reducing natural ventilation, could improve thermal comfort and reduce energy usage while reducing the influence of outdoor pollutant sources. However, increased airtightness will trap particles generated by indoor sources and may exacerbate the problem of inter-unit pollutant transfer. There is evidence of some lower-SES homes experiencing higher concentrations of $\mathrm{PM}_{2.5}$ and other pollutants nitrogen dioxide as a result of low air-exchange rates, in some cases following retrofits [44,96]. Richardson et al. [97] reported increased indoor PM concentrations after building retrofits that improved airtightness; while they attribute this increase to higher outdoor concentrations during the post-retrofit period, the reduced leakage flows may have also been a contributing factor. Considering the relative influence of smoking compared to season and building as well as the higher source affected proportions in these homes, it is clear that indoor sources are a major concern in these apartments. To compensate for the reduced natural ventilation, it would be necessary to improve the mechanical ventilation in these buildings. Retrofitting the mechanical ventilation system has significant implications for energy usage and capital cost. It may be necessary to ventilate individual apartments directly rather than use corridor pressurization.

Indoor concentrations of PM are influenced by both indoor and outdoor sources, an ideal retrofitting plan would increase the airtightness of the building in combination with improved ventilation and sealing of individual apartments (compartmentalization, discussed previously with regards to controlling smoking). If compartmentalization cannot be performed effectively, then caution should be taken before increasing airtightness in buildings where outdoor concentrations are not a dominant concern. It should be additionally recommended that on- 
demand ventilation such as range hoods and bathroom fans be installed and used consistently to reduce the impact of cooking as an indoor source of pollutants, especially in homes with low air exchange rates. Given the considerable disruption to residents that may be required to perform retrofitting, consideration may be given to portable air cleaners which can be readily deployed at low-cost while considerably reducing occupant $\mathrm{PM}_{2.5}$ exposure $[28,30,31]$. As part of a combined approach, communication about common particle sources and mitigation strategies has been shown to improve occupant health outcomes and may reduce indoor pollutants $[98,99]$. More needs to be understood about how this information can be widely and effectively communicated.

\subsection{Conclusions}

PM concentrations in non-smoking apartments from this study investigation were two times higher than comparable measurements from single-family homes in Toronto, while smoking apartments from this investigation had concentrations that were higher by a further factor of two to three. Using a source detection algorithm, we found that PM concentrations were elevated during $57 \% \pm 12 \%$ of each monitoring period which was significantly higher than in the singlefamily homes. The smoking differences were also reflected in TSP concentrations. The potential exposure disparity that arises from these higher concentrations is concerning given that residents of social housing buildings are generally more vulnerable to health problems when compared to the general population and should be addressed through mitigation strategies. Improved ventilation and sealing of individual apartments (compartmentalization) may reduce inter-unit transfer of pollutants generated by smoking and other indoor sources. Compartmentalization could further allow for increases to building airtightness during energy retrofits without increasing the effect of indoor pollutant sources.

\subsection{Acknowledgements}

The authors would like to thank the social housing provider, building management and the residents for their cooperation throughout the study, as well as The Atmospheric Fund who led the field work in the larger investigation. The Natural Sciences and Engineering Research Council of Canada (Grant RGPIN-2014-06698) and the Canada Foundation for Innovation (Grant 32319) provided funding. 


\section{Chapter 3: \\ Evaluation of fixed and adaptive concentration thresholds for particle filter systems}

Reference: Mendell, A. Y., Olson, A. W., Siegel, J. A. 2021. Evaluation of fixed and adaptive concentration thresholds for particle filter systems. Submitted to Building and Environment.

\subsection{Abstract}

Particle filtration can effectively reduce indoor concentrations of particulate matter (PM), but may incur high energy use. This study evaluates fixed and adaptive concentration thresholds to automate the operation of filtration systems, as well as the influence of clean air delivery rate (CADR) and the monitor used to measure particle concentrations. Simulated environments were derived from week-long continuous PM measurements from Dylos DC1700 $(N=104)$ and Alphasense OPC-N2 $(N=100)$ particle counters deployed in apartments in Toronto. A fixed threshold of $4.0 \mu \mathrm{g} \cdot \mathrm{m}^{-3}$ resulted in a mean air cleaner runtime of $6.9 \%$ to $21.0 \%$ depending on CADR and sensor, while providing mean concentration reductions of $67 \%$ to $71 \%$ when compared to operating the air cleaner constantly. In most environments, runtime could be further reduced by raising the fixed threshold while resulting in only a modest decrease in absolute and normalized mean exposure reduction. Using an adaptive threshold derived from a k-means clustering approach generally provided substantial exposure reduction while preventing high runtimes. Altogether this suggests that the implementation of fixed and adaptive thresholds can improve different facets of performance. Reducing the energy usage of particle filter systems will make them a more viable and sustainable means of improving occupant health. 


\subsection{Introduction}

Particulate matter (PM) is among the most harmful air pollutants in terms of its chronic health impact and is widely linked to cardiovascular and respiratory illness [4,9]. Indoor PM concentrations are influenced by both indoor and outdoor sources [2,4,5], often greatly exceeding outdoor concentrations during indoor source events such as cooking or smoking $[3,5,100]$. Given this, and that North Americans spend more than $90 \%$ of their time indoors $[40,41]$, indoor building environments form the most important component of PM exposure. Health Canada recommends that indoor concentrations of $\mathrm{PM}_{2.5}$ (particulate matter with a diameter less than $2.5 \mu \mathrm{m}$ ) be kept as low as possible since there is no level at which health issues are eliminated [15].

Particle filter systems such as HVAC filters and portable air cleaners (PACs) are commonly employed to reduce indoor PM concentrations and therefore occupant exposure [28-31]. PACs can be readily deployed at low cost without seriously disrupting residents, making them a appropriate exposure reduction strategy in buildings without HVAC systems. While particle filter systems can demonstrably improve occupant health [28,31,32], it has been observed that their long-term energy usage can be substantial given that they operate frequently and/or for long durations [101]. If particle filter systems are to be recommended as a widespread public health measure the associated energy usage must be addressed.

Many commercial particle filter systems are automated to only engage the fan when the concentrations of indoor pollutants are elevated [33-35]. There is evidence that users will opt for automation when provided the opportunity, which may permit the fan to operate at higher speeds than users would select themselves [33]. Automation can therefore improve reductions in indoor PM concentration [34]. However, it is unclear whether it also lowers energy usage and noise in practice [35]. Li and Siegel [102] reported that, in simulated environments, using a fixed $\mathrm{PM}_{2.5}$ concentration threshold can reduce runtime while achieving high levels of exposure reduction. However, $\mathrm{PM}_{2.5}$ concentrations vary widely between homes and therefore one fixed threshold may not be universally appropriate. High thresholds will result in little exposure reduction, while low thresholds will result in increased energy usage, filter replacement, and noise. The goal of this investigation is to explore how different fixed thresholds affect exposure reduction and 
runtime, and whether there is a practical benefit to an adaptive threshold that tailors itself to an individual environment.

\subsection{Methods}

\subsubsection{Measured concentrations}

Time-resolved number concentrations of PM were measured from 91 apartments in seven multiunit social housing buildings located in Toronto, Canada as part of larger investigation of indoor environmental quality. The collection and analysis of these PM measurements are described elsewhere in Mendell et al. [103]. Measurements were collected during four rounds, twice each in 2015 and 2017. In each year, there was one term during the spring season (late May, June, and early July) and one during the fall season (November and early December). Each monitoring period of a given apartment lasted for approximately seven days during one of these rounds. Altogether, 254 sets of continuous PM measurements were collected.

Two optical particle counters were used: Dylos DC1700 monitors were deployed during 2015, as well as a limited number of homes during the fall season of 2017. Alphasense OPC-N2 monitors were deployed only in 2017. No direct comparisons were made between the two monitors, as it was determined that there is too much difference in their response [103]. After excluding monitoring periods with less than 2.5 days of complete data, as well as the limited number of DC1700 measurements from 2017, there were 206 sets of continuous PM measurements. OPC$\mathrm{N} 2$ monitors report a native $\mathrm{PM}_{2.5}$ mass concentration equivalent [66]; for the DC1700 monitors, the conversion factor from Semple et al. [104] was used. For simplicity, these reported mass concentrations are subsequently referred to as measured concentrations.

\subsubsection{Simulated concentrations}

Previous investigations of particle filter system performance by Li and Siegel [102,105] used a simulated mass balance model, with probabilistic input parameters and stochastically distributed source events. This approach has limitations regarding how realistically it can simulate homes with different occupant behaviour (e.g., frequency and strength of source-emitting activities, use of range hoods, opening of windows). To evaluate the fixed and adaptive air cleaner thresholds, we created simulations derived from the optical particle counter measurements. Our goal was to 
accurately capture both the real frequency and distribution of source emission events as well as the variation in source strength. This relied on the same mass balance model described in Li and Siegel [105], with a simulation algorithm identifying the source emission rate and loss rate at each timestep of each monitoring period.

The loss rate $\left(\mathrm{h}^{-1}\right)$ was calculated as the sum of the average loss rate of the home $\left(L_{1}\right)$ and the loss rate provided by the particle filter system at times when it is operating $\left(L_{2}\right)$. $L_{1}$ was determined separately for individual simulations. $L_{2}$ was defined as a constant ratio of clean air delivery rate (CADR) to indoor volume (V) with fixed values of $1.0 \mathrm{~h}^{-1}, 2.5 \mathrm{~h}^{-1}$, and $5.0 \mathrm{~h}^{-1}$ to simulate different amounts of filtration cleaning power. The source rate $\left(\mu \mathrm{g} \cdot \mathrm{m}^{-3} \cdot \mathrm{h}^{-1}\right)$ was calculated as the sum of the background source rate $\left(S_{1}\right)$ and the particle emission rate of all active indoor source events $\left(S_{2}\right)$, both normalized by indoor volume. $S_{1}$ was calculated as a fixed value $2.0 \mu \mathrm{g} \cdot \mathrm{m}^{-3}$ using average conditions reported in Li and Siegel [102]. $S_{2}$ was calculated by assuming steadystate conditions when peak concentrations occurred and multiplying the peak concentration by the loss rate of the following decay period. The simulation algorithm is further described in Appendix A2.1. Two simulated environments did not have any peak concentrations and were excluded, bringing the final total to 204 concentration profiles.

\subsubsection{Air cleaning thresholds}

Three fixed thresholds were selected based on the 2020 Canadian Ambient Air Quality Standards (CAAQS) [106]. The CAAQS recommends that annual and 24-hour mean $\mathrm{PM}_{2.5}$ concentrations remain below $8.8 \mu \mathrm{g} \cdot \mathrm{m}^{-3}$ and $27.0 \mu \mathrm{g} \cdot \mathrm{m}^{-3}$ respectively. The CAAQS defines an annual mean concentration below $4.0 \mu \mathrm{g} \cdot \mathrm{m}^{-3}$ as meeting its highest air quality management level. These three concentrations were selected to act as the fixed thresholds for this analysis. For comparison, the US EPA National Ambient Air Quality Standards (NAAQS) recommend that annual and 24-hour mean $\mathrm{PM}_{2.5}$ concentrations remain below $12.0 \mu \mathrm{g} \cdot \mathrm{m}^{-3}$ and $35.0 \mu \mathrm{g} \cdot \mathrm{m}^{-3}$ respectively [107]. Indoor air quality equivalents do not exist for either the CAAQS or NAAQS.

This analysis also considers constant air cleaning, effectively a fixed threshold of $0 \mu \mathrm{g} \cdot \mathrm{m}^{-3}$. Constant air cleaning should represent the best-case scenario in terms of exposure reduction as well as the worst-case scenario in terms of energy usage because the system operates continuously. The results of the constant air cleaning will be used to evaluate the relative 
effectiveness and efficacy of the various thresholds. Li and Siegel [102] previously examined constant air cleaning in comparison to a range of fixed thresholds as well as other strategies to reduce system runtime.

To calculate an adaptive air cleaning threshold, we performed k-means clustering on the timeresolved data to classify measurements as either elevated or background. Four clusters were grouped, the highest three of which were defined as elevated. The threshold between the elevated and background concentrations was defined as the boundary between the lowest two clusters. We found that four clusters were the fewest that adequately separated elevated and background concentrations when visually assessed. Clustering was performed using the kmeans function from R package stats 4.0.3 [74]. We found that, for 73 monitoring periods of DC1700 measurements with more than four days of complete data, an adaptive threshold calculated using two days of time-resolved measurements (2880 measurements at a 1-minute timestep) would be $0.78 \pm 0.48$ times the threshold calculated using the full week of data. We interpreted this to indicate that two days of measurements generally represented the environments' concentration profiles and could therefore be used to determine the initial adaptive threshold values. To evaluate the effectiveness of the adaptive threshold compared with the fixed thresholds, we evaluated all simulated concentrations following the first 2880 minutes and re-calculated the adaptive threshold every 60 minutes from this point forward.

\subsubsection{Evaluation metrics}

Each threshold was evaluated using five metrics, with the goal of understanding both absolute and relative performance. Total energy usage was evaluated using the runtime (Equation 1) of the particle filter system, with the assumption these two parameters scale proportionally for a fixed CADR (i.e., there is no additional energy usage from cycling on and off). In this paper, runtime is expressed in \% but used in its fractional form for all calculations. Effectiveness was evaluated using absolute mean exposure reduction (AMER) and normalized mean exposure reduction (NMER). AMER is the mean redution in particle concentration compared to no air cleaning, whereas NMER indicates how well AMER performs compared to the theoretical maximum provided by constant air cleaning. AMER (Equation 2) is calculated as the mean concentration using air cleaning and a given threshold minus the mean concentration without any

air cleaning $\left(\mu \mathrm{g} \cdot \mathrm{m}^{-3}\right)$. NMER (Equation 3 ) is calculated as the AMER when using a threshold 
divided by the AMER when using constant air cleaning (dimensionless fraction with a maximum value of 1). Absolute removal efficacy (ARE) and normalized removal efficacy (NRE) were defined as the respective ratios of AMER and NMER to runtime (Equations 4 and 5 respectively), expanding on how removal efficacy was evaluated in Li and Siegel [105]. ARE $\left(\mu \mathrm{g} \cdot \mathrm{m}^{-3}\right)$ and NRE (dimensionless) both communicate how many times more energy efficient a threshold is per unit of exposure reduction when compared to constant air cleaning.

Runtime $=t_{\text {on }} / t_{\text {total }}$

$\mathrm{AMER}=\bar{C}_{\mathrm{w}}-\bar{C}_{\mathrm{wo}}$

$\mathrm{NMER}=\mathrm{AMER} / \mathrm{AMER}_{\text {constant }}$

$\mathrm{ARE}=\mathrm{AMER} /$ Runtime

$\mathrm{NRE}=\mathrm{NMER} /$ Runtime

$t_{\mathrm{on}}$ is the proportion of time that the particle filter system is operating in minutes.

$t_{\text {total }}$ is the total length of the simulation in minutes.

$\bar{C}_{\mathrm{w}}$ is the mean concentration with a particle filter system operating.

$\bar{C}_{\text {wo }}$ is the mean concentration without a particle filter system.

\subsubsection{Analysis}

This investigation examines three key parameters that likely have practical implications for particle filter system performance. First, the fixed and adaptive thresholds are compared to one another using the defined evaluation metrics. The aim of this analysis is to quantify the absolute and relative performance of each air cleaning approach, describe which approach is most appropriate under different circumstances, and identify whether an adaptive threshold can offer any benefit. Next, the ratio of clean air delivery rate to indoor volume (CADR/V) is varied to examine how the size and/or fan speed of the air cleaner influences exposure reduction and runtime. Finally, the simulated concentrations derived from the two optical particle counters are 
compared to evaluate how the performance of the fixed and adaptive thresholds are dependent on the choice of sensors.

\subsection{Results and Discussion}

\subsubsection{Adaptive threshold values}

For the DC1700-derived simulated data, the initial adaptive threshold value ranges from 0.7 $\mu \mathrm{g} \cdot \mathrm{m}^{-3}$ to $122.2 \mu \mathrm{g} \cdot \mathrm{m}^{-3}$ (mean $16.0 \pm 17.5 \mu \mathrm{g} \cdot \mathrm{m}^{-3}$ ). The final adaptive threshold values range from $2.4 \mu \mathrm{g} \cdot \mathrm{m}^{-3}$ to $83.5 \mu \mathrm{g} \cdot \mathrm{m}^{-3}$ (mean $13.7 \pm 12.2 \mu \mathrm{g} \cdot \mathrm{m}^{-3}$ ), $2.5 \mu \mathrm{g} \cdot \mathrm{m}^{-3}$ to $64.8 \mu \mathrm{g} \cdot \mathrm{m}^{-3}$ (mean $14.9 \pm 11.7$

$\mu \mathrm{g} \cdot \mathrm{m}^{-3}$ ), and $2.5 \mu \mathrm{g} \cdot \mathrm{m}^{-3}$ to $158.4 \mu \mathrm{g} \cdot \mathrm{m}^{-3}$ (mean $17.1 \pm 18.2 \mu \mathrm{g} \cdot \mathrm{m}^{-3}$ ) for CADR/V ratios of 1.0, 2.5, and 5.0 respectively. Figure 8 shows the initial adaptive threshold values in comparison to the fixed thresholds. There is considerable variation, which indicates that the threshold is satisfying the goal of varying by environment. There are several cases at both relatively low and high mean concentrations where the method for determining the adaptive threshold fails. When the adaptive threshold is too high, the absolute mean exposure reduction (AMER) is poor compared to the fixed thresholds and the runtime is very low. When the adaptive threshold is too low, the AMER and runtime are both relatively high compared to the fixed thresholds. Failure to find an appropriate adaptive threshold likely occurs in cases where the first 2880 minutes of simulated concentrations are uncharacteristically high or low compared to the following days. This indicates a need to improve how the adaptive threshold changes with time, especially because when a particle filter system is introduced to a space the concentration profile will change. The difference in means, which increase with $\mathrm{CADR} / \mathrm{V}$ ratio, may indicate that the adaptive threshold is responsive to the effects of the air cleaner however it is not clear how quickly this occurs. It may be possible to improve the method used to determine the adaptive threshold by recalculating it with a different frequency or by re-calculating without older measurements. 


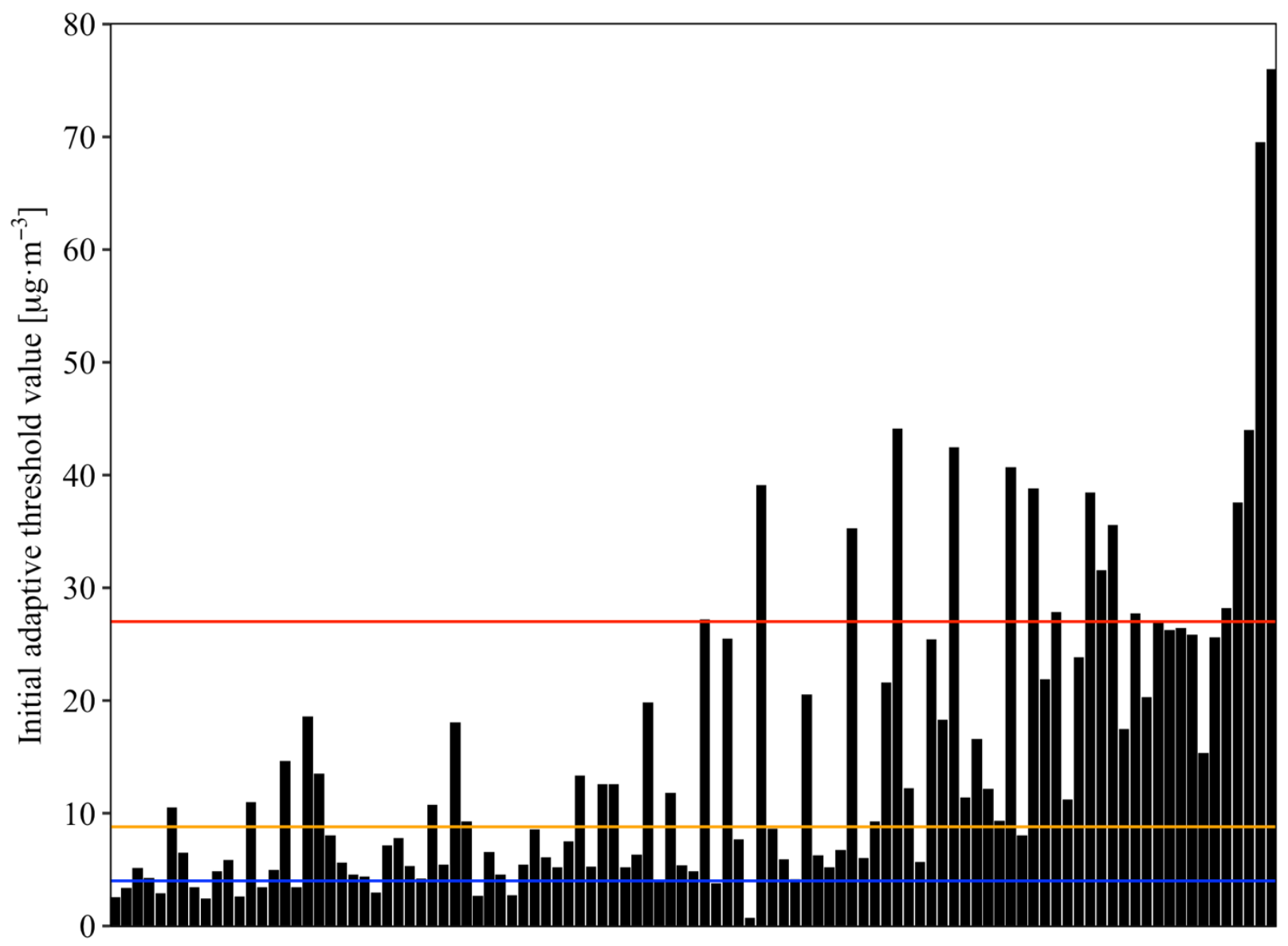

Figure 8. Initial adaptive threshold values for the simulated environments derived from Dylos DC1700 measurements. Results are arranged by the simulated mean concentration in each environment without air cleaning. Horizontal lines represent the fixed $4.0 \mu \mathrm{g} \cdot \mathrm{m}^{-3}$ (blue), 8.8 $\mu \mathrm{g} \cdot \mathrm{m}^{-3}$ (orange), and $27.0 \mu \mathrm{g} \cdot \mathrm{m}^{-3}$ (red) thresholds respectively. One case $\left(122.2 \mu \mathrm{g} \cdot \mathrm{m}^{-3}\right)$ is excluded for visual clarity.

\subsubsection{Exposure reduction}

Figure 9 shows the AMER and runtime for the simulated concentrations derived from Dylos DC1700 measurements using a CADR/V ratio of 2.5. In all 104 simulations, constant air cleaning increases the AMER compared to the fixed thresholds as well as the adaptive threshold. However, constant air cleaning significantly increases the runtime as well. The adaptive threshold tends to provide a lower AMER than the fixed $4.0 \mu \mathrm{g} \cdot \mathrm{m}^{-3}$ threshold (higher in 9 of 104 cases), and a higher AMER than the fixed $27.0 \mu \mathrm{g} \cdot \mathrm{m}^{-3}$ threshold (higher in $87 \mathrm{of} 104 \mathrm{cases}$ ); when compared with the fixed $8.8 \mu \mathrm{g} \cdot \mathrm{m}^{-3}$ threshold, the AMER is higher in 45 of 104 cases. However, the absolute difference between the AMER of the fixed and adaptive thresholds is 
relatively small compared to the total AMER in most cases. Since the AMER and runtime are proportional to one another, the adaptive threshold generally has a lower runtime than the fixed $4.0 \mu \mathrm{g} \cdot \mathrm{m}^{-3}$ and $8.8 \mu \mathrm{g} \cdot \mathrm{m}^{-3}$ thresholds, and a higher runtime than the fixed $27.0 \mu \mathrm{g} \cdot \mathrm{m}^{-3}$ threshold.

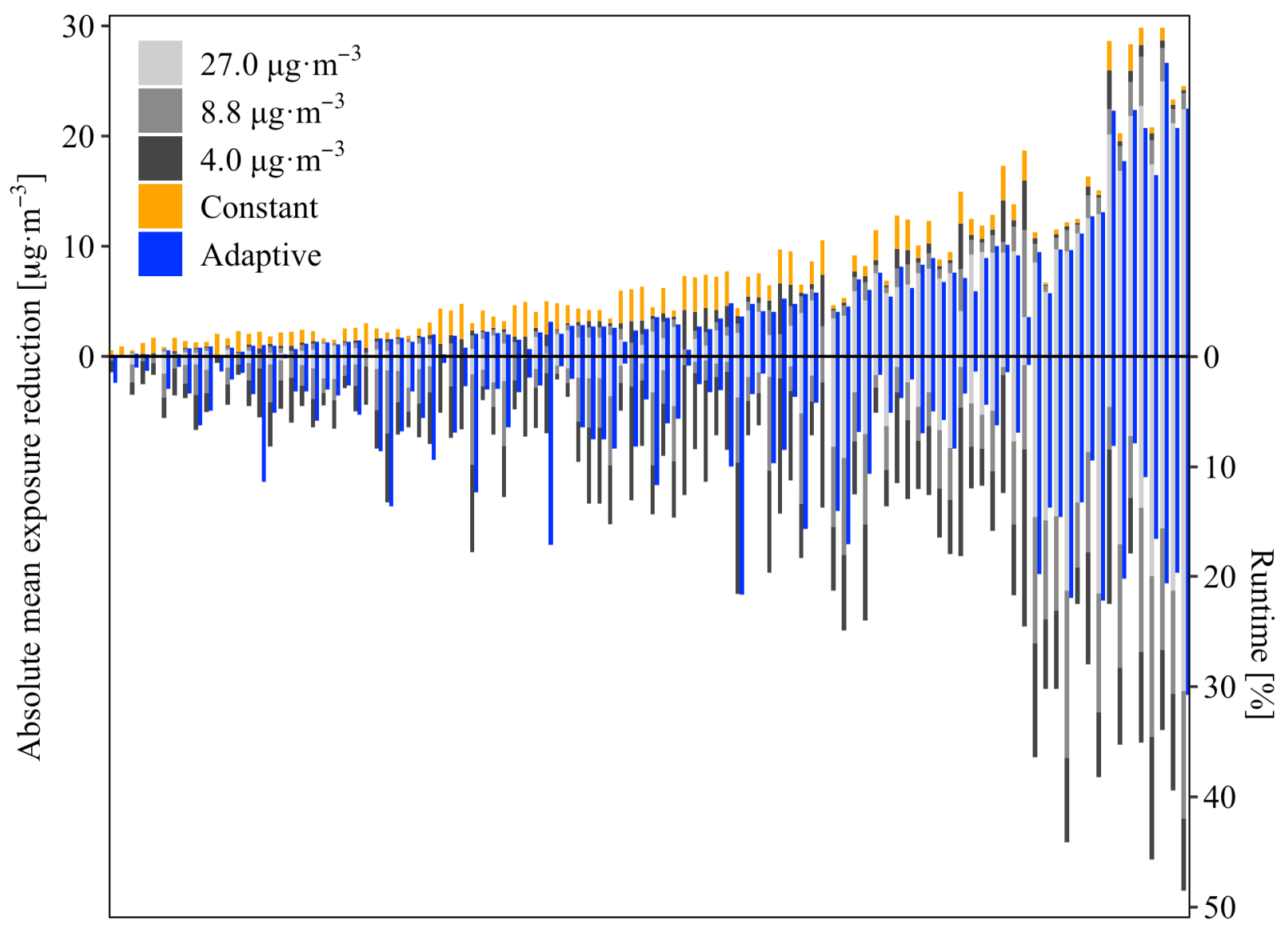

Figure 9. Absolute mean exposure reduction (upper portion, left axis) and runtime (lower portion, right axis) of the selected thresholds using a CADR/V ratio of 2.5 for the simulated environments derived from Dylos DC1700 measurements. Results are arranged by the simulated mean concentration in each environment without air cleaning. The runtime fraction for constant air cleaning is not shown as this will always extend to $100 \%$. The two environments with the highest simulated mean concentration are not included to improve visual clarity; a complete version of this figure is included in Appendix A2.2.

Exposure reduction is highest when the particle filter system is operating most frequently. Therefore, constant air cleaning will always result in the highest AMER. Considering that there is no concentration threshold at which the negative health effects of $\mathrm{PM}_{2.5}$ are eliminated, constant air cleaning is the best approach from an occupant health perspective. If constant air 
cleaning is not feasible, the lowest feasible fixed threshold is best. However, constant air cleaning is the worst approach from the perspective of energy use. Raising the air cleaning threshold to $4.0 \mu \mathrm{g} \cdot \mathrm{m}^{-3}$ results in the mean runtime dropping by approximately $86.4 \%$ for a $\mathrm{CADR} / \mathrm{V}$ ratio of 2.5. For PACs with power draws of $10 \mathrm{~W}$ and $50 \mathrm{~W}$ at low- and high-end fan speeds and a standby power draw of $4 \mathrm{~W}$ (values reported in Xiang et al. [35]), this figure corresponds to daily reductions of approximately $0.2 \mathrm{kWh}$ and $1.0 \mathrm{kWh}$ respectively; PACs with greater power draws of $167 \mathrm{~W}$ and $226 \mathrm{~W}$ (values reported in Sultan et al. [108]) would realize daily reductions of approximately $3.4 \mathrm{kWh}$ and $4.6 \mathrm{kWh}$ respectively. While this translates to only modest cost savings for users and a limited benefit at a large scale, HVAC fans usually draw far more power than PACs [101] and can therefore achieve greater reductions in energy usage. For both types of particle filter system, a low fixed threshold is a worthwhile consideration given the large reduction in energy usage relative to the generally small decrease in AMER. In circumstances where energy is very limited, even small reductions may be greatly beneficial. Seasonal wildfires are an excellent example of when the deployment of particle filter systems can provide large reductions in indoor $\mathrm{PM}_{2.5}$ concentration and improve health outcomes $[29,109,110]$. During wildfires, it is also quite common for power outages to occur [111] and thus particle filter systems may be powered by a battery with a finite storage capacity. Under these conditions, there is a benefit to significantly reducing the runtime. Greater reductions in energy usage can be achieved by further raising the threshold, although the marginal benefit quickly decreases. For a CADR/V ratio of 2.5, the absolute difference in runtime between fixed thresholds of $4.0 \mu \mathrm{g} \cdot \mathrm{m}^{-3}$ and $8.8 \mu \mathrm{g} \cdot \mathrm{m}^{-3}$ is $5.3 \%$. When energy is limited, the highest feasible fixed threshold that provides exposure reduction is best for occupant health. Another benefit of reducing the runtime is that the fan is producing noise less often. This may be important for ensuring occupant satisfaction and continued use of particle filter systems [33].

\subsubsection{Removal efficacy}

ARE has limited use in evaluating the relationship between AMER and runtime, providing little insight when a higher runtime can be tolerated to increase AMER. However, ARE does help to illustrate the benefits of an adaptive threshold. Figure 10 shows ARE for constant air cleaning, a fixed threshold of $8.8 \mu \mathrm{g} \cdot \mathrm{m}^{-3}$, and an adaptive threshold for the same simulated environments derived from Dylos DC1700 measurements using a CADR/V ratio of 2.5 . The fixed $8.8 \mu \mathrm{g} \cdot \mathrm{m}^{-3}$ 
threshold and adaptive threshold each have a higher ARE than constant air cleaning in 102 of 104 cases, the two exceptions occurring when the threshold is never exceeded and therefore the runtime is $0 \%$. The adaptive threshold results in a higher ARE than the fixed $8.8 \mu \mathrm{g} \cdot \mathrm{m}^{-3}$ threshold in 56 of 104 cases. When the mean concentration without air cleaning is greater than the fixed threshold, this proportion increases to 39 of 46 cases; when the mean concentration without air cleaning is below the fixed threshold, this drops to 17 of 58 cases. The inverse is true for the AMER: the adaptive threshold generally has a higher AMER when the mean concentration without air cleaning is below the fixed threshold (39 of 58 cases below the fixed threshold compared to 6 of 46 cases above). Comparing the adaptive threshold to the fixed 4.0 $\mu \mathrm{g} \cdot \mathrm{m}^{-3}$ and $27.0 \mu \mathrm{g} \cdot \mathrm{m}^{-3}$ thresholds, the ARE is higher in 92 and 29 of 104 simulations respectively. It can be inferred that, relative to any fixed threshold, an adaptive threshold generally has a higher AMER when mean concentrations are below the fixed threshold and a higher RE when mean concentrations are above the fixed threshold. This would suggest that an adaptive threshold generally optimizes AMER while restricting very high runtimes. The mean absolute reduction in runtime for the adaptive threshold compared to the fixed $8.8 \mu \mathrm{g} \cdot \mathrm{m}^{-3}$ threshold ranges from approximately $1-2 \%$ which is not very high. In relative terms, this improvement is more than $15 \%$ in all cases and can be much larger in environments with high mean concentrations. It may be possible to improve AMER and runtime across a range of different environments using a hybrid approach of an adaptive threshold with fixed maximum and/or minimum allowable threshold(s). This would affect a reasonable proportion of cases, given the low frequency with which the adaptive threshold is outside of the range of $4.0 \mu \mathrm{g} \cdot \mathrm{m}^{-3}$ to $27.0 \mu \mathrm{g} \cdot \mathrm{m}^{-3}$. 


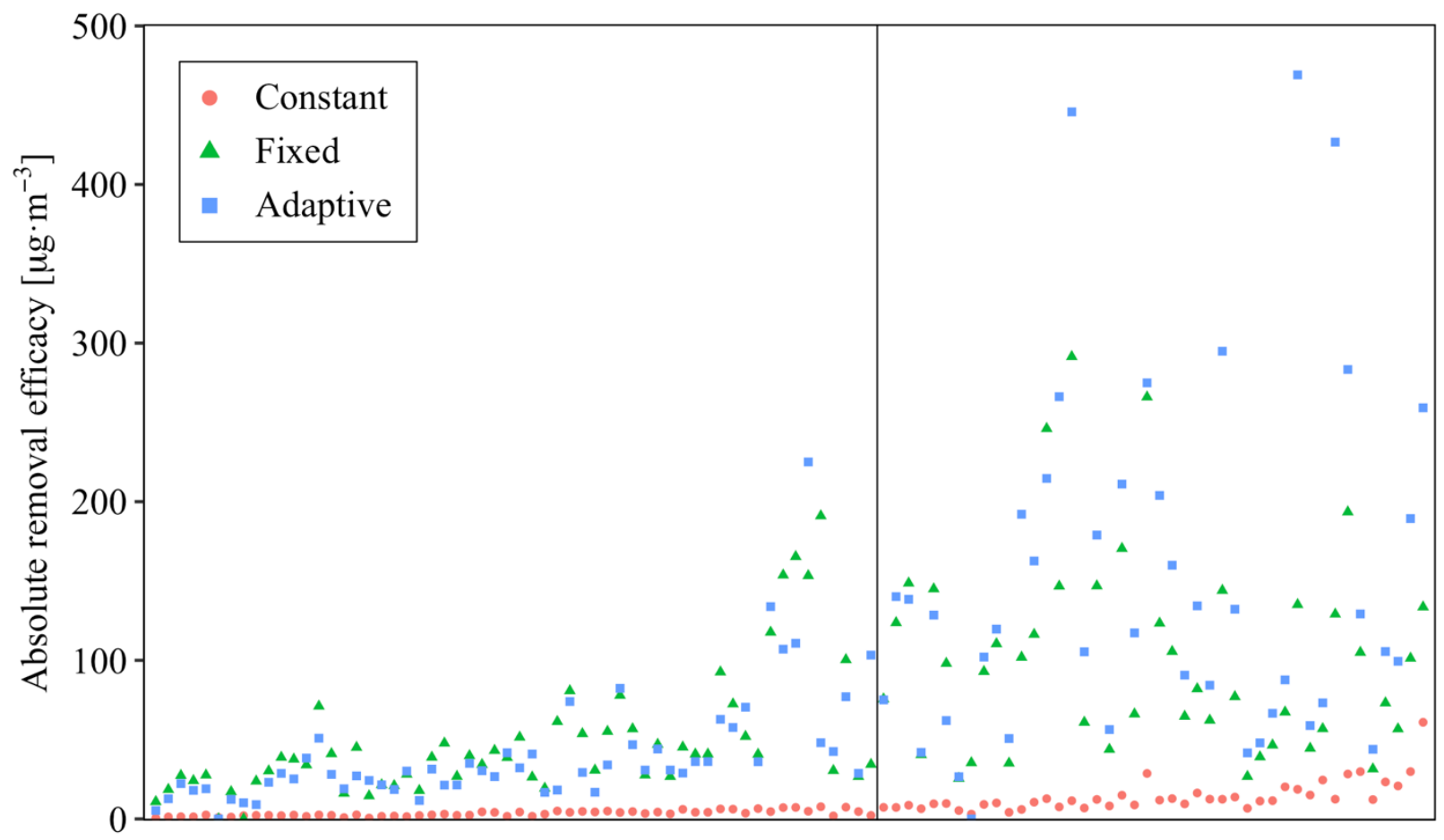

Figure 10. Absolute removal efficacy (absolute mean exposure reduction divided by runtime fraction) of constant air cleaning, a fixed threshold of $8.8 \mu \mathrm{g} \cdot \mathrm{m}^{-3}$, and an adaptive threshold for the simulated environments derived from Dylos DC1700 measurements. Results are arranged by the simulated mean concentration in each environment without air cleaning. For each simulated environment there is one set of points corresponding to each air cleaning mode. The vertical line separates simulations where the mean concentration without air cleaning is below (left) and above (right) the fixed threshold of $8.8 \mu \mathrm{g} \cdot \mathrm{m}^{-3}$. Two simulated environments are not included to improve visual clarity; a complete version of this figure is included in Appendix A2.2.

Figure 11 shows the marginal increase in AMER and runtime as the fixed threshold is reduced. Reducing the fixed threshold from $27.0 \mu \mathrm{g} \cdot \mathrm{m}^{-3}$ to $8.8 \mu \mathrm{g} \cdot \mathrm{m}^{-3}$ increases the AMER by $1.36 \mu \mathrm{g} \cdot \mathrm{m}^{-3}$ or less in $75 \%$ of cases while the median runtime increases by more than three times. If the fixed threshold is further reduced from $8.8 \mu \mathrm{g} \cdot \mathrm{m}^{-3}$ to $4.0 \mu \mathrm{g} \cdot \mathrm{m}^{-3}$, in $75 \%$ of cases the AMER increases by $0.80 \mu \mathrm{g} \cdot \mathrm{m}^{-3}$ or less while the median runtime increases by a further two times. For constant air cleaning, the AMER is increased by $1.18 \mu \mathrm{g} \cdot \mathrm{m}^{-3}$ or less in $75 \%$ of cases while the median runtime increases by approximately 18.7 times. This shows that the marginal improvements in ARE tend to be reduced as the threshold is lowered. Considering the significant increase in runtime associated with modest reductions in mean $\mathrm{PM}_{2.5}$ concentration, it is not efficient from an energy usage perspective to set the fixed air cleaning threshold to low concentrations (or 
constant air cleaning). A further consideration is that lower thresholds increase how often the fan is generating noise, which has the potential to reduce user compliance thereby negating the potential for exposure reduction.

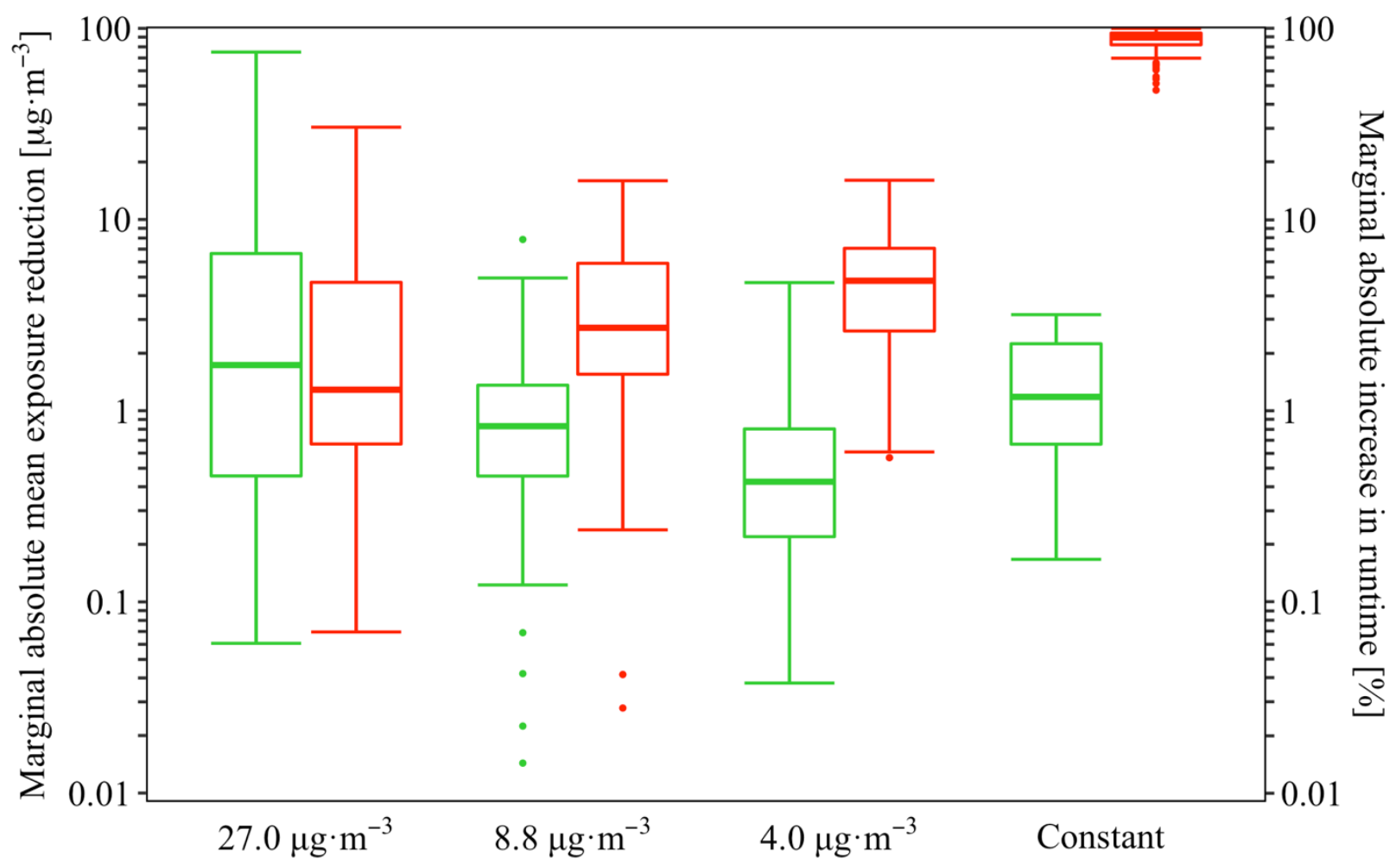

Threshold

Absolute exposure removal 官 Runtime

Figure 11. Marginal absolute mean exposure reduction (AMER, left axis) and marginal absolute increase in runtime (right axis) as the fixed threshold is reduced. The $27.0 \mu \mathrm{g} \cdot \mathrm{m}^{-3}$ fixed threshold boxes show the increase from no air cleaning. To accommodate a logarithmic scale without biasing the results, zeros were replaced with a value of $0.001 \mu \mathrm{g} \cdot \mathrm{m}^{-3}$.

\subsubsection{Clean air delivery rate}

Table 3 reports the runtime, AMER, ARE, NMER, and NRE of each threshold with CADR/V ratios of 1.0, 2.5, and 5.0. For all CADR/V ratios, the mean runtime and mean AMER decrease as the threshold is raised. The proportional decrease is such that mean ARE increases with the threshold, illustrating when low and high fixed thresholds are most beneficial. The mean ARE of the adaptive threshold is greater than all fixed thresholds except for $27.0 \mu \mathrm{g} \cdot \mathrm{m}^{-3}$. However, the 
adaptive threshold has a higher AMER than the $27.0 \mu \mathrm{g} \cdot \mathrm{m}^{-3}$ threshold and is lower than all others. The NMER and NRE of the adaptive threshold are approximately the same as the fixed $8.8 \mu \mathrm{g} \cdot \mathrm{m}^{-3}$ threshold. This suggests that, across a range of different environments, an adaptive threshold with a mean value of $16.0 \mu \mathrm{g} \cdot \mathrm{m}^{-3}$ performs comparably to a fixed threshold of 8.8 $\mu \mathrm{g} \cdot \mathrm{m}^{-3}$. Given the reductions in energy usage and noise, there is potential for an adaptive threshold to be used as the basis for a low-energy use mode in automated particle filter systems. As the $\mathrm{CADR} / \mathrm{V}$ ratio increases, there is a corresponding decrease in mean runtime and increase in mean AMER, therefore mean ARE increases as well. A higher CADR/V ratio may be associated with a more energy-intensive and/or loud fan so this increase in ARE does not necessarily reflect a practical improvement. The NMER is approximately the same for all $\mathrm{CADR} / \mathrm{V}$ ratios, which may indicate that NMER is proportional to the threshold rather than runtime. The NRE changes proportionally with runtime and ARE. Further investigation is warranted to evaluate the benefits of higher and lower CADRs given the energy requirements and noise produced by different fan speeds. It would also be valuable to evaluate the benefits of using different thresholds to control fan speed: higher CADRs may increase concentration reduction at the expense of greater energy usage and noise, suggesting it may be beneficial to use higher fan speeds exclusively during periods of uncharacteristically elevated concentrations. One approach to doing this would be to derive multiple adaptive thresholds from the elevated kmeans cluster groups. 
Table 3. Runtime, absolute mean exposure reduction (AMER), absolute removal efficacy (ARE), normalized mean exposure reduction (NMER), and normalized removal efficacy (NRE) of constant air cleaning, fixed thresholds, and adaptive threshold for simulated data derived from Dylos DC1700 optical particle counters $(N=104)$. Values are reported as mean \pm standard deviation. The initial adaptive threshold values range from $0.7 \mu \mathrm{g} \cdot \mathrm{m}^{-3}$ to $122.2 \mu \mathrm{g} \cdot \mathrm{m}^{-3}$ (mean 16.0 $\left.\pm 17.5 \mu \mathrm{g} \cdot \mathrm{m}^{-3}\right)$.

\begin{tabular}{ccccccc}
\hline $\begin{array}{c}\text { CADR/V } \\
{\left[\mathrm{h}^{-1}\right]}\end{array}$ & Threshold & $\begin{array}{c}\text { Runtime } \\
{[\%]}\end{array}$ & $\begin{array}{c}\text { AMER } \\
{\left[\mu \mathrm{g} \cdot \mathrm{m}^{-3}\right]}\end{array}$ & $\begin{array}{c}\text { ARE } \\
{\left[\mu \mathrm{g} \cdot \mathrm{m}^{-3}\right]}\end{array}$ & $\begin{array}{c}\text { NMER } \\
{[-]}\end{array}$ & $\begin{array}{c}\text { NRE } \\
{[-]}\end{array}$ \\
\hline & Constant & 100 & $6.2 \pm 8.1$ & $6.2 \pm 8.1$ & 1 & 1 \\
& $4.0 \mu \mathrm{g} \cdot \mathrm{m}^{-3}$ & $21.0 \pm 15.2$ & $5.2 \pm 8.1$ & $19.9 \pm 17.5$ & $0.71 \pm 0.23$ & $4.8 \pm 2.9$ \\
1.0 & $8.8 \mu \mathrm{g} \cdot \mathrm{m}^{-3}$ & $12.1 \pm 12.9$ & $4.6 \pm 7.9$ & $34.4 \pm 35.2$ & $0.59 \pm 0.29$ & $7.7 \pm 4.4$ \\
& $27.0 \mu \mathrm{g} \cdot \mathrm{m}^{-3}$ & $6.1 \pm 8.9$ & $3.8 \pm 7.5$ & $57.6 \pm 67.0$ & $0.43 \pm 0.30$ & $12.5 \pm 9.7$ \\
& Adaptive & $10.1 \pm 8.5$ & $4.1 \pm 6.4$ & $47.3 \pm 69.7$ & $0.57 \pm 0.24$ & $8.7 \pm 6.3$ \\
\hline \multirow{2}{*}{2.5} & Constant & 100 & $8.8 \pm 11.1$ & $8.8 \pm 11.1$ & 1 & 1 \\
& $4.0 \mu \mathrm{g} \cdot \mathrm{m}^{-3}$ & $13.6 \pm 11.4$ & $7.4 \pm 11.0$ & $46.0 \pm 39.9$ & $0.69 \pm 0.23$ & $7.4 \pm 4.3$ \\
& $8.8 \mu \mathrm{g} \cdot \mathrm{m}^{-3}$ & $8.3 \pm 9.7$ & $6.6 \pm 10.9$ & $79.5 \pm 82.2$ & $0.58 \pm 0.29$ & $12.1 \pm 7.0$ \\
& $27.0 \mu \mathrm{g} \cdot \mathrm{m}^{-3}$ & $4.2 \pm 6.4$ & $5.5 \pm 10.3$ & $132.6 \pm 153.4$ & $0.43 \pm 0.30$ & $19.6 \pm 15.6$ \\
& Adaptive & $7.0 \pm 6.2$ & $6.0 \pm 9.3$ & $101.5 \pm 135.6$ & $0.57 \pm 0.25$ & $13.1 \pm 9.8$ \\
\hline 5.0 & Constant & 100 & $10.4 \pm 12.8$ & $10.4 \pm 12.8$ & 1 & 1 \\
& $4.8 \mu \mathrm{g} \cdot \mathrm{m}^{-3}$ & $9.3 \pm 8.6$ & $8.7 \pm 12.8$ & $83.4 \pm 71.1$ & $0.68 \pm 0.24$ & $11.2 \pm 6.4$ \\
& $27.0 \mu \mathrm{g} \cdot \mathrm{m}^{-3}$ & $3.0 \pm 4.7$ & $6.5 \pm 11.9$ & $238.3 \pm 271.3$ & $0.43 \pm 0.29$ & $29.8 \pm 24.5$ \\
& Adaptive & $5.0 \pm 4.7$ & $7.1 \pm 10.6$ & $179.7 \pm 251.7$ & $0.57 \pm 0.25$ & $19.4 \pm 15.3$ \\
\hline & & & & & &
\end{tabular}

To examine whether similar results can be achieved using different PM monitors, this analysis was repeated using the simulated environments derived from Alphasense OPC-N2 monitors after downsampling the data from 15.379-second to approximately 1-minute sampling intervals. These results are similar to those from the Dylos DC1700 monitor. Companion figures and tables can be found in Appendix A2.3. In all 100 simulations, constant air cleaning increases the AMER compared to the fixed and adaptive thresholds while also significantly increasing the runtime. The adaptive threshold has a higher AMER, and therefore higher runtime, than the fixed 4.0 $\mu \mathrm{g} \cdot \mathrm{m}^{-3}, 8.8 \mu \mathrm{g} \cdot \mathrm{m}^{-3}$, and $27.0 \mu \mathrm{g} \cdot \mathrm{m}^{-3}$ thresholds in 12,36 , and 77 of 100 cases respectively. The 
fixed $8.8 \mu \mathrm{g} \cdot \mathrm{m}^{-3}$ threshold and adaptive threshold have a higher RE than constant air cleaning in 96 and 99 of 100 cases respectively, all exceptions being where the threshold is never exceeded and therefore the runtime is $0 \%$. The adaptive threshold results in a higher ARE than the fixed $8.8 \mu \mathrm{g} \cdot \mathrm{m}^{-3}$ threshold in 61 of 100 cases. In simulation environments where the mean concentration without air cleaning is greater than the fixed $8.8 \mu \mathrm{g} \cdot \mathrm{m}^{-3}$ threshold this proportion increases to 30 of 32 cases; when the mean concentrations without air cleaning is below the fixed threshold this drops to 31 of 68 cases. Once again, the inverse is true for AMER: the adaptive threshold generally has a higher AMER when the mean concentration without air cleaning is below the fixed threshold ( 35 of 68 cases below the fixed threshold compared to 1 of 32 cases above). Comparing the adaptive threshold to the fixed $4.0 \mu \mathrm{g} \cdot \mathrm{m}^{-3}$ and $27.0 \mu \mathrm{g} \cdot \mathrm{m}^{-3}$ thresholds, the ARE is higher in 85 and 27 of 100 simulations respectively. The initial adaptive threshold value ranges from $1.4 \mu \mathrm{g} \cdot \mathrm{m}^{-3}$ to $76.5 \mu \mathrm{g} \cdot \mathrm{m}^{-3}$ (mean $13.4 \pm 14.6 \mu \mathrm{g} \cdot \mathrm{m}^{-3}$ ). The final adaptive threshold values range from $2.4 \mu \mathrm{g} \cdot \mathrm{m}^{-3}$ to $118.4 \mu \mathrm{g} \cdot \mathrm{m}^{-3}$ (mean $22.4 \pm 21.0 \mu \mathrm{g} \cdot \mathrm{m}^{-3}$ ), $2.2 \mu \mathrm{g} \cdot \mathrm{m}^{-3}$ to 119.5 $\mu \mathrm{g} \cdot \mathrm{m}^{-3}$ (mean $20.0 \pm 19.1 \mu \mathrm{g} \cdot \mathrm{m}^{-3}$ ), and $2.1 \mu \mathrm{g} \cdot \mathrm{m}^{-3}$ to $85.3 \mu \mathrm{g} \cdot \mathrm{m}^{-3}$ (mean $16.4 \pm 14.2 \mu \mathrm{g} \cdot \mathrm{m}^{-3}$ ) for $\mathrm{CADR} / \mathrm{V}$ ratios of 1.0, 2.5, and 5.0 respectively. These adaptive thresholds skew higher than those for the DC1700-derived simulations, which may indicate a difference in how the monitors report $\mathrm{PM}_{2.5}$ concentration. NMER values are approximately the same as those from the DC1700 derived concentrations, while NRE behaves similarly with higher values.

\subsubsection{Sensor differences}

The simulation concentrations are derived from the Dylos DC1700 and Alphasense OPC-N2 measurements using the same method. As a result, both groups should be characteristically similar with only variation attributable to real variation in the measured data. Otherwise, this would suggest that the monitors influence the results due to differing responses to aerosols or how the particle number count is converted to a mass concentration equivalent. Paired $t$-tests were used to evaluate potential inter- and intra-monitor differences by comparing the mean concentration without air cleaning and the final adaptive threshold value. A CADR/V ratio of 2.5 was used. For inter-monitor differences, paired measurements were grouped by home and season and tested by device. For intra-monitor differences, paired measurements were grouped by home and device and tested by season. Mendell et al. [103] reported no differences across season and year for the measured concentrations, although comparisons by year were primarily made using 
measurements of total suspended particles rather than the optical particle counters. Smoking and non-smoking homes were tested separately, as this was previously found to have a large effect on measured concentrations [103]. 60 of 204 simulations were derived from homes that were classified as having smoking residents. No significant differences were found for any parameters in the smoking homes using a CADR/V ratio of 2.5. For non-smoking homes using a CADR/V ratio of 2.5 , the mean concentration without air cleaning was significantly different between the different devices $(p=0.013)$ as well as between different seasons measured by the DC1700 $(p=$ $0.028)$, but not by the OPC-N2 $(p=0.34)$. The mean concentration without air cleaning was 8.0 $\pm 6.6 \mu \mathrm{g} \cdot \mathrm{m}^{-3}$ for the DC1700 and $5.3 \pm 2.8 \mu \mathrm{g} \cdot \mathrm{m}^{-3}$ for the OPC-N2. For simulations modelled from the same home, there can be meaningful variation in the frequency and strength of sources attributable to both real variation and a monitor difference. The monitor difference implies that the performance of a fixed threshold may depend on how the particle filter system measures $\mathrm{PM}_{2.5}$ concentration. The final adaptive threshold value was not significantly different between the different devices $(p=0.060)$ or between different seasons measured by the DC1700 ( $p=$ $0.87)$ and the OPC-N2 $(p=0.55)$, although as noted above the thresholds for OPC-N2 derived simulations are higher by a mean of $5.1 \mu \mathrm{g} \cdot \mathrm{m}^{-3}(34 \%)$. Comparing the AMER and NMER values from across both groups for all CADR/V ratios (see Table 1 and Table C.1), it appears as though the relative performance of the fixed and adaptive thresholds is not dependent on how the particle filter system detects $\mathrm{PM}_{2.5}$ concentration. These results support the generalizability of fixed and adaptive thresholds for use in the automation of particle filter systems deployed in real environments using low-cost particle sensors. Many commercially available portable air cleaners are already equipped with low-cost particle sensors and with the addition of a data storage mechanism and a processor to calculate an adaptive threshold (using k-means clustering or another simple algorithm), it should be feasible to implement this approach without significantly increasing the cost or size of these devices.

Based on the evidence presented here, it would be worthwhile to examine how the method of determining the adaptive threshold can be further improved, and whether there are benefits to using fixed thresholds as a factor of safety when there is insufficient data to determine a reasonable adaptive threshold. It would also be worthwhile to investigate total energy usage and fan noise in terms of CADR (fan speed and/or size), and whether removal efficacy can be improved by using different thresholds to control fan speed. There is also an overarching need to 
test fixed and adaptive thresholds with measured data and, in particular, to explore the practical issues of compliance and performance with alternate filtration control strategies.

\subsection{Conclusions}

These findings suggest that automating particle filter systems with fixed or adaptive thresholds can significantly reduce total energy usage while maintaining effective exposure reduction, building on the earlier findings of Li and Siegel [102] and providing support for the use of this method in real environments. Compared to constant air cleaning, fixed thresholds of a low concentration provide substantial reductions in runtime and therefore reductions in total energy usage and fan noise while providing substantial exposure reduction. Fixed thresholds of a high concentration provide further reductions in runtime but consequently provide less exposure reduction, sometimes substantially. The adaptive threshold generally provides high absolute and normalized mean exposure reduction while preventing high runtimes. This potentially benefits energy usage and user compliance while continuing to provide a level of exposure reduction that could benefit occupant health. Continuing to improve the performance of particle filter systems will help to make them a more viable and sustainable means of improving occupant health.

\subsection{Acknowledgements}

Raheleh Givehchi contributed to the ideas and the preliminary work that was used in this paper. The authors would like to thank the social housing provider, building management and the residents for their cooperation throughout the study, as well as The Atmospheric Fund who led the field work in the larger investigation. The Natural Sciences and Engineering Research Council of Canada (Grant RGPIN-2014-06698) provided funding. 


\section{Chapter 4: \\ Conclusions}

This research was motivated by the findings of Adamkiewicz et al. [26] and Diaz Lozano Patiño and Siegel [56], which both reported that $\mathrm{PM}_{2.5}$ exposure is disproportionately higher for residents of social housing and other low-income housing. These results are the first to make a direct comparison between PM concentrations low-income multi-unit housing and single-family dwellings, providing more evidence of such a disparity. Given the increased vulnerability of social housing residents to health problems, it is crucial that housing authorities and associated stakeholders pursue strategies to reduce indoor concentrations of PM and other harmful indoor pollutants in these buildings and homes. It is very important that PM reduction strategies are practical and equitable. To this point, most strategies to control smoking (identified as an important source of indoor PM in this study and many others [3,7,8,52-55]) have focused on bans, the efficacy of which varies $[8,54,88,89]$ and which create ethical concerns surrounding enforcement $[88,90]$. A different approach to the problem of smoking, and indoor PM more widely, is required. The primary recommendation of this research is that improved sealing ventilation of individual apartments (compartmentalization) be revisited as a comprehensive strategy to reduce indoor concentrations and prevent the inter-unit transfer of pollutants.

Secondary recommendations include installing range hoods in homes where these are not already present as well as encouraging their use. Further improvements could be made by reducing the emissions of outdoor sources such as vehicles and industry, which tend to be located near lowincome housing and therefore contribute to the overall disparity [26].

Such recommendations may be expensive, slow to implement, and highly disruptive to building residents. Portable air cleaners are another promising strategy to reduce indoor PM exposure which can be readily deployed at low cost. This research proposes using fixed and/or adaptive concentration thresholds to improve on existing approaches to automating the operation of these systems. Our results find that significant reductions in runtime can be achieved using this approach, potentially reducing the total energy usage of these devices as well as how frequently they produce unwanted noise. Reducing the noise of these devices is likely one of the best ways to improve user satisfaction, and therefore how often they are used and reducing occupant PM 
exposure. Improving portable air cleaners may provide an excellent short-term solution while more comprehensive strategies are evaluated and implemented. 


\section{References}

[1] United States Environmental Protection Agency, Particulate Matter (PM) Pollution, (2021). https://www.epa.gov/pm-pollution (accessed July 11, 2021).

[2] E. Abt, H.H. Suh, P. Catalano, P. Koutrakis, Relative Contribution of Outdoor and Indoor Particle Sources to Indoor Concentrations, Environ. Sci. Technol. 34 (2000) 3579-3587. https://doi.org/10.1021/es990348y.

[3] L.A. Wallace, M. Mitchell, G.T. O’Connor, L. Neas, M. Lippman, M. Kattan, J. Koenig, J.W. Stout, B.J. Vaughn, D. Wallace, M. Walter, K. Adams, L.-J.S. Liu, Particle concentrations in inner-city homes of children with asthma: the effect of smoking, cooking, and outdoor pollution., Environ. Health Perspect. 111 (2003) 1265-1272. https://doi.org/10.1289/ehp.6135.

[4] J.O. Anderson, J.G. Thundiyil, A. Stolbach, Clearing the Air: A Review of the Effects of Particulate Matter Air Pollution on Human Health, J. Med. Toxicol. 8 (2012) 166-175. https://doi.org/10.1007/s13181-011-0203-1.

[5] N.R. Martins, G. Carrilho da Graça, Impact of PM2.5 in indoor urban environments: A review, Sustain. Cities Soc. 42 (2018) 259-275. https://doi.org/10.1016/j.scs.2018.07.011.

[6] H. Schwartz-Narbonne, B. Du, J.A. Siegel, Volatile organic compound and particulate matter emissions from an ultrasonic essential oil diffuser, Indoor Air. (2021). https://doi.org/10.1111/ina.12845.

[7] B.A. King, M.J. Travers, K.M. Cummings, M.C. Mahoney, A.J. Hyland, Secondhand Smoke Transfer in Multiunit Housing, Nicotine Tob. Res. 12 (2010) 1133-1141. https://doi.org/10.1093/ntr/ntq162.

[8] E.T. Russo, T.E. Hulse, G. Adamkiewicz, D.E. Levy, L. Bethune, J. Kane, M. Reid, S.N. Shah, Comparison of Indoor Air Quality in Smoke-Permitted and Smoke-Free Multiunit Housing: Findings From the Boston Housing Authority, Nicotine Tob. Res. 17 (2015) 316-322. https://doi.org/10.1093/ntr/ntu146.

[9] J.M. Logue, P.N. Price, M.H. Sherman, B.C. Singer, A Method to Estimate the Chronic Health Impact of Air Pollutants in U.S. Residences, Environ. Health Perspect. 120 (2012) 216-222. https://doi.org/10.1289/ehp.1104035.

[10] K. Donaldson, V. Stone, A. Clouter, L. Renwick, W. MacNee, Ultrafine particles, Occup. Environ. Med. 58 (2001) 211. https://doi.org/10.1136/oem.58.3.211.

[11] D.E. Schraufnagel, The health effects of ultrafine particles, Exp. Mol. Med. 52 (2020) 311317. https://doi.org/10.1038/s12276-020-0403-3.

[12] Centers for Disease Control and Prevention (US), National Center for Chronic Disease Prevention and Health Promotion (US), How Tobacco Smoke Causes Disease: The 
Biology and Behavioral Basis for Smoking-Attributable Disease: A Report of the Surgeon General, Atlanta, Georgia, USA, 2010. https://www.ncbi.nlm.nih.gov/books/NBK53017/.

[13] M. Park, H.S. Joo, K. Lee, M. Jang, S.D. Kim, I. Kim, L.J.S. Borlaza, H. Lim, H. Shin, K.H. Chung, Y.-H. Choi, S.G. Park, M.-S. Bae, J. Lee, H. Song, K. Park, Differential toxicities of fine particulate matters from various sources, Sci. Rep. 8 (2018) 17007. https://doi.org/10.1038/s41598-018-35398-0.

[14] C.J. Matz, M. Egyed, G. Xi, J. Racine, R. Pavlovic, R. Rittmaster, S.B. Henderson, D.M. Stieb, Health impact analysis of PM2.5 from wildfire smoke in Canada (2013-2015, 2017-2018), Sci. Total Environ. 725 (2020) 138506. https://doi.org/10.1016/j.scitotenv.2020.138506.

[15] Health Canada, Guidance for fine particulate matter (PM2.5) in residential indoor air, 2012. https://www.canada.ca/en/health-canada/services/publications/healthy-living/guidancefine-particulate-matter-pm2-5-residential-indoor-air.html (accessed May 19, 2021).

[16] Statistics Canada, Table 11-10-0135-01 Low income statistics by age, sex and economic family type, 2020. https://doi.org/10.25318/1110013501-eng.

[17] J. Semega, M. Kollar, E.A. Shrider, J. Creamer, Income and Poverty in the United States: 2019, United States Census Bureau, 2020. https://www.census.gov/content/dam/Census/library/publications/2020/demo/p60-270.pdf (accessed May 10, 2021).

[18] J. Claveau, The Canadian Housing Survey, 2018: Core housing need of renter households living in social and affordable housing, Statistics Canada, 2020. https://www150.statcan.gc.ca/n1/pub/75f0002m/75f0002m2020003-eng.htm (accessed July 13, 2020).

[19] United States Census Bureau, American Housing Survey (AHS), (2019). https://www.census.gov/programs-surveys/ahs/data/interactive/ahstablecreator.html (accessed July 13, 2021).

[20] Statistics Canada, Children living in low-income households, (2017). https:/www12.statcan.gc.ca/census-recensement/2016/as-sa/98-200-x/2016012/98-200x2016012-eng.cfm (accessed May 7, 2021).

[21] Statistics Canada, Household income in Canada: Key results from the 2016 Census, (2017). https://www150.statcan.gc.ca/n1/daily-quotidien/170913/dq170913a-eng.htm (accessed May 7, 2021).

[22] K. Wall, Low income among persons with a disability in Canada, Statistics Canada, 2017. https://www150.statcan.gc.ca/n1/pub/75-006-x/2017001/article/54854-eng.htm (accessed May 7, 2021).

[23] J.R. Masuda, T. Zupancic, B. Poland, D.C. Cole, Environmental health and vulnerable populations in Canada: mapping an integrated equity-focused research agenda, Can. 
Geogr. Géographe Can. 52 (2008) 427-450. https://doi.org/10.1111/j.15410064.2008.00223.x.

[24] D. Raphael, Poverty in childhood and adverse health outcomes in adulthood, Maturitas. 69 (2011) 22-26. https://doi.org/10.1016/j.maturitas.2011.02.011.

[25] T. Bushnik, M. Tjepkema, L. Martel, Socioeconomic disparities in life and health expectancy among the household population in Canada, Health Rep. (2020). https://www.doi.org/10.25318/82-003-x202000100001-eng.

[26] G. Adamkiewicz, A.R. Zota, M.P. Fabian, T. Chahine, R. Julien, J.D. Spengler, J.I. Levy, Moving Environmental Justice Indoors: Understanding Structural Influences on Residential Exposure Patterns in Low-Income Communities, Am. J. Public Health. 101 (2011) S238-S245. https://doi.org/10.2105/AJPH.2011.300119.

[27] E. Diaz Lozano Patino, J.A. Siegel, Indoor environmental quality in social housing: A literature review, Build. Environ. 131 (2018) 231-241. https://doi.org/10.1016/j.buildenv.2018.01.013.

[28] D.G. Karottki, M. Spilak, M. Frederiksen, L. Gunnarsen, E.V. Brauner, B. Kolarik, Z.J. Andersen, T. Sigsgaard, L. Barregard, B. Strandberg, G. Sallsten, P. Møller, S. Loft, An indoor air filtration study in homes of elderly: cardiovascular and respiratory effects of exposure to particulate matter, Environ. Health. 12 (2013) 116. https://doi.org/10.1186/1476-069X-12-116.

[29] W.J. Fisk, W.R. Chan, Health benefits and costs of filtration interventions that reduce indoor exposure to PM2.5 during wildfires, Indoor Air. 27 (2017) 191-204. https://doi.org/10.1111/ina.12285.

[30] M. Morishita, S.D. Adar, J. D’Souza, R.A. Ziemba, R.L. Bard, C. Spino, R.D. Brook, Effect of Portable Air Filtration Systems on Personal Exposure to Fine Particulate Matter and Blood Pressure Among Residents in a Low-Income Senior Facility: A Randomized Clinical Trial, JAMA Intern. Med. 178 (2018) 1350-1357. https://doi.org/10.1001/jamainternmed.2018.3308.

[31] M.M. Maestas, R.D. Brook, R.A. Ziemba, F. Li, R.C. Crane, Z.M. Klaver, R.L. Bard, C.A. Spino, S.D. Adar, M. Morishita, Reduction of personal PM2.5 exposure via indoor air filtration systems in Detroit: an intervention study, J. Expo. Sci. Environ. Epidemiol. 29 (2019) 484-490. https://doi.org/10.1038/s41370-018-0085-2.

[32] W.J. Fisk, Health benefits of particle filtration, Indoor Air. 23 (2013) 357-368. https://doi.org/10.1111/ina.12036.

[33] J. Pei, C. Dong, J. Liu, Operating behavior and corresponding performance of portable air cleaners in residential buildings, China, Build. Environ. 147 (2019) 473-481. https://doi.org/10.1016/j.buildenv.2018.08.009.

[34] C.-H. Huang, J. Xiang, E. Austin, J. Shirai, Y. Liu, C. Simpson, C.J. Karr, A.L. FyfeJohnson, T. Kronborg Larsen, E. Seto, Impacts of using auto-mode portable air cleaner on 
indoor PM2.5 levels: An intervention study, Build. Environ. 188 (2021) 107444. https://doi.org/10.1016/j.buildenv.2020.107444.

[35] J. Xiang, C.-H. Huang, E. Austin, J. Shirai, Y. Liu, E. Seto, Energy consumption of using HEPA-based portable air cleaner in residences: A monitoring study in Seattle, US, Energy Build. 236 (2021) 110773. https://doi.org/10.1016/j.enbuild.2021.110773.

[36] World Health Organization, WHO Air quality guidelines for particulate matter, ozone, nitrogen dioxide and sulfur dioxide: global update 2005: summary of risk assessment, 2006.

[37] Q. Di, L. Dai, Y. Wang, A. Zanobetti, C. Choirat, J.D. Schwartz, F. Dominici, Association of Short-term Exposure to Air Pollution With Mortality in Older Adults, JAMA. 318 (2017) 2446-2456. https://doi.org/10.1001/jama.2017.17923.

[38] A. Vodonos, Y.A. Awad, J. Schwartz, The concentration-response between long-term PM2.5 exposure and mortality; A meta-regression approach, Environ. Res. 166 (2018) 677-689. https://doi.org/10.1016/j.envres.2018.06.021.

[39] B. Wang, K.-D. Eum, F. Kazemiparkouhi, C. Li, J. Manjourides, V. Pavlu, H. Suh, The impact of long-term PM2.5 exposure on specific causes of death: exposure-response curves and effect modification among 53 million U.S. Medicare beneficiaries, Environ. Health. 19 (2020) 20. https://doi.org/10.1186/s12940-020-00575-0.

[40] N.E. Klepeis, W.C. Nelson, W.R. Ott, J.P. Robinson, A.M. Tsang, P. Switzer, J.V. Behar, S.C. Hern, W.H. Engelmann, The National Human Activity Pattern Survey (NHAPS): a resource for assessing exposure to environmental pollutants, J. Expo. Sci. Environ. Epidemiol. 11 (2001) 231-252. https://doi.org/10.1038/sj.jea.7500165.

[41] J.A. Leech, W.C. Nelson, R.T. Burnett, S. Aaron, M.E. Raizenne, It's about time: A comparison of Canadian and American time-activity patterns, J. Expo. Sci. Environ. Epidemiol. 12 (2002) 427-432. https://doi.org/10.1038/sj.jea.7500244.

[42] S. Burgos, P. Ruiz, R. Koifman, Changes to indoor air quality as a result of relocating families from slums to public housing, Atmos. Environ. 70 (2013) 179-185. https://doi.org/10.1016/j.atmosenv.2012.12.044.

[43] R.A. Sharpe, C.R. Thornton, V. Nikolaou, N.J. Osborne, Fuel poverty increases risk of mould contamination, regardless of adult risk perception \& ventilation in social housing properties, Environ. Int. 79 (2015) 115-129. https://doi.org/10.1016/j.envint.2015.03.009.

[44] Á. Broderick, M. Byrne, S. Armstrong, J. Sheahan, A.M. Coggins, A pre and post evaluation of indoor air quality, ventilation, and thermal comfort in retrofitted cooperative social housing, Build. Environ. 122 (2017) 126-133. https://doi.org/10.1016/j.buildenv.2017.05.020.

[45] P.K. Cheung, C.Y. Jim, Indoor air quality in substandard housing in Hong Kong, Sustain. Cities Soc. 48 (2019) 101583. https://doi.org/10.1016/j.scs.2019.101583. 
[46] D. Kajjoba, H. Kasedde, P.W. Olupot, J.D. Lwanyaga, Evaluation of thermal comfort and air quality of low-income housing in Kampala City, Uganda, Energy Built Environ. (2021). https://doi.org/10.1016/j.enbenv.2021.05.007.

[47] T.A. Kraev, G. Adamkiewicz, S.K. Hammond, J.D. Spengler, Indoor concentrations of nicotine in low-income, multi-unit housing: associations with smoking behaviours and housing characteristics, Tob. Control. 18 (2009) 438-444. https://doi.org/10.1136/tc.2009.029728.

[48] D.L. Bohac, M.J. Hewett, S.K. Hammond, D.T. Grimsrud, Secondhand smoke transfer and reductions by air sealing and ventilation in multiunit buildings: PFT and nicotine verification, Indoor Air. 21 (2011) 36-44. https://doi.org/10.1111/j.16000668.2010.00680.x.

[49] L. Ricketts, J. Straube, A field study of airflow in mid to high-rise multi-unit residential buildings, in: 2014. http://obec.on.ca/sites/default/uploads/files/members/CCBST-Oct2014/A3-2-a.pdf.

[50] D.J. Corsi, M.H. Boyle, S.A. Lear, C.K. Chow, K.K. Teo, S.V. Subramanian, Trends in smoking in Canada from 1950 to 2011: progression of the tobacco epidemic according to socioeconomic status and geography, Cancer Causes Control. 25 (2014) 45-57. https://doi.org/10.1007/s10552-013-0307-9.

[51] M. Chaiton, C. Callard, Mind the Gap: Disparities in Cigarette Smoking in Canada, Tob. Use Insights. 12 (2019) 1179173X19839058. https://doi.org/10.1177/1179173X19839058.

[52] R.E. Arku, G. Adamkiewicz, J. Vallarino, J.D. Spengler, D.E. Levy, Seasonal variability in environmental tobacco smoke exposure in public housing developments, Indoor Air. 25 (2015) 13-20. https://doi.org/10.1111/ina.12121.

[53] S. Semple, A. Apsley, T. Azmina Ibrahim, S.W. Turner, J.W. Cherrie, Fine particulate matter concentrations in smoking households: just how much secondhand smoke do you breathe in if you live with a smoker who smokes indoors?, Tob. Control. 24 (2015) e205. https://doi.org/10.1136/tobaccocontrol-2014-051635.

[54] P. MacNaughton, G. Adamkiewicz, R.E. Arku, J. Vallarino, D.E. Levy, The impact of a smoke-free policy on environmental tobacco smoke exposure in public housing developments, Sci. Total Environ. 557-558 (2016) 676-680. https://doi.org/10.1016/j.scitotenv.2016.03.110.

[55] S.M. Holm, J. Balmes, D. Gillette, K. Hartin, E. Seto, D. Lindeman, D. Polanco, E. Fong, Cooking behaviors are related to household particulate matter exposure in children with asthma in the urban East Bay Area of Northern California, PLOS ONE. 13 (2018) e0197199. https://doi.org/10.1371/journal.pone.0197199.

[56] E. Diaz Lozano Patiño, D. Vakalis, M. Touchie, E. Tzekova, J.A. Siegel, Thermal comfort in multi-unit social housing buildings, Build. Environ. 144 (2018) 230-237. https://doi.org/10.1016/j.buildenv.2018.08.024. 
[57] D. Vakalis, M. Touchie, E. Tzekova, H.L. MacLean, J.A. Siegel, Indoor environmental quality perceptions of social housing residents, Build. Environ. 150 (2019) 135-143. https://doi.org/10.1016/j.buildenv.2018.12.062.

[58] Y. Wan, M.L. Diamond, J.A. Siegel, Elevated Concentrations of Semivolatile Organic Compounds in Social Housing Multiunit Residential Building Apartments, Environ. Sci. Technol. Lett. 7 (2020) 191-197. https://doi.org/10.1021/acs.estlett.0c00068.

[59] D. Vakalis, E. Diaz Lozano Patino, T. Opher, M. Touchie, K. Burrows, H.L. MacLean, J.A. Siegel, Quantifying thermal comfort and carbon savings from energy-retrofits in social housing, Energy Build. (2021) 110950. https://doi.org/10.1016/j.enbuild.2021.110950.

[60] Y. Zhang, T. Li, J.A. Siegel, Investigating the impact of filters on long-term particle concentration measurements in residences (RP-1649), Sci. Technol. Built Environ. 26 (2020) 1037-1047. https://doi.org/10.1080/23744731.2020.1778402.

[61] A. Mahdavi, J.A. Siegel, Quantitative filter forensics: Size distribution and particulate matter concentrations in residential buildings, Indoor Air. 31 (2021) 1050-1060. https://doi.org/10.1111/ina.12782.

[62] J. Liu, S. Cui, Meteorological Influences on Seasonal Variation of Fine Particulate Matter in Cities over Southern Ontario, Canada, Adv. Meteorol. 2014 (2014) 169476. https://doi.org/10.1155/2014/169476.

[63] S. Semple, A.E. Ibrahim, A. Apsley, M. Steiner, S. Turner, Using a new, low-cost air quality sensor to quantify second-hand smoke (SHS) levels in homes, Tob. Control. 24 (2013) 153. https://doi.org/10.1136/tobaccocontrol-2013-051188.

[64] S. Steinle, S. Reis, C.E. Sabel, S. Semple, M.M. Twigg, C.F. Braban, S.R. Leeson, M.R. Heal, D. Harrison, C. Lin, H. Wu, Personal exposure monitoring of PM2.5 in indoor and outdoor microenvironments, Sci. Total Environ. 508 (2015) 383-394. https://doi.org/10.1016/j.scitotenv.2014.12.003.

[65] R. Franken, T. Maggos, A. Stamatelopoulou, M. Loh, E. Kuijpers, J. Bartzis, S. Steinle, J.W. Cherrie, A. Pronk, Comparison of methods for converting Dylos particle number concentrations to PM2.5 mass concentrations, Indoor Air. 29 (2019) 450-459. https://doi.org/10.1111/ina.12546.

[66] Alphasense, User Manual: OPC-N2 Optical Particle Counter, 072-0300(5), Alphasense, Great Notley, United Kingdom, 2015.

[67] S. Sousan, K. Koehler, L. Hallett, T.M. Peters, Evaluation of the Alphasense optical particle counter (OPC-N2) and the Grimm portable aerosol spectrometer (PAS-1.108), Aerosol Sci. Technol. 50 (2016) 1352-1365. https://doi.org/10.1080/02786826.2016.1232859.

[68] M. Badura, P. Batog, A. Drzeniecka-Osiadacz, P. Modzel, Evaluation of Low-Cost Sensors for Ambient PM2.5 Monitoring, J. Sens. 2018 (2018) 5096540. https://doi.org/10.1155/2018/5096540. 
[69] L.R. Crilley, M. Shaw, R. Pound, L.J. Kramer, R. Price, S. Young, A.C. Lewis, F.D. Pope, Evaluation of a low-cost optical particle counter (Alphasense OPC-N2) for ambient air monitoring, Atmos Meas Tech. 11 (2018) 709-720. https://doi.org/10.5194/amt-11-7092018.

[70] R. Dobson, S. Semple, "How do you know those particles are from cigarettes?": An algorithm to help differentiate second-hand tobacco smoke from background sources of household fine particulate matter, Environ. Res. 166 (2018) 344-347. https://doi.org/10.1016/j.envres.2018.06.019.

[71] Y. Wan, Impacts of Household Characteristics, Activities and Building Characteristics on Indoor Concentrations of Semi-Volatile Organic Compounds, $\mathrm{PhD}$ thesis, University of Toronto Scarborough, 2020. https://tspace.library.utoronto.ca/bitstream/1807/103465/3/Wan_Yuchao_202011_PhD_th esis.pdf.

[72] R. Givehchi, J.P. Maestre, C. Bi, D. Wylie, Y. Xu, K.A. Kinney, J.A. Siegel, Quantitative filter forensics with residential HVAC filters to assess indoor concentrations, Indoor Air. 29 (2019) 390-402. https://doi.org/10.1111/ina.12536.

[73] R Core Team, R: A Language and Environment for Statistical Computing, R Foundation for Statistical Computing, Vienna, Austria, 2020. https://www.R-project.org/.

[74] H. Wickham, ggplot2: Elegant Graphics for Data Analysis, Springer-Verlag New York, 2016. https://ggplot2.tidyverse.org.

[75] F. Noris, G. Adamkiewicz, W.W. Delp, T. Hotchi, M. Russell, B.C. Singer, M. Spears, K. Vermeer, W.J. Fisk, Indoor environmental quality benefits of apartment energy retrofits, Build. Environ. 68 (2013) 170-178. https://doi.org/10.1016/j.buildenv.2013.07.003.

[76] L.K. Baxter, J.E. Clougherty, F. Laden, J.I. Levy, Predictors of concentrations of nitrogen dioxide, fine particulate matter, and particle constituents inside of lower socioeconomic status urban homes, J. Expo. Sci. Environ. Epidemiol. 17 (2007) 433-444. https://doi.org/10.1038/sj.jes.7500532.

[77] C. O’Leary, Y. de Kluizenaar, P. Jacobs, W. Borsboom, I. Hall, B. Jones, Investigating measurements of fine particle (PM2.5) emissions from the cooking of meals and mitigating exposure using a cooker hood, Indoor Air. 29 (2019) 423-438. https://doi.org/10.1111/ina.12542.

[78] D. Brugge, J. Vallarino, L. Ascolillo, N.-D. Osgood, S. Steinbach, J. Spengler, Comparison of multiple environmental factors for asthmatic children in public housing, Indoor Air. 13 (2003) 18-27. https://doi.org/10.1034/j.1600-0668.2003.01130.x.

[79] M.D. Colton, P. MacNaughton, J. Vallarino, J. Kane, M. Bennett-Fripp, J.D. Spengler, G. Adamkiewicz, Indoor Air Quality in Green Vs Conventional Multifamily Low-Income Housing, Environ. Sci. Technol. 48 (2014) 7833-7841. https://doi.org/10.1021/es501489u. 
[80] D.E. Jacobs, E. Ahonen, S.L. Dixon, S. Dorevitch, J. Breysse, J. Smith, A. Evens, D. Dobrez, M. Isaacson, C. Murphy, L. Conroy, P. Levavi, Moving Into Green Healthy Housing, J. Public Health Manag. Pract. 21 (2015). https://doi.org/10.1097/PHH.0000000000000047.

[81] K.C. Coombs, G.L. Chew, C. Schaffer, P.H. Ryan, C. Brokamp, S.A. Grinshpun, G. Adamkiewicz, S. Chillrud, C. Hedman, M. Colton, J. Ross, T. Reponen, Indoor air quality in green-renovated vs. non-green low-income homes of children living in a temperate region of US (Ohio), Sci. Total Environ. 554-555 (2016) 178-185. https://doi.org/10.1016/j.scitotenv.2016.02.136.

[82] M. Braun, F. Koger, D. Klingelhöfer, R. Müller, D.A. Groneberg, Particulate Matter Emissions of Four Different Cigarette Types of One Popular Brand: Influence of Tobacco Strength and Additives, Int. J. Environ. Res. Public. Health. 16 (2019) 263. https://doi.org/10.3390/ijerph16020263.

[83] J.E. Thompson, Airborne Particulate Matter: Human Exposure and Health Effects, J. Occup. Environ. Med. 60 (2018). https://doi.org/10.1097/JOM.0000000000001277.

[84] T. Li, M. Alavy, J.A. Siegel, Measurement of residential HVAC system runtime, Build. Environ. 150 (2019) 99-107. https://doi.org/10.1016/j.buildenv.2019.01.004.

[85] Statistics Canada, Canadian Tobacco and Nicotine Survey (CTNS): summary of results for 2019, 2020. https://www.canada.ca/en/health-canada/services/canadian-tobacco-nicotinesurvey/2019-summary.html (accessed May 11, 2021).

[86] M.R. Creamer, T.W. Wang, S. Babb, K.A. Cullen, H. Day, G. Willis, A. Jamal, L. Neff, Tobacco Product Use and Cessation Indicators Among Adults - United States, 2018, 68 (2019) 1013-1019. https://doi.org/10.15585/mmwr.mm6845a2.

[87] United States Department of Housing and Urban Development, Instituting Smoke-Free Public Housing, 2017. https://www.federalregister.gov/documents/2016/12/05/201628986/instituting-smoke-free-public-housing (accessed April 22, 2021).

[88] D. Hernández, C.B. Swope, C. Azuogu, E. Siegel, D.P. Giovenco, 'If I pay rent, I'm gonna smoke': Insights on the social contract of smokefree housing policy in affordable housing settings, Health Place. 56 (2019) 106-117.

https://doi.org/10.1016/j.healthplace.2019.01.007.

[89] S. Rokicki, G. Adamkiewicz, S.C. Fang, N.A. Rigotti, J.P. Winickoff, D.E. Levy, Assessment of Residents' Attitudes and Satisfaction Before and After Implementation of a Smoke-Free Policy in Boston Multiunit Housing, Nicotine Tob. Res. Off. J. Soc. Res. Nicotine Tob. 18 (2016) 1282-1289. https://doi.org/10.1093/ntr/ntv239.

[90] D.E. Levy, I.F. Adams, G. Adamkiewicz, Delivering on the Promise of Smoke-Free Public Housing, Am. J. Public Health. 107 (2017) 380-383. https://doi.org/10.2105/AJPH.2016.303606. 
[91] M. Roterman, What has changed since cannabis was legalized?, Statistics Canada, 2020. https://www.doi.org/10.25318/82-003-x202000200002-eng.

[92] B.M. Graves, T.J. Johnson, R.T. Nishida, R.P. Dias, B. Savareear, J.J. Harynuk, M. Kazemimanesh, J.S. Olfert, A.M. Boies, Comprehensive characterization of mainstream marijuana and tobacco smoke, Sci. Rep. 10 (2020) 7160. https://doi.org/10.1038/s41598020-63120-6.

[93] A. Keethakumar, V.M. Mehra, N. Khanlou, H. Tamim, Cannabis use and patterns among middle and older aged Canadians prior to legalization: a sex-specific analysis of the Canadian Tobacco, Alcohol and Drugs Survey, BMC Public Health. 21 (2021) 26. https://doi.org/10.1186/s12889-020-10074-z.

[94] G. Adamkiewicz, J.D. Spengler, A.E. Harley, A. Stoddard, M. Yang, M. Alvarez-Reeves, G. Sorensen, Environmental Conditions in Low-Income Urban Housing: Clustering and Associations With Self-Reported Health, Am. J. Public Health. 104 (2013) 1650-1656. https://doi.org/10.2105/AJPH.2013.301253.

[95] American Society for Heating Refrigerating and Air-Conditioning Engineers, ASHRAE Position Document on Environmental Tobacco Smoke, (2020). https://www.ashrae.org/File\%20Library/About/Position\%20Documents/pd_environmental -tobacco-smoke-2020-07-1.pdf.

[96] A. Zota, G. Adamkiewicz, J.I. Levy, J.D. Spengler, Ventilation in public housing: implications for indoor nitrogen dioxide concentrations, Indoor Air. 15 (2005) 393-401. https://doi.org/10.1111/j.1600-0668.2005.00375.x.

[97] G. Richardson, A. Barton, M. Basham, C. Foy, S.A. Eick, M. Somerville, The Watcombe housing study: The short-term effect of improving housing conditions on the indoor environment, Sci. Total Environ. 361 (2006) 73-80. https://doi.org/10.1016/j.scitotenv.2005.05.007.

[98] D.D. Crocker, S. Kinyota, G.G. Dumitru, C.B. Ligon, E.J. Herman, J.M. Ferdinands, D.P. Hopkins, B.M. Lawrence, T.A. Sipe, Effectiveness of Home-Based, Multi-Trigger, Multicomponent Interventions with an Environmental Focus for Reducing Asthma Morbidity: A Community Guide Systematic Review, Reducing Asthma Morb. HomeBased Environ. Interv. 41 (2011) S5-S32. https://doi.org/10.1016/j.amepre.2011.05.012.

[99] R. Singleton, A.J. Salkoski, L. Bulkow, C. Fish, J. Dobson, L. Albertson, J. Skarada, T. Ritter, T. Kovesi, T.W. Hennessy, Impact of home remediation and household education on indoor air quality, respiratory visits and symptoms in Alaska Native children, Int. J. Circumpolar Health. 77 (2018) 1422669. https://doi.org/10.1080/22423982.2017.1422669.

[100] C. He, L. Morawska, J. Hitchins, D. Gilbert, Contribution from indoor sources to particle number and mass concentrations in residential houses, Atmos. Environ. 38 (2004) 34053415. https://doi.org/10.1016/j.atmosenv.2004.03.027. 
[101] M. Alavy, T. Li, J.A. Siegel, Energy use in residential buildings: Analyses of highefficiency filters and HVAC fans, Energy Build. 209 (2020) 109697. https://doi.org/10.1016/j.enbuild.2019.109697.

[102] T. Li, J.A. Siegel, The impact of control strategies on filtration performance, Energy Build. (2021) 111378. https://doi.org/10.1016/j.enbuild.2021.111378.

[103] A.Y. Mendell, A. Mahdavi, J.A. Siegel, Particulate matter concentrations in social housing, Sustain. Cities Soc. Under Review (2021).

[104] S. Semple, A. Apsley, L. MacCalman, An inexpensive particle monitor for smoker behaviour modification in homes, Tob. Control. 22 (2012) 295. https://doi.org/10.1136/tobaccocontrol-2011-050401.

[105] T. Li, J.A. Siegel, Assessing the impact of filtration systems in indoor environments with effectiveness, Build. Environ. 187 (2021) 107389. https://doi.org/10.1016/j.buildenv.2020.107389.

[106] Canadian Council of Ministers of the Environment, Guidance Document on Air Zone Management, PN 1593, 2019.

https://ccme.ca/en/res/guidancedocumentonairzonemanagement_secured.pdf.

[107] United States Environmental Protection Agency, Clean Air Act, 2013. https://ecfr.federalregister.gov/current/title-40/chapter-I/subchapter-C/part-50/section50.18 .

[108] Z.M. Sultan, G.J. Nilsson, R.J. Magee, Removal of ultrafine particles in indoor air: Performance of various portable air cleaner technologies, HVACR Res. 17 (2011) $513-$ 525. https://doi.org/10.1080/10789669.2011.579219.

[109] D.E. Henderson, J.B. Milford, S.L. Miller, Prescribed Burns and Wildfires in Colorado: Impacts of Mitigation Measures on Indoor Air Particulate Matter, J. Air Waste Manag. Assoc. 55 (2005) 1516-1526. https://doi.org/10.1080/10473289.2005.10464746.

[110] P. Barn, T. Larson, M. Noullett, S. Kennedy, R. Copes, M. Brauer, Infiltration of forest fire and residential wood smoke: an evaluation of air cleaner effectiveness, J. Expo. Sci. Environ. Epidemiol. 18 (2008) 503-511. https://doi.org/10.1038/sj.jes.7500640.

[111] N. Rhodes, L. Ntaimo, L. Roald, Balancing Wildfire Risk and Power Outages Through Optimized Power Shut-Offs, IEEE Trans. Power Syst. 36 (2021) 3118-3128. https://doi.org/10.1109/TPWRS.2020.3046796.

[112] W.R. Chan, J.M. Logue, X. Wu, N.E. Klepeis, W.J. Fisk, F. Noris, B.C. Singer, Quantifying fine particle emission events from time-resolved measurements: Method description and application to 18 California low-income apartments, Indoor Air. 28 (2018) 89-101. https://doi.org/10.1111/ina.12425. 
[113] A. Mahdavi, J. Dingle, A.W.H. Chan, J.A. Siegel, HVAC filtration of particles and trace metals: Airborne measurements and the evaluation of quantitative filter forensics, Environ. Pollut. 271 (2021) 116388. https://doi.org/10.1016/j.envpol.2020.116388.

[114] H.W. Borchers, pracma: Practical Numerical Math Functions, 2021. https://CRAN.Rproject.org/package $=$ pracma. 


\section{Appendices}

\section{A1. Supplementary information for Chapter 2}

\section{A1.1. Smoking status assessment}

The smoking status of each participating apartment was evaluated through an occupant survey as well as through evidence collected during the deployment of instruments. Upon enrolling in the study, a study facilitator interviewed an occupant of each apartment using a comprehensive survey of their perceived indoor environmental quality. One question asked "Do you allow smoking in your apartment?" with one permitted response of "No" $(\mathrm{N}=141)$, "Sometimes" $(\mathrm{N}=$ 22), "Balcony only" $(\mathrm{N}=3)$, or "Yes" $(\mathrm{N}=14)$. Residents who responded "Yes" or "Sometimes" were classified as living in smoking apartments.

During the installation and retrieval of instruments, study facilitators once again asked the residents who were present in the home whether they smoked indoors. During these visits, study facilitators were instructed to document any evidence of indoor smoking that they encountered in the home such as the odour of tobacco smoke or whether ashtrays and cigarette packs were visible. The observations of study facilitators generally aligned with the self-reported smoking status of the residents. In all cases where a discrepancy was identified, we examined the field data sheets where observations were recorded and considered whether there was clear evidence to overrule the self-identification. In six instances, two of which responded "Balcony only" during the earlier survey, the status of an apartment was changed to smoking.

In two instances, there was limited evidence of smoking in the homes of residents who said they do not permit indoor smoking. This evidence was deemed insufficient to classify these as smoking apartments. In the first apartment, "smoking items" (not otherwise specified) were noted as being visible during a single visit, however there was no odour and the resident did not report that they smoked indoors. In the second apartment, a strong odour of smoke was observed during a single visit. However, in subsequent visits the use of incense was reported and it is possible that the previous observation was mistaken. 
In four instances (two of which reported indoor smoking "Sometimes"), residents said that they permit indoor smoking in the occupant survey although no smoking was reported during the site visits. These apartments were classified as smoking apartments based on the initial selfreporting. 


\section{A1.2. Additional equipment deployment information}

Tables A1-1 through A1-3 show the equipment deployed to each apartment during the four study periods. For the optical particle counter measurements (Dylos DC1700 and Alphasense OPC-N2) only monitoring periods meeting quality control are shown, reducing the total number of apartments to 88 .

Table A1-1. Equipment deployment (Buildings A and B)

\begin{tabular}{|c|c|c|c|c|c|c|c|c|c|c|c|c|}
\hline \multirow{3}{*}{ Apartment $^{3}$} & \multicolumn{12}{|c|}{ Equipment/Rounds ${ }^{1,2}$} \\
\hline & \multicolumn{4}{|c|}{ DC1700 } & \multicolumn{4}{|c|}{$\mathrm{OPC}-\mathrm{N} 2$} & \multicolumn{4}{|c|}{ TSP } \\
\hline & 1 & 2 & 3 & 4 & 1 & 2 & 3 & 4 & 1 & 2 & 3 & 4 \\
\hline mrl_02ag & $\times$ & & & & & $\times$ & $x$ & & & $x$ & & \\
\hline $\mathrm{mrl} 02 \mathrm{bi}$ & & & & & & & & $x$ & & & $x$ & $x$ \\
\hline mrl_02df & & & & & & & $x$ & $x$ & & & & $x$ \\
\hline mr1_02ea & & & & & & & $x$ & $x$ & & & & \\
\hline mr1_02eb & $\times$ & & & & & & $x$ & $\times$ & & $x$ & $x$ & \\
\hline mr1_02eh & & $x$ & & & & & & & & & & \\
\hline $\mathrm{mrl} 02 \mathrm{ei}$ & $\times$ & & & & & & $x$ & $x$ & & $x$ & $x$ & $x$ \\
\hline mr1_03ag & & $\times$ & & & & & $x$ & & & & & \\
\hline mr1_03bc & & & & & & & $x$ & $\times$ & & $x$ & $x$ & $x$ \\
\hline mr1_03ea & $x$ & $\times$ & & & & & $x$ & $x$ & & & $x$ & \\
\hline mr1_03eb & $\times$ & $\times$ & & & & & $\times$ & $\times$ & & $\times$ & $\times$ & $x$ \\
\hline mr1_03ec & & $x$ & & & & & $x$ & & & & & \\
\hline mrl_03ei & $x$ & & & & & & $x$ & $\times$ & & & $\times$ & \\
\hline mrl_03fd & & & & & & & & $\times$ & & & & $x$ \\
\hline mr1_03fe & & & & & & & & $\times$ & & & & \\
\hline $\mathrm{mr} 202 \mathrm{bb}$ & $\times$ & $\times$ & & & & & $x$ & $\times$ & & $\times$ & $x$ & $x$ \\
\hline $\mathrm{mr} 2=02 \mathrm{db}$ & $\times$ & $\times$ & & $x$ & & & & $\times$ & & & $x$ & $x$ \\
\hline mr2_02dh & & $x$ & & $x$ & & & & & & & $x$ & $x$ \\
\hline $\mathrm{mr} 2-02 \mathrm{di}$ & & & & & & & $x$ & & & & $x$ & $x$ \\
\hline mr2_02ea & $\times$ & & & & & & & & & & & \\
\hline mr2_02ec & & & $\times$ & & & & $x$ & $x$ & & & & $x$ \\
\hline mr2_02ed & $x$ & & & & & & & & & & & \\
\hline mr2_02ee & $x$ & $\times$ & & & & & & & & & & \\
\hline $\mathrm{mr2} 03 \mathrm{bc}$ & $\times$ & $\times$ & & & & & $x$ & $x$ & & & $x$ & $x$ \\
\hline mr2_03be & $\times$ & & & & & & $x$ & $\times$ & & $x$ & $x$ & $\times$ \\
\hline mr2_03ee & & $\times$ & & & & & $\times$ & $x$ & & & $x$ & \\
\hline
\end{tabular}

1 Dylos DC1700 optical particle counter, Alphasense OPC-N2 optical particle counter, Amaircare XR-100 with high efficiency media filter (total suspended particles)

2 1: Pre-retrofit spring, 2: Pre-retrofit fall, 3: Post-retrofit spring, 4: Pre-retrofit fall.

3 The $5^{\text {th }}$ and $6^{\text {th }}$ characters represent the floor number (e.g., 03: $3^{\text {rd }}$ floor, 11: $11^{\text {th }}$ floor). 
Table A1-2. Equipment deployment (Buildings C, D and E)

\begin{tabular}{|c|c|c|c|c|c|c|c|c|c|c|c|c|}
\hline \multirow{3}{*}{ Apartment } & \multicolumn{12}{|c|}{ Equipment/Period } \\
\hline & \multicolumn{4}{|c|}{$\mathrm{DC} 1700$} & \multicolumn{4}{|c|}{ OPC-N2 } & \multicolumn{4}{|c|}{ TSP } \\
\hline & 1 & 2 & 1 & 4 & 1 & 2 & 1 & 4 & 1 & 2 & 1 & 4 \\
\hline mr3_02af & $x$ & & & & & & & & & & & \\
\hline mr3_02ai & $x$ & $\times$ & & & & & & $x$ & & $\times$ & $\times$ & $x$ \\
\hline mr3_02aj & $x$ & $x$ & & & & & & & & $x$ & & $x$ \\
\hline mr3_02bg & & & & & & & & & & & $x$ & $x$ \\
\hline mr3_02bh & & & & & & & & $x$ & & $x$ & $x$ & $x$ \\
\hline mr3 03ag & & $x$ & & & & & $x$ & $x$ & & $x$ & $x$ & $x$ \\
\hline $\mathrm{mr} 3 \_03 \mathrm{bg}$ & $\times$ & & & & & & & & & & & \\
\hline $\mathrm{mr} 303 \mathrm{bh}$ & $x$ & & & & & & & & & & & \\
\hline mr3 04bd & $x$ & & & & & & & & & & & \\
\hline mr3 $04 \mathrm{bf}$ & $x$ & $\times$ & & & & & & & & $\times$ & & \\
\hline mr3_04bh & $x$ & $x$ & & & & & & $x$ & & & $x$ & $x$ \\
\hline mr3 06aj & $x$ & $x$ & & & & & & & & $x$ & $x$ & $x$ \\
\hline mr3 06bc & $x$ & & & & & & & & & $x$ & & \\
\hline mr3_06bd & $x$ & $\times$ & & & & & $x$ & $x$ & & $\times$ & $\times$ & $x$ \\
\hline mr3_06bi & $x$ & $x$ & & & & & & & & $x$ & $x$ & \\
\hline mr3_06ci & & & & & & & $x$ & $x$ & & & $x$ & \\
\hline mr3_06da & & & & & & & & $x$ & & & $x$ & $x$ \\
\hline mr4_02ai & $\times$ & $\times$ & & & & & $x$ & $x$ & & $x$ & $x$ & $x$ \\
\hline mr4_03ah & $x$ & $x$ & & & & & $x$ & $x$ & & $x$ & $x$ & $x$ \\
\hline mr4_04ai & $x$ & & & & & & & & & & & \\
\hline mr4_05ai & $x$ & $\times$ & & & & & $x$ & $x$ & & $\times$ & $x$ & $x$ \\
\hline mr5_02ad & & $x$ & & & & & $x$ & $x$ & & $x$ & $x$ & $x$ \\
\hline mr5_02af & $\times$ & $x$ & & & & & & $x$ & & & & $x$ \\
\hline mr5 02ag & $x$ & $x$ & & & & & & & & & & \\
\hline mr5_03ag & $x$ & $x$ & & & & & $x$ & $x$ & & $\times$ & $\times$ & $x$ \\
\hline mr5 03be & $x$ & $\times$ & & & & & & & & $x$ & & \\
\hline $\mathrm{mr} 503 \mathrm{bf}$ & $x$ & $x$ & & & & & $x$ & $x$ & & & & \\
\hline mr5_03bg & & & & & & & $x$ & & & & $\times$ & $x$ \\
\hline mr5_05af & & & & & & & $x$ & $x$ & & & $x$ & $x$ \\
\hline mr5_06ae & & $\times$ & & & & & & $x$ & & & $\times$ & $x$ \\
\hline $\mathrm{mr} 5 \_06 \mathrm{bb}$ & & & & & & & & $x$ & & & $x$ & $x$ \\
\hline mr5_08af & & & & & & & $\times$ & $x$ & & & $x$ & $x$ \\
\hline mr5_08ag & $\times$ & $\times$ & & & & & & & & & & \\
\hline $\mathrm{mr} 508 \mathrm{bb}$ & $x$ & $x$ & & & & & $x$ & $x$ & & & $\times$ & \\
\hline mr5_09ad & $x$ & $x$ & & & & & $\times$ & $x$ & & $x$ & $x$ & $x$ \\
\hline mr5 10be & $x$ & $x$ & & & & & & $x$ & & & $x$ & $x$ \\
\hline
\end{tabular}


Table A1-3. Equipment deployment (Buildings F and G)

\begin{tabular}{|c|c|c|c|c|c|c|c|c|c|c|c|c|}
\hline \multirow{3}{*}{ Apartment } & \multicolumn{12}{|c|}{ Equipment/Period } \\
\hline & \multicolumn{4}{|c|}{ DC 1700} & \multicolumn{4}{|c|}{$\mathrm{OPC}-\mathrm{N} 2$} & \multicolumn{4}{|c|}{ TSP } \\
\hline & 1 & 2 & 1 & 4 & 1 & 2 & 1 & 4 & 1 & 2 & 1 & 4 \\
\hline mr6_02aj & $x$ & $x$ & & & & & & $\times$ & & $\times$ & & \\
\hline mr6_03aj & & & & & & & $\times$ & $x$ & & & & \\
\hline mr6_05ac & $x$ & $x$ & & & & & $\times$ & $\times$ & & $\times$ & $x$ & $x$ \\
\hline mr6_05af & $x$ & & & & & & $x$ & & & & $\times$ & \\
\hline mr6_06ac & & & & & & & $x$ & $\times$ & & & $x$ & $x$ \\
\hline mr6_08ac & $x$ & $x$ & & & & & $x$ & $x$ & & $\times$ & $x$ & $x$ \\
\hline mr6_09aj & $x$ & $x$ & & $x$ & & & $x$ & & & $\times$ & $x$ & $x$ \\
\hline mr6_11ac & $x$ & & & & & & $x$ & $\times$ & & $x$ & $x$ & $x$ \\
\hline mr6_12af & $x$ & $\times$ & & & & & $x$ & $\times$ & & & & $x$ \\
\hline mr6 15af & $x$ & $\times$ & & & & & & & & $\times$ & & \\
\hline mr6_15aj & & & & & & & $x$ & & & & & \\
\hline mr6_18ac & $x$ & & & & & & & & & & & \\
\hline mr6_18ag & $x$ & $\times$ & & $x$ & & & $\times$ & & & $\times$ & $x$ & \\
\hline mr7 04ag & $x$ & $x$ & & & & & $x$ & $\times$ & & $x$ & $x$ & $x$ \\
\hline mr7_05ac & $x$ & $x$ & & $x$ & & & $\times$ & & & $\times$ & $x$ & \\
\hline mr7 $05 \mathrm{ad}$ & $x$ & & & & & & $x$ & $\times$ & & & $\times$ & $x$ \\
\hline mr7_05aj & $\times$ & $\times$ & & & & & $x$ & & & $\times$ & $x$ & $x$ \\
\hline mr7 06ac & & & & $x$ & & & $\times$ & $\times$ & & & $\times$ & $x$ \\
\hline mr7 06ah & $\times$ & & & & & & & & & & & \\
\hline mr7_11ac & & & $\times$ & & & & & & & & & \\
\hline $\mathrm{mr} 7 \quad 11 \mathrm{ad}$ & $\times$ & & & & & & & & & & & \\
\hline $\mathrm{mr} 7 \quad 12 \mathrm{ac}$ & & & & & & & $\times$ & $\times$ & & & $\times$ & $\times$ \\
\hline mr7 12ah & $\times$ & $\times$ & & & & & & $\times$ & & & & $\times$ \\
\hline mr7 14aj & $\times$ & $\times$ & & & & & $\times$ & $\times$ & & $\times$ & $\times$ & $x$ \\
\hline mr7 16ah & $x$ & $\times$ & & & & & & & & & & \\
\hline mr7 17ac & & $\times$ & & & & & $\times$ & $\times$ & & & $\times$ & $\times$ \\
\hline
\end{tabular}




\section{A1.3. Source detection algorithm}

The source affected proportion (SAP) was calculated by taking the number of measurements found to occur during a source event and dividing that number by the total of non-zero measurements in the monitoring period. Three criteria determined whether a measurement occurred during a source event: 1) all concentrations in a source event exceed a baseline threshold, 2) the instantaneous rate of change between two measurements exceeds a threshold at least once during a source event, and 3) each source event must be longer than a defined length of time.

Due to the significant variation in measured concentrations between apartments, we found that different thresholds needed to be set for each monitoring period. As noted in Zhang et al. [60], apartments with high source activity are at risk of being underestimated and apartments with low source activity are at risk of false positives. To smooth the data, a $3^{\text {rd }}$ order Savitzky-Golay filter with a half-window size of 10 measurements (21-point averaging) was used following the approach used by Chan et al. [112]. The 21-point average applied to the DC1700 and OPC-N2 data corresponds to periods of 21 minutes and 5.25 minutes respectively.

The first criteria of a source event is that all measurements must exceed a baseline threshold. This value was determined using the following formula:

Baseline threshold $=\tilde{X}+\alpha \cdot \operatorname{median}\left(\left|X_{i}-\tilde{Y}\right|\right)$

Where $\tilde{X}$ is the peak value of a probability density function of all measurements in the sampling after the $3^{\text {rd }}$ order Savitzky-Golay filter is applied, $\alpha$ is a calibration factor, $X_{i}$ is each measurement in the sampling, and $\tilde{Y}$ is the peak value of a probability density function of all (non-filtered) measurements from the same monitor type. For $\tilde{X}$, the peak value of a probability density function was used because this was found to be more robust than the median, especially when analyzing samplings with very high source activity. For the DC1700 measurements, $\tilde{X}$ was approximately $1.38 \cdot 10^{6} \mathrm{~m}^{-3}$, which corresponds to $2.3 \mu \mathrm{g} \cdot \mathrm{m}^{-3}$ using the conversion factors from Semple et al. [104]. Through visual inspection, we found that a calibration factor of $\alpha=0.35$ would limit both underestimation and false positives. The median baseline threshold corresponds to $3.4 \mu \mathrm{g} \cdot \mathrm{m}^{-3}$ (mean $5.8 \pm 7.4 \mu \mathrm{g} \cdot \mathrm{m}^{-3}$ ). For comparison, Dobson and Semple [70] used a threshold of $5 \mu \mathrm{g} \cdot \mathrm{m}^{-3}$ when considering only cigarette smoke as a source. For zeros and negative values, 
which indicate device failure rather than actual measurements, any period shorter than 10 minutes was replaced with the last positive measurement. For any period longer than 10 minutes, these measurements were not included in the baseline threshold calculation and were otherwise treated as zeros.

The second criteria of a source event is that the instantaneous rate of change between two measurements must exceed a threshold at least once. To find an appropriate threshold for measurements collected using both monitor types, we plotted the instantaneous rate of change $\left(x_{\mathrm{n}+1}-x_{\mathrm{n}}\right)$ for numerous samplings and overlayed percentiles of the absolute value instantaneous rate of change $\left(\left|x_{\mathrm{n}+1}-x_{\mathrm{n}}\right|\right)$. Through visual inspection, we found that the $85^{\text {th }}$ percentile was the highest threshold that would limit both underestimation and false positives.

The final criteria of a source event is that it must last a defined length of time. We set this length of time to be 10 minutes, which corresponds to 10 measurements with the DC1700 and 40 measurements with the OPC-N2. For comparison, Dobson and Semple [70] set this threshold at only three minutes for a similar approach which examined only cigarette smoke as a source. Figure A1.1 shows the SAP proportion and median small particle count of each Dylos DC1700 monitoring period. 


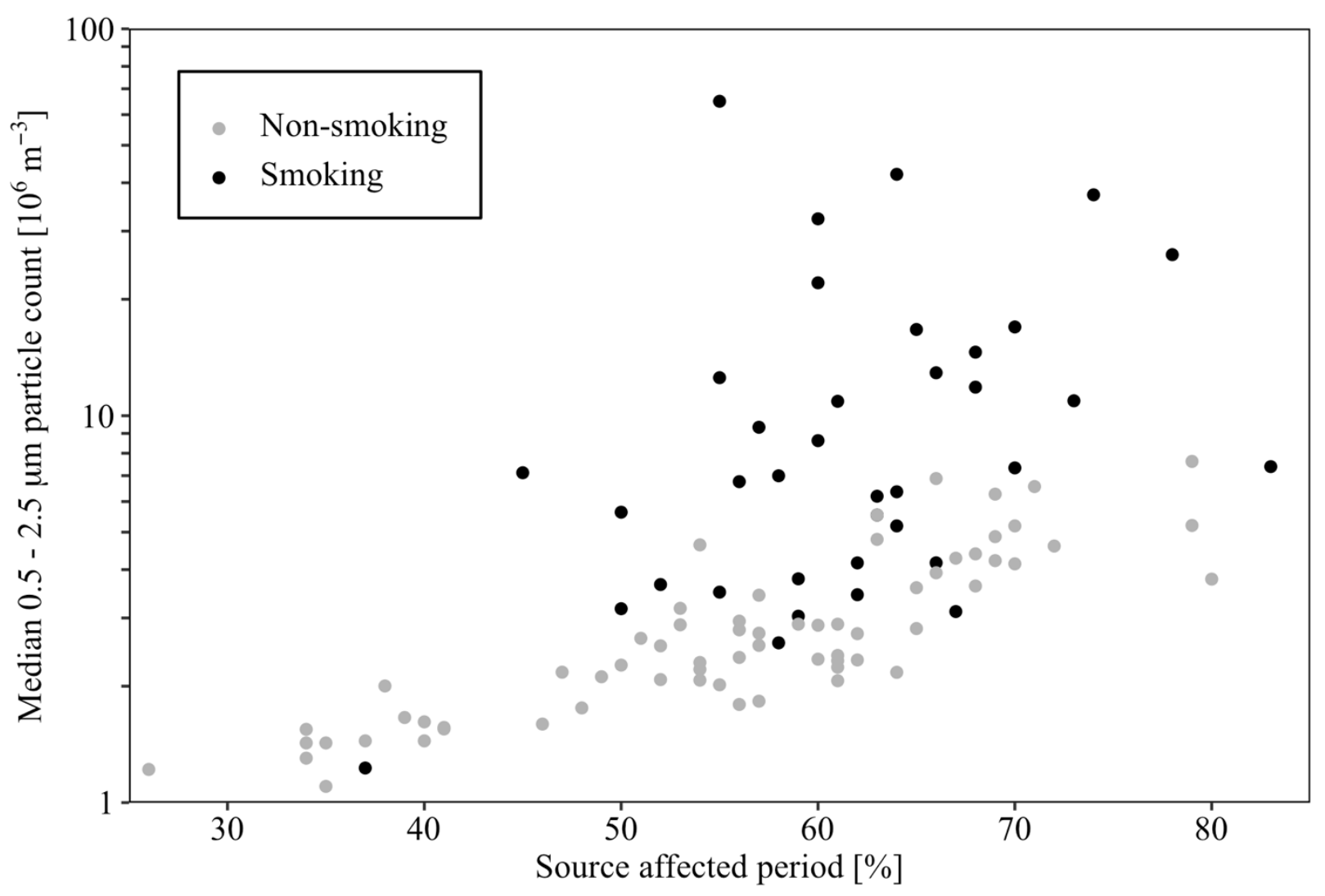

Figure A1-1. Source affected period (SAP) proportion and median small particle count of each Dylos DC1700 monitoring period. One point (SAP of 9\%) has been excluded for visual clarity.

The method from Dobson and Semple [70] to differentiate smoking from other sources detection was incorporated into our source detection algorithm to evaluate smoking frequency. Any measurement during a source event that also had a concentration equivalent to $5 \mu \mathrm{g} \cdot \mathrm{m}^{-3}$ and comprised of less than $1.8 \%$ large $(>2.5 \mu \mathrm{m}$ ) particles contributed to the smoking source affected proportion ( $\mathrm{SAP}_{\text {smoking }}$ ). Figure $\mathrm{C} .2$ shows the $\mathrm{SAP}_{\text {smoking }}$ and median small particle count of each Dylos DC1700 monitoring period. 


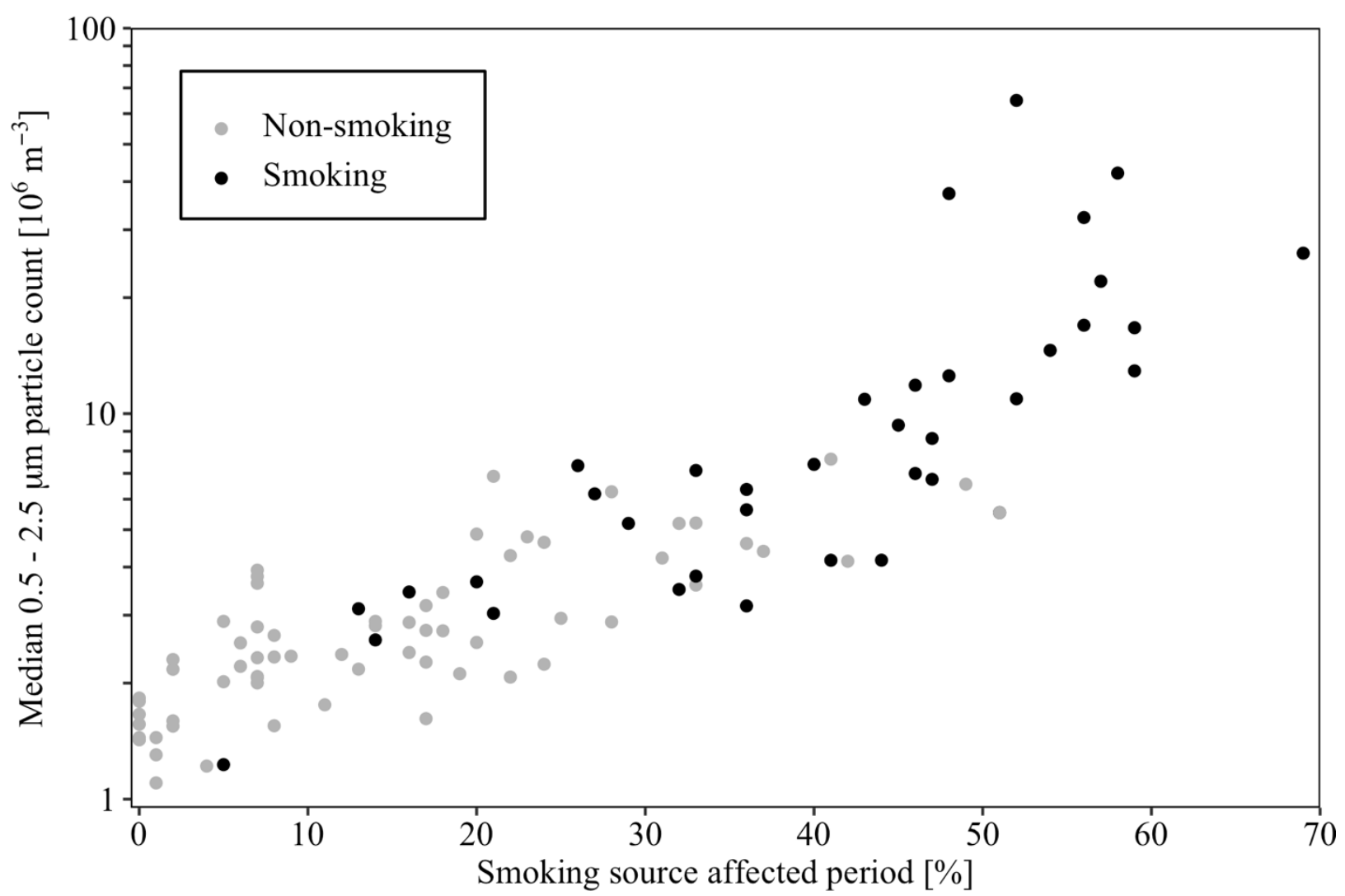

Figure A1-2. Smoking source affected proportion ( $\left.\mathrm{SAP}_{\text {smoking }}\right)$ and median small particle count

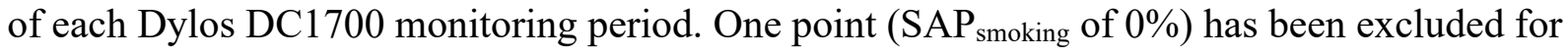
visual clarity. 


\section{A1.4. TSP concentration uncertainty}

The total suspended particle (TSP) concentration uncertainties were calculated by the error propagation of the TSP mass collected on the filters and the filtration volumes of XR100 filters. The TSP mass error was calculated similar to the approach we developed earlier [113]. The only difference was that, in this study, we used field blank filters (instead of travel blank) to assess the TSP mass errors. The field blank filters were deployed in a few randomly selected suites per visits by leaving a filter in a Petri dish or in an open antistatic bag left on a horizontal surface (e.g., above wall cabinets or refrigerators). This method of TSP mass error calculation is more conservative than that of Mahdavi et al. [113] since the field blank filter mass change is often overestimated due to gradual settling of some particles on the filter surface. The filtration volume uncertainty was calculated using the error propagation of filtration runtime, flowrate and filter efficiency. The runtime uncertainty was assumed 8 hours per a seven-day filtration runtime due to the daily working time. The relative uncertainty of the flowrates for post-retrofit and preretrofit filters was calculated as 3\% and 13\%. A 10\% higher relative uncertainty for pre-retrofit filters was due to the use of a cardboard box instead a highly sealed chamber for flowrate measurements. No uncertainty was associated with filtration efficiency due to a nominal 100\% filtration efficiency of these filters because of being a high-efficiency particulate air (HEPA) filter. Due to using two different chambers (i.e., cardboard box vs. transparent fiberglass) for the same pre- and post-retrofit filter materials and potential size and leakage errors introduced by the cardboard box, we corrected all the pre-retrofit flows by multiplying all the pre-retrofit flows to a correction factor calculated based on the ratio of the median of all post-deployment flow to the median of all pre-deployment flow. 


\section{A2. Supplementary information for Chapter 3}

\section{A2.1. Simulated concentration algorithm}

Previous investigations of air cleaner effectiveness by Li and Siegel $[102,105]$ have used Monte Carlo simulations of input parameters to Equation A2-1 combined with stochastically distributed source events in order simulate PM concentrations in indoor environments. This approach is limited with regards to how realistically it can model homes with vastly different occupant behaviour (e.g. frequency and strength of source-emitting activities, use of range hoods, opening of windows). To evaluate the fixed and adaptive air cleaner thresholds, we instead created simulated data that was derived from the real optical particle counter data. Our goal was to create a large number of "simulated environments" that reflect homes with different occupant behaviour and building characteristics, namely varying frequency and strength of source events as well as varying loss rate due to particle removal mechanisms other than an air cleaner.

$C\left(t_{n}\right)=C\left(t_{n-1}\right) \cdot e^{-\left(L_{1}+L_{2} \cdot S O\right) \Delta t}+S /\left(L_{1}+L_{2} \cdot S O\right) \cdot\left(1-e^{-\left(L_{1}+L_{2} \cdot S O\right) \Delta t}\right)$

where:

$C\left(t_{\mathrm{n}}\right)$ is the concentration at each timestep. The initial simulation concentration is the is equal to the initial measured concentration.

$L_{1}$ is the average loss rate of the home, calculated using Equation A2-1.

$L_{2}$ is the loss rate of the air cleaner, defined as a ratio of clean air delivery rate (CADR) to volume (V). The results presented here assume constant CADR/V ratios of 1.0, 2.5, and 5.0 .

$S O$ is the system operation status, 1 when the air cleaner is running and 0 when it is not, determined using the concentration of the previous timestep and the air cleaner threshold value.

$\Delta t$ is the time interval between steps, defined as 1 minute. 
$S$ is the combined sum of volume normalized indoor particle source emissions at $t_{\mathrm{n}}$, calculated using Equation A2-3.

The particle number counts measured by the Dylos DC1700 were converted to a $\mathrm{PM}_{2.5}$ mass concentration equivalent using the conversion factor from Semple et al. [104]. To prepare the reported mass concentrations for processing, they were smoothed using a $3^{\text {rd }}$ order SavitzkyGolay filter with a half-window size of 10 measurements (21-point averaging, corresponding to 21 minutes) following the approach used by Chan et al. [112]. This smoothed data (heretofore referred to as the measured concentrations) was used to prepare the simulated concentrations in addition to providing a baseline comparison. The input parameters for Equation A2-1 were calculated using Equations A2-2 through A2-5.

$L=L_{1}+L_{2}$

$L_{1}=\operatorname{median}\left(L_{\mathrm{e}}\right)$

where:

$L_{1}$ is the average loss rate of the home.

$L_{2}$ is the loss rate provided by the particle filter system, defined as a ratio of the system's clean air delivery rate (CADR) to the volume of the indoor environment (V). The results presented here assume constant CADR/V ratios of 1.0, 2.5, and 5.0.

$L_{\mathrm{e}}$ is the loss rate of each emission event, calculated by locating the peak concentration of each source event and performing a linear regression on the log-transformed concentrations of the following 10-minute decay. If the coefficient of determination is below 0.8 , the emission event is ignored.

$S=S_{\mathrm{b}}+S_{\mathrm{e}}$ 
$S_{e}=L_{\mathrm{e}} \cdot C_{\max }$

where:

$S_{\mathrm{b}}$ is the background source rate due to infiltration of outdoor air. This is calculated as 2.0 $\mu \mathrm{g} \cdot \mathrm{m}^{-3}$ using average conditions reported in Li and Siegel [102].

$S_{\mathrm{e}}$ is the particle emission rate of each indoor source event. Source events were defined similarly to in Mendell et al. [103], but do not consider rate of increase. Source events must exceed a baseline threshold (calculated using Equation A2-6) for at least 10 minutes.

$C_{\max }$ is the peak concentration of each indoor source event, which is assumed to represent the steady-state concentration. Peak concentrations were identified using findpeaks from R package pracma 2.3.3 [114], requiring 10 minutes of increase prior to the peak and spacing of at least 30 minutes. The maximum concentration during a source event was used as a peak if it otherwise did not satisfy those conditions.

Baseline threshold $=\tilde{X}+\alpha \cdot \operatorname{median}\left(\left|X_{i}-\tilde{Y}\right|\right)$

where:

$\tilde{X}$ is the peak value of a probability density function of all measurements in the sampling after the $3^{\text {rd }}$ order Savitzky-Golay filter is applied, $\alpha$ is a calibration factor, $X_{i}$ is each measurement in the sampling, and $\tilde{Y}$ is the peak value of a probability density function of all (non-filtered) measurements from the same monitor type. This approach is previously described in Mendell et al. [103].

The largest assumption made here is that all sources detected by the optical particle counters originate indoors, as the indoor $\left(S_{\mathrm{e}}\right)$ and outdoor $\left(S_{\mathrm{b}}\right)$ source emissions are added together to find the combined sum of volume normalized indoor particle source emissions $(S)$. This addition could also result in overestimation of concentrations given that $S_{\mathrm{e}}$ should already account for $S_{\mathrm{b}}$, 
however in practice underestimation is a larger issue. Several source events are ignored or excluded because they fail to exceed the baseline threshold, have peaks that occur too close together, or have a loss rate with a low coefficient of determination. Two simulations from the OPC-N2 measurements never exceed the baseline threshold and so no peaks were located; both were excluded from analysis.

Figure A2-1 shows the measured (Dylos DC1700) and simulated concentrations of a typical monitoring period. The simulated concentrations are generally lower than the measured concentrations during source events, often by more than $50 \%$. The concentration during extended periods without source events are often much lower, and there are fewer total source events. As a result, the median concentration of each week of DC1700 measurements ranges from $0.7 \mu \mathrm{g} \cdot \mathrm{m}^{-3}$ to $136.5 \mu \mathrm{g} \cdot \mathrm{m}^{-3}$ (mean $9.4 \pm 17.2 \mu \mathrm{g} \cdot \mathrm{m}^{-3}$ ) while the simulated data ranges from $0.4 \mu \mathrm{g} \cdot \mathrm{m}^{-3}$ to 63.0 $\mu \mathrm{g} \cdot \mathrm{m}^{-3}$ (mean $4.7 \pm 7.3 \mu \mathrm{g} \cdot \mathrm{m}^{-3}$ ). For the OPC-N2, the median concentration of each week of measurements ranges from $1.1 \mu \mathrm{g} \cdot \mathrm{m}^{-3}$ to $147.9 \mu \mathrm{g} \cdot \mathrm{m}^{-3}$ (mean $8.4 \pm 17.3 \mu \mathrm{g} \cdot \mathrm{m}^{-3}$ ) while the simulated data ranges from $0.3 \mu \mathrm{g} \cdot \mathrm{m}^{-3}$ to $16.4 \mu \mathrm{g} \cdot \mathrm{m}^{-3}$ (mean $2.1 \pm 2.2 \mu \mathrm{g} \cdot \mathrm{m}^{-3}$ ). While these do represent large differences, the simulated data does appear to accurately capture both the real frequency and distribution of source emission events as well as the variation in source strength. For the purposes of evaluating the performance of particle filter systems, this approach may present an improvement over using stochastically distributed source events. 


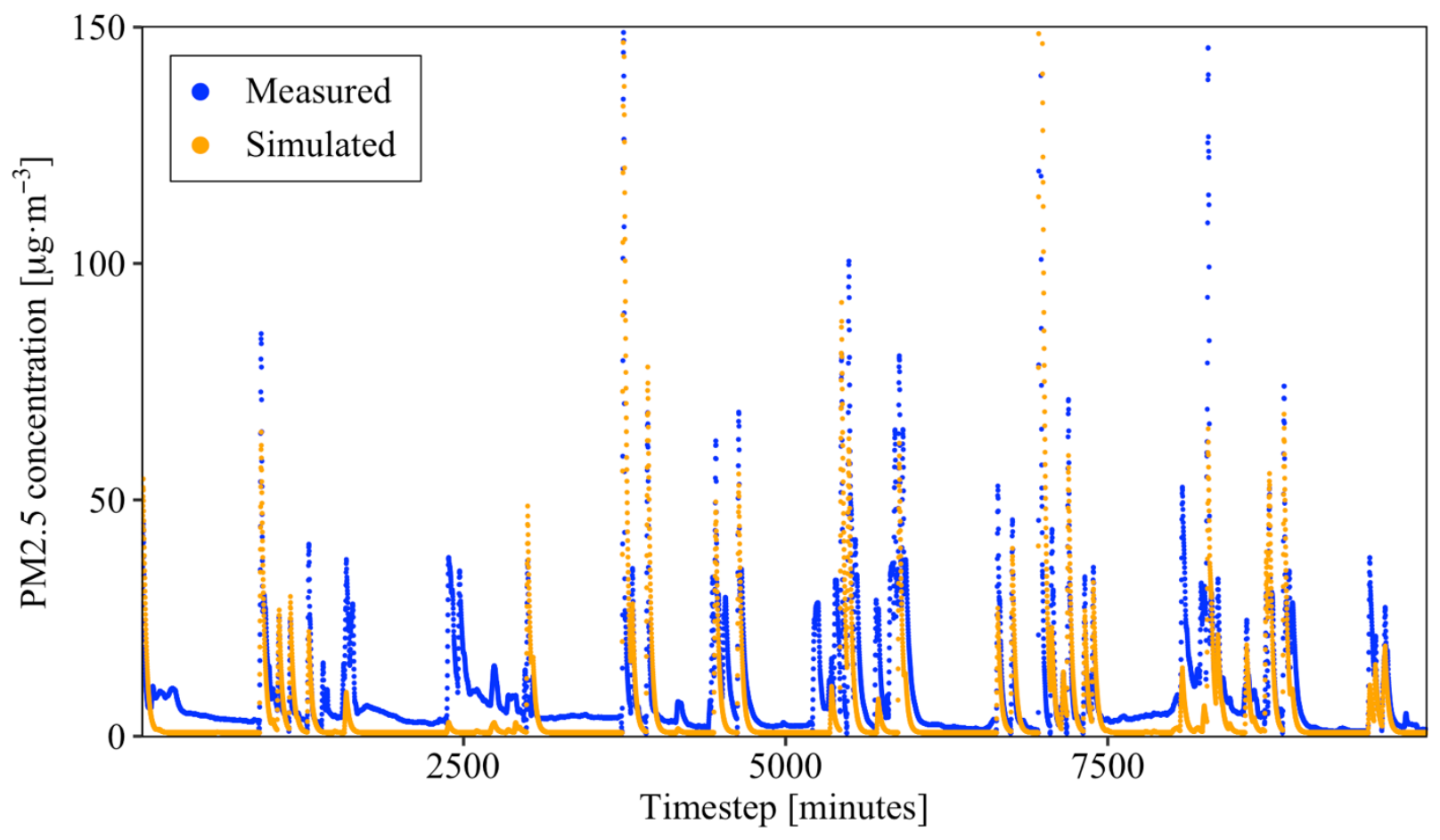

Figure A2-1. Measured (DC1700) concentrations of a typical monitoring period and simulated concentrations. The median concentrations are $4.5 \mu \mathrm{g} \cdot \mathrm{m}^{-3}$ and $0.8 \mu \mathrm{g} \cdot \mathrm{m}^{-3}$ (means $9.8 \mu \mathrm{g} \cdot \mathrm{m}^{-3}$ and $5.6 \mu \mathrm{g} \cdot \mathrm{m}^{-3}$ ) for the real and simulated concentrations respectively. 
A2.2. Complete figures for DC1700 derived simulations

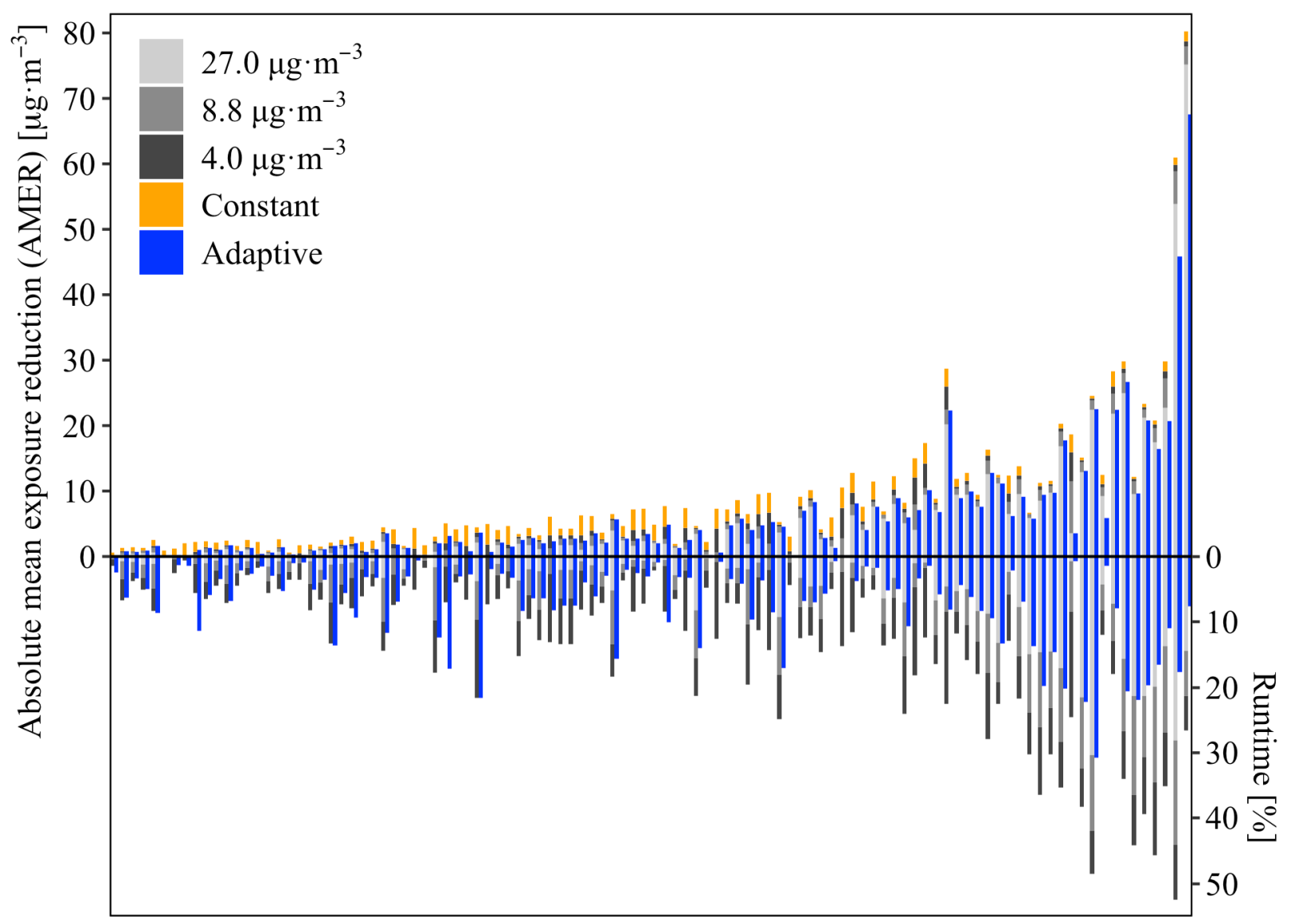

Figure A2-2. Absolute mean exposure reduction (upper portion, left axis) and runtime (lower portion, right axis) of the selected thresholds using a CADR/V ratio of 2.5 for the simulated environments derived from DC1700 measurements. Results are arranged by the simulated mean concentration in each environment without air cleaning. The runtime fraction for constant air cleaning is not shown as this will always extend to $100 \%$. 


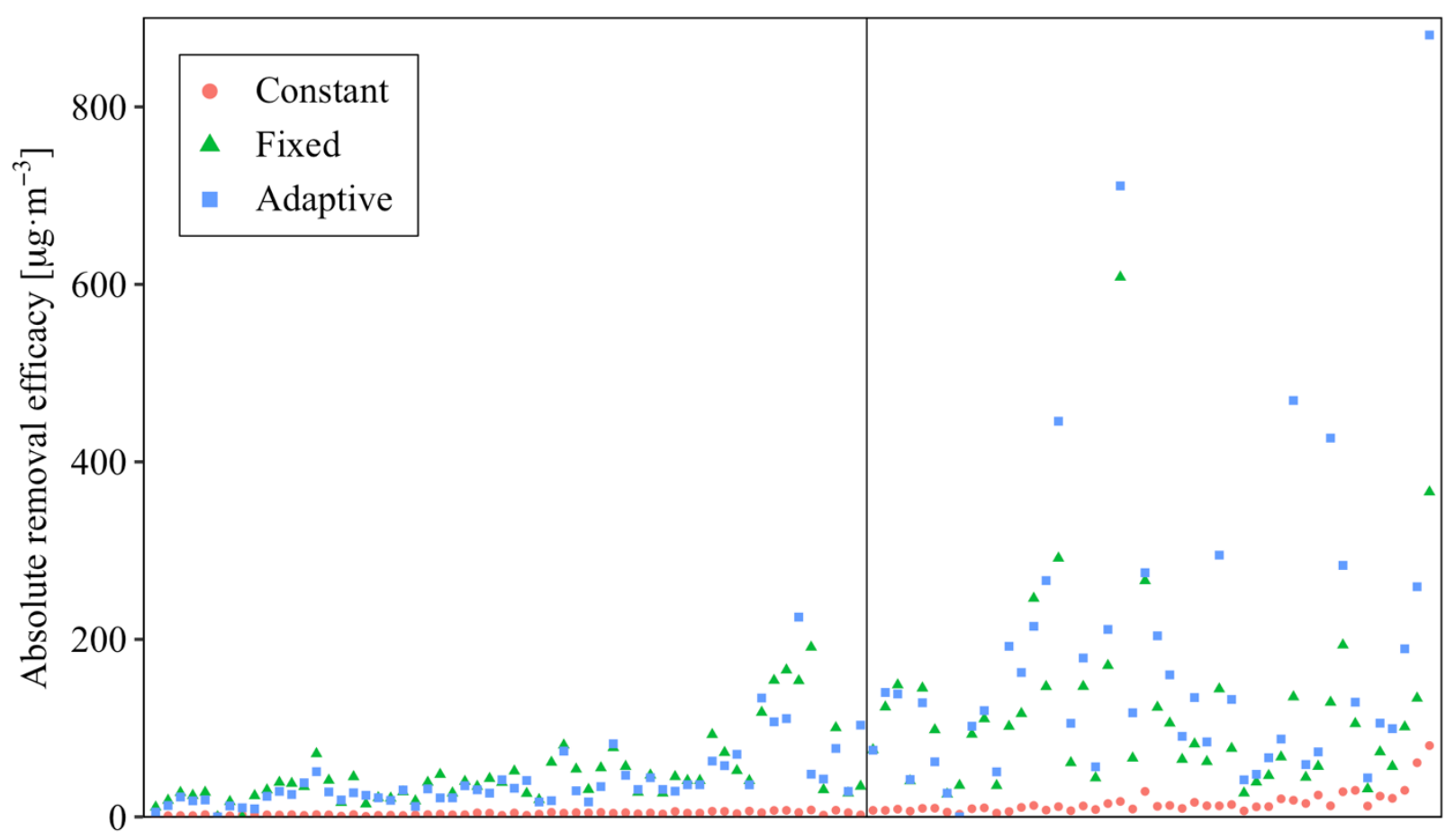

Figure A2-3. Absolute removal efficacy (absolute mean exposure reduction divided by runtime fraction) of constant air cleaning, a fixed threshold of $8.8 \mu \mathrm{g} \cdot \mathrm{m}^{-3}$, and an adaptive threshold for the simulated environments derived from Dylos DC1700 measurements. Results are arranged by the simulated mean concentration in each environment without air cleaning. For each simulated environment there is one set of points corresponding to each air cleaning mode. The vertical line separates simulations where the mean concentration without air cleaning is below (left) and above (right) the fixed threshold of $8.8 \mu \mathrm{g} \cdot \mathrm{m}^{-3}$. 
A2.3. Companion figures and tables for Alphasense OPC-N2 derived simulations

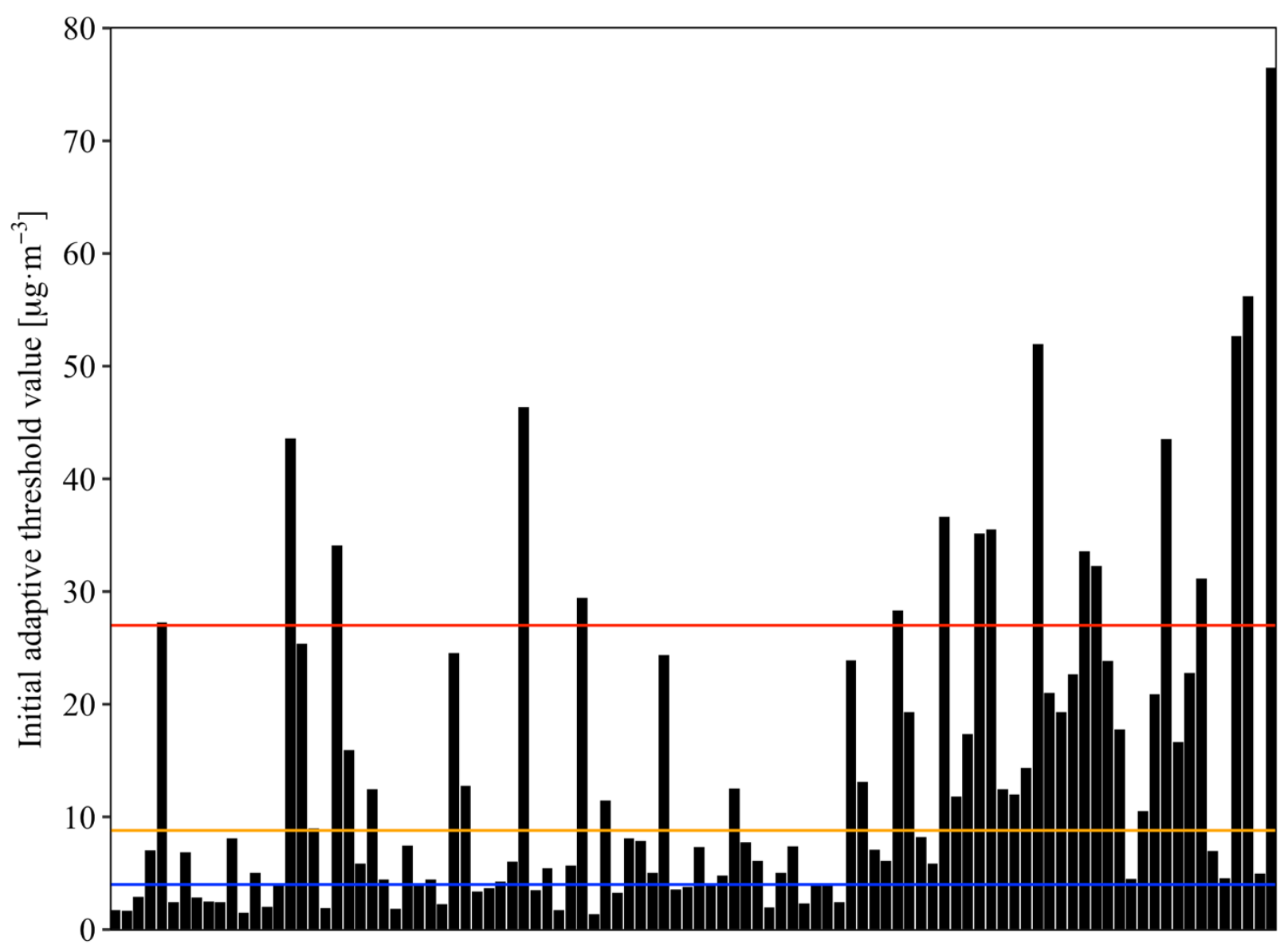

Figure A2-4. Initial adaptive threshold values for the simulated environments derived from Alphasense OPC-N2 measurements. Results are arranged by the simulated mean concentration in each environment without air cleaning. Horizontal lines represent the fixed $4.0 \mu \mathrm{g} \cdot \mathrm{m}^{-3}$ (blue), 8.8 $\mu \mathrm{g} \cdot \mathrm{m}^{-3}$ (orange), and $27.0 \mu \mathrm{g} \cdot \mathrm{m}^{-3}$ (red) thresholds respectively. 


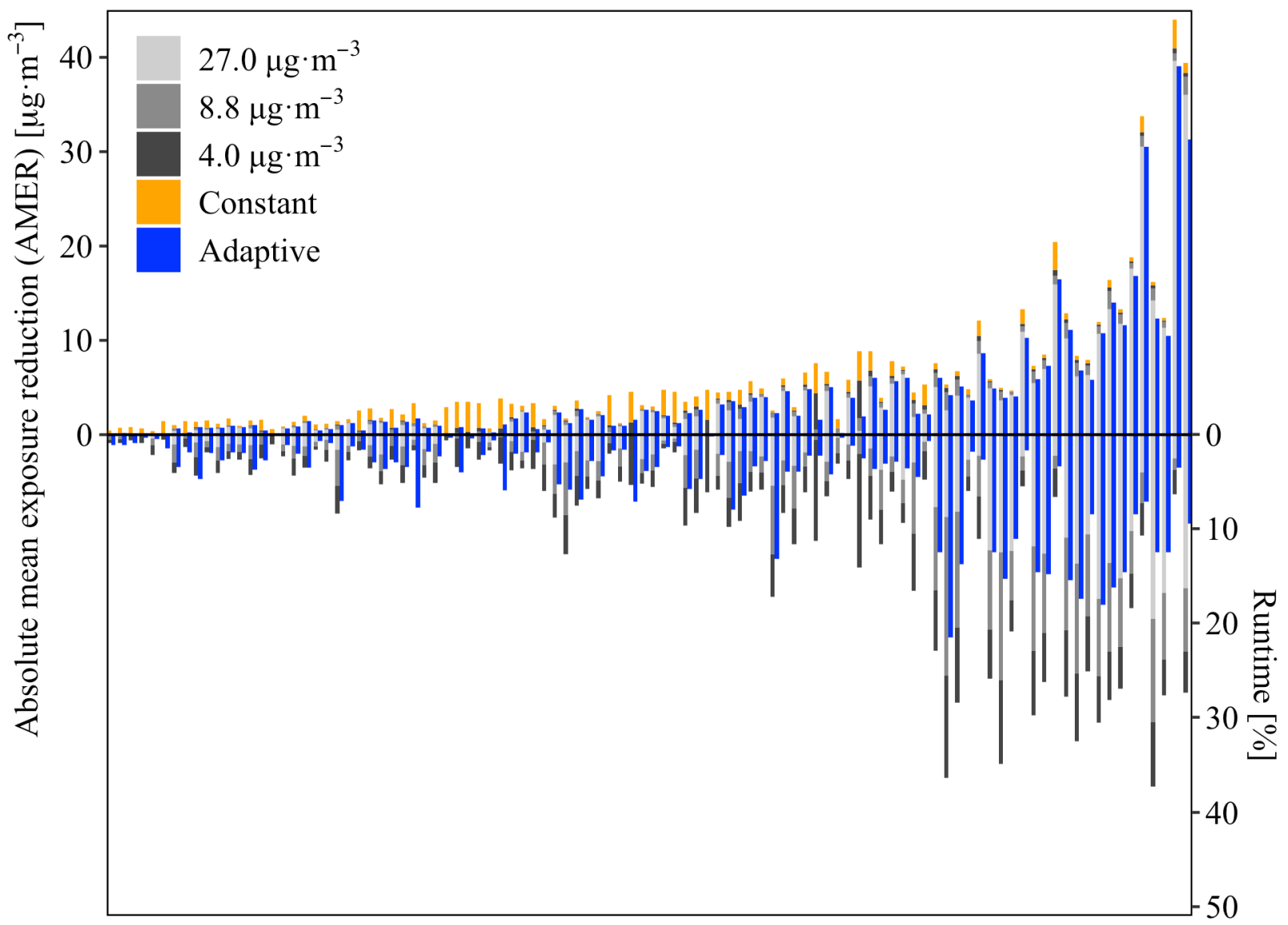

Figure A2-5. Absolute mean exposure reduction (upper portion, left axis) and runtime (lower portion, right axis) of the selected thresholds using a CADR/V ratio of 2.5 for the simulated environments derived from Alphasense OPC-N2 measurements. Results are arranged by the simulated mean concentration in each environment without air cleaning. The runtime fraction for constant air cleaning is not shown as this will always extend to $100 \%$. 


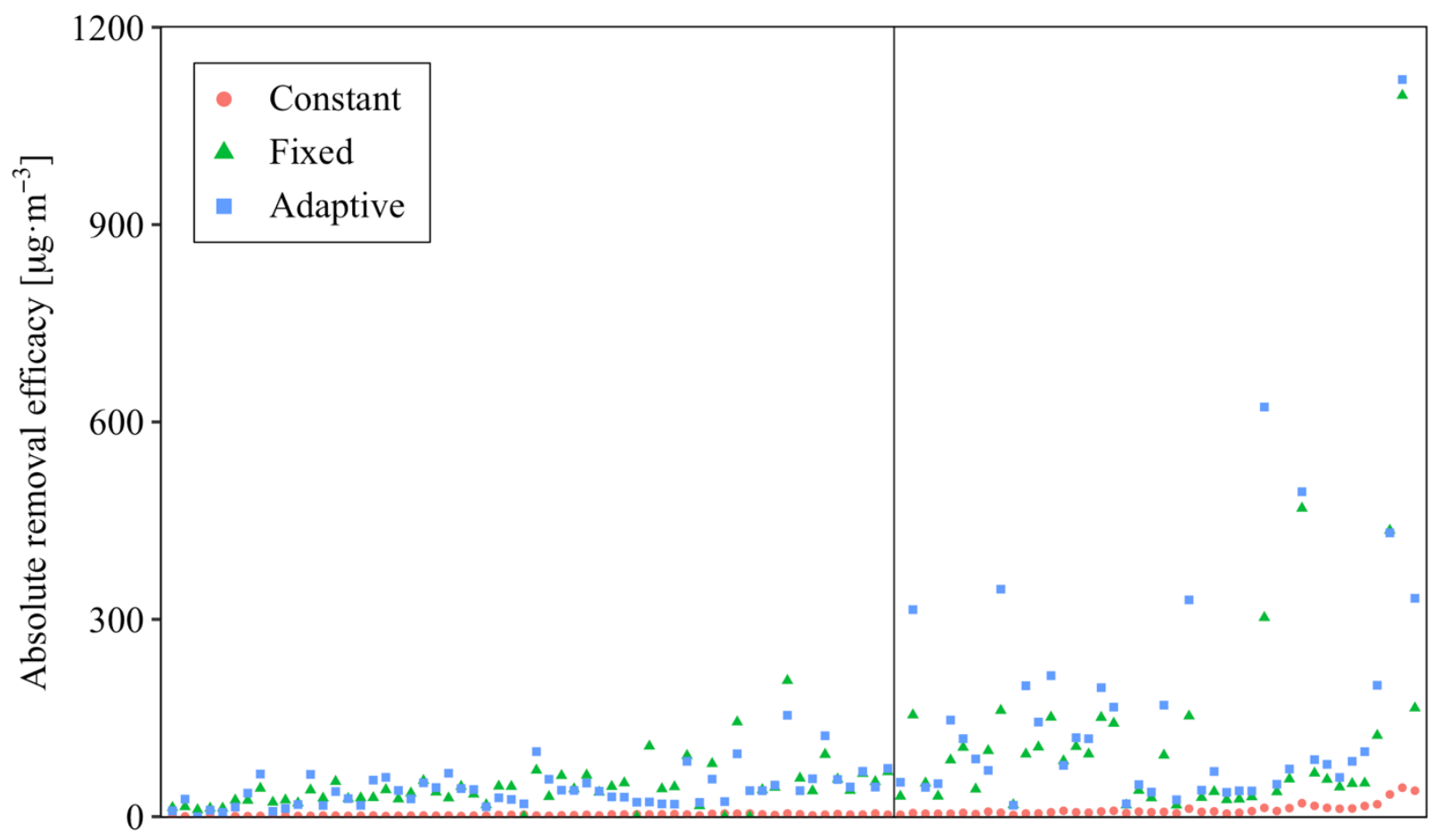

Figure A2-6. Absolute removal efficacy (absolute mean exposure reduction divided by runtime fraction) of constant air cleaning, a fixed threshold of $8.8 \mu \mathrm{g} \cdot \mathrm{m}^{-3}$, and an adaptive threshold for the simulated environments derived from Alphasense OPC-N2 measurements. Results are arranged by the simulated mean concentration in each environment without air cleaning. For each simulated environment there is one set of points corresponding to each air cleaning mode. The vertical line separates simulations where the mean concentration without air cleaning is below (left) and above (right) the fixed threshold of $8.8 \mu \mathrm{g} \cdot \mathrm{m}^{-3}$. 


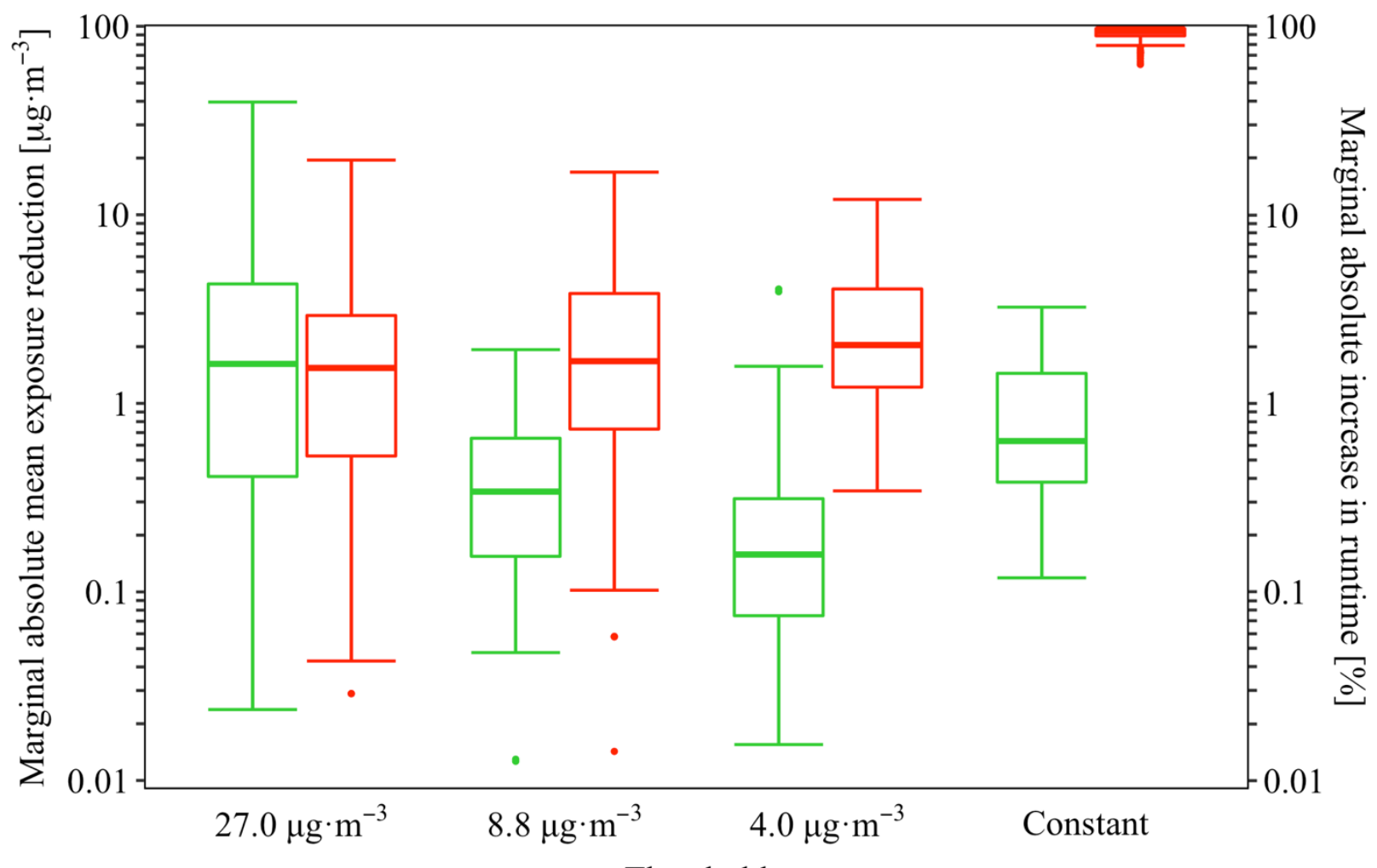

Threshold

Absolute exposure removal 官 Runtime

Figure A2-7. Marginal absolute mean exposure reduction (AMER, left axis) and marginal absolute increase in runtime (right axis) as the fixed threshold is reduced. The $27.0 \mu \mathrm{g} \cdot \mathrm{m}^{-3}$ fixed threshold boxes show the increase from no air cleaning. To accommodate a logarithmic scale without biasing the results, zeros were replaced with a value of $0.001 \mu \mathrm{g} \cdot \mathrm{m}^{-3}$. 
Table A2-1. Runtime, absolute mean exposure reduction (AMER), absolute removal efficacy (ARE), normalized mean exposure reduction (NMER), and normalized removal efficacy (NRE) of constant air cleaning, fixed thresholds, and adaptive threshold for simulated data derived Alphasense OPC-N2 optical particle counters $(N=100)$. Values are reported as mean \pm standard deviation. The initial adaptive threshold values range from $1.4 \mu \mathrm{g} \cdot \mathrm{m}^{-3}$ to $76.5 \mu \mathrm{g} \cdot \mathrm{m}^{-3}$ (mean 14.0 $\left.\pm 14.6 \mu \mathrm{g} \cdot \mathrm{m}^{-3}\right)$.

\begin{tabular}{|c|c|c|c|c|c|c|}
\hline $\begin{array}{c}\mathrm{CADR} / \mathrm{V} \\
{\left[\mathrm{h}^{-1}\right]}\end{array}$ & Threshold & $\begin{array}{c}\text { Runtime } \\
\text { [\%] }\end{array}$ & $\begin{array}{c}\text { AMER } \\
{\left[\mu \mathrm{g} \cdot \mathrm{m}^{-3}\right]}\end{array}$ & $\begin{array}{c}\mathrm{ARE} \\
{\left[\mu \mathrm{g} \cdot \mathrm{m}^{-3}\right]}\end{array}$ & $\begin{array}{c}\text { NMER } \\
{[-]}\end{array}$ & $\begin{array}{c}\text { NRE } \\
\text { [-] }\end{array}$ \\
\hline \multirow{5}{*}{1.0} & Constant & 100 & $3.8 \pm 5.2$ & $3.8 \pm 5.2$ & 1 & 1 \\
\hline & $4.0 \mu \mathrm{g} \cdot \mathrm{m}^{-3}$ & $13.1 \pm 12.1$ & $3.0 \pm 5.1$ & $21.9 \pm 31.1$ & $0.68 \pm 0.28$ & $8.4 \pm 5.8$ \\
\hline & $8.8 \mu \mathrm{g} \cdot \mathrm{m}^{-3}$ & $8.6 \pm 9.9$ & $2.8 \pm 5.0$ & $33.1 \pm 53.2$ & $0.61 \pm 0.32$ & $12.3 \pm 8.4$ \\
\hline & $27.0 \mu \mathrm{g} \cdot \mathrm{m}^{-3}$ & $4.6 \pm 6.1$ & $2.5 \pm 4.8$ & $53.2 \pm 82.4$ & $0.50 \pm 0.31$ & $19.7 \pm 15.4$ \\
\hline & Adaptive & $6.6 \pm 6.2$ & $2.6 \pm 4.5$ & $44.7 \pm 70.8$ & $0.58 \pm 0.26$ & $15.2 \pm 12.9$ \\
\hline \multirow{5}{*}{2.5} & Constant & $9.4 \pm 9.7$ & $4.7 \pm 7.1$ & $5.7 \pm 7.2$ & 1 & 1 \\
\hline & $4.0 \mu \mathrm{g} \cdot \mathrm{m}^{-3}$ & $6.5 \pm 7.9$ & $4.4 \pm 7.0$ & $51.8 \pm 76.3$ & $0.67 \pm 0.29$ & $12.1 \pm 7.7$ \\
\hline & $8.8 \mu \mathrm{g} \cdot \mathrm{m}^{-3}$ & $3.4 \pm 4.7$ & $3.9 \pm 6.8$ & $77.1 \pm 126.7$ & $0.61 \pm 0.32$ & $17.6 \pm 11.3$ \\
\hline & $27.0 \mu \mathrm{g} \cdot \mathrm{m}^{-3}$ & $4.9 \pm 4.9$ & $4.1 \pm 6.4$ & $124.5 \pm 193.7$ & $0.50 \pm 0.31$ & $28.2 \pm 21.0$ \\
\hline & Adaptive & $9.4 \pm 9.7$ & $7.1 \pm 8.5$ & $94.9 \pm 147.3$ & $0.58 \pm 0.27$ & $20.3 \pm 16.2$ \\
\hline \multirow{5}{*}{5.0} & Constant & 100 & $7.1 \pm 8.5$ & $7.1 \pm 8.5$ & 1 & 1 \\
\hline & $4.0 \mu \mathrm{g} \cdot \mathrm{m}^{-3}$ & $6.9 \pm 7.5$ & $5.8 \pm 8.4$ & $95.0 \pm 143.3$ & $0.67 \pm 0.29$ & $17.5 \pm 10.8$ \\
\hline & $8.8 \mu \mathrm{g} \cdot \mathrm{m}^{-3}$ & $4.8 \pm 6.1$ & $5.5 \pm 8.3$ & $140.0 \pm 233.5$ & $0.61 \pm 0.32$ & $25.3 \pm 16.0$ \\
\hline & $27.0 \mu \mathrm{g} \cdot \mathrm{m}^{-3}$ & $2.6 \pm 3.7$ & $4.8 \pm 8.0$ & $225.6 \pm 353.6$ & $0.50 \pm 0.31$ & $40.5 \pm 30.2$ \\
\hline & Adaptive & $3.8 \pm 3.9$ & $5.2 \pm 7.7$ & $161.6 \pm 253.4$ & $0.59 \pm 0.27$ & $27.4 \pm 21.6$ \\
\hline
\end{tabular}

